\title{
DBM-tree: Método de acesso métrico sensível à densidade local ${ }^{1}$
}

\author{
Marcos Rodrigues Vieira
}

Orientador: Prof. Dr. Caetano Traina Júnior

Dissertação apresentada ao Instituto de Ciências Matemáticas e de Computação - ICMC-USP, como parte dos requisitos para obtenção do título de Mestre em Ciências de Computação e Matemática Computacional.

\section{USP - São Carlos}
Abril/2004

\footnotetext{
${ }^{1}$ Este trabalho foi desenvolvido com o apoio financeiro da FAPESP (Fundação de Amparo à Pesquisa do Estado de São Paulo).
} 


\section{Agradecimentos}

Aos meus pais, Darci e Benita, pela educação, amor, carinho e por sempre confiarem em seus filhos.

Ao meu orientador, Prof. Dr. Caetano Traina Júnior, sempre presente e atencioso, agradeço o apoio, a confiança e a orientação indispensáveis para a minha formação como pesquisador.

À Profa. Dra. Agma Juci Machado Traina por todo o apoio e conhecimentos que ofereceu nestes anos de trabalho no GBDI.

Ao Fabio Jun Takada Chino pelos prestimosos conselhos e às sugestões valiosas que muito contribuíram para o aprimoramento deste trabalho.

À minha grande amiga Alessandra Solano, por acreditar em mim e no meu trabalho, mesmo nos momentos difíceis.

À Elaine da Silveira Leite, pela atenção e preocupação que teve comigo durante a elaboração deste trabalho.

Aos meus amigos de república (em ordem cronológica): Eric, Roberto (Gu), Fausto, Juliano, Guilherme e Estevan pelo companheirismo e pelas horas de alegria e descontração que passamos juntos, e ainda, por me ajudarem a fazer esta parte de agradecimentos.

Aos meus amigos e companheiros de laboratório Adriano Siqueira Arantes, Josiel Maimone de Figueiredo e Humberto Luiz Hazente pelos seus conselhos e amizade.

Aos membros do GBDI, que participaram do meu mestrado oferecendo sugestões durante as reuniões e prévias de defesa e, principalmente, pela amizade.

À FAPESP, pelo apoio financeiro à realização deste trabalho. 


\section{RESUMO}

Um espaço métrico é definido por um conjunto de objetos e uma função de distância métrica, que é utilizada para avaliar o nível de similaridade entre estes objetos. Isto permite a elaboração de Métodos de Acesso Métricos (MAMs) capazes de responder consultas por similaridade nesses conjuntos em um tempo reduzido. Em geral, esses MAMs são materializados através de uma estrutura hierárquica chamada de árvore métrica. Normalmente essas árvores são mantidas balanceadas, pois isto tende a manter a altura da árvore mínima, reduzindo o número de acessos a disco necessários para responder às consultas. No entanto, é difícil manter as estruturas balanceadas sem a existência de sobreposição entre os nós que cobrem regiões de alta densidade de objetos. O efeito disto é a degradação do tempo das consultas, pois várias subárvores devem ser analisadas para compor as consultas. Em outras palavras, minimizar a sobreposição entre os nós aumenta a eficiência das árvores métricas. Um meio efetivo para isto é flexibilizar o balanceamento das árvores métricas. Este trabalho apresenta um novo MAM dinâmico, chamado de DBM-tree (Density-Based Metric tree), que permite flexibilizar o balanceamento da estrutura, minimizando o grau de sobreposição entre os nós em regiões densas e, conseqüentemente, aumentando o seu desempenho para responder às consultas. Essa flexibilização é ajustada pelo usuário e é rigidamente controlada pela estrutura. A profundidade da árvore é maior em regiões de alta densidade, procurando um equilíbrio entre o número de acessos a disco para avaliar múltiplas subárvores e para a busca em profundidade em cada subárvore. A DBM-tree possui um algoritmo de otimização chamado de DBM-Slim-Down, que melhora o desempenho das árvores através da reorganização de elementos entre os seus nós. Os experimentos feitos com dados reais e sintéticos mostram que a DBM-tree supera em desempenho os MAMs tradicionais. Ela é, em média, $50 \%$ mais rápida que os MAMs tradicionais e reduz o número de acessos a disco e cálculos de distância em até 50\%. Depois de executado o algoritmo DBM-Slim-Down, o seu desempenho melhorou em até $30 \%$ para as consultas por abrangência e aos vizinhos mais próximos. Ainda, a $D B M$-tree é escalável considerando tempo total de processamento, número de acessos a disco e de cálculos de distância em relação ao tamanho do conjunto de dados indexado.

VIEIRA, M. R. DBM-tree: Método de acesso métrico sensível à densidade local, São Carlos, 2004. 69 p. Dissertação de Mestrado - Instituto de Ciências Matemáticas e de Computação - ICMC, USP. 


\begin{abstract}
A metric space is defined as a set of objects and a metric distance function that is used to measure the similarity between these objects. It allows the development of Metric Access Methods (MAMs) that are able to answer similarity queries in these datasets quickly. Usually these MAMs are materialized through a hierarchical structure called metric trees. These trees are kept balanced because it tends to maintain the height of the tree small, aiming to reduce the number of disk access required to answer queries. However, it is difficult to maintain the tree balanced without overlapping nodes covering a large number of objects, leading to the degradation of query performance. In other words, reducing the overlap among nodes increases the performance of metric trees. A possible solution is to relax the need to keep metric trees balanced. This work presents a new dynamic MAM called DBM-tree (Density-Based Metric tree), which changes the rule that imposes a rigid balancing policy, allowing a small amount of unbalancing in some regions of it. This unbalancing minimizes the degree of overlapping among some high-density nodes and, consequently, increases query answering performance. The amount of relaxation is set by the user and is strongly enforced in the tree. The height of the tree is higher in high-density regions, in order to keep a balance between searching in various subtrees and searching deeply in each subtree. The DBM-tree has an optimization algorithm called DBM-SlimDown that improves the performance in trees through reorganizing the elements among its nodes. The experiments performed over synthetic and real-world datasets showed that the DBM-tree outperforms the traditional MAMs. The DBM-tree is, in average, 50\% faster than traditional MAMs and reduces the number of distance calculations and disk accesses up to $50 \%$. After executing the DBM-Slim-Down algorithm, the performance achieves improvements up to $30 \%$ for range and k-nearest neighbor queries. Moreover, the DBM-tree is scalable regarding time, number of disk accesses and distance calculations.
\end{abstract}




\section{Lista de Figuras}

2.1 Exemplo de consultas por similaridade utilizando a função de distância $L_{2}$. O objeto $o_{q}$ é o objeto de busca enquanto os objetos cinza constituem os objetos do conjunto resposta $\boldsymbol{A}$. (a) Ilustra uma consulta por abrangência - $R Q\left(o_{q}, r_{q}\right)$ e (b) ilustra uma consulta aos $k$-vizinhos mais próximos -

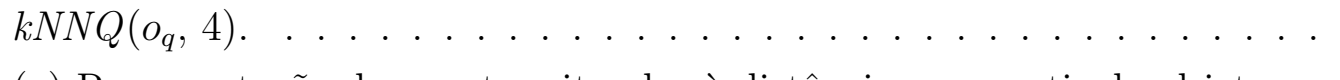

2.2 (a) Representação dos pontos situados à distância $r_{q}$ a partir do objeto $o_{q}$, considerando as diferentes métricas da família $L_{p}$. (b) Exemplos de consultas por abrangência em um conjunto de objetos: $R Q\left(o_{q}, r_{q}\right)$ sobre $<\mathfrak{D}$, $L_{1}>=\left\{o_{6}, o_{9}, o_{10}, o_{14}\right\} ; R Q\left(o_{q}, r_{q}\right)$ sobre $<\mathfrak{D}, L_{2}>=\left\{o_{4}, o_{6}, o_{9}, o_{10}, o_{14}\right\} ; \mathrm{e}$ $R Q\left(o_{q}, r_{q}\right)$ sobre $<\mathfrak{D}, L_{\infty}>=\left\{o_{1}, o_{2}, o_{4}, o_{6}, o_{9}, o_{10}, o_{14}\right\} \ldots \ldots \ldots$

3.1 Através da propriedade de desigualdade triangular é possível descartar qualquer objeto que esteja na região 1 ou 3, sem mesmo calcular a distância entre os objetos contidos nestas regiões e o objeto de consulta. Já os objetos que estiverem na região 2 não podem ser descartados apenas com o uso da desigualdade triangular. . . . . . . . . . . . . . . . . . . 16

3.2 Exemplo do primeiro nível de uma GH-tree [Chávez et al., 2001] . . . . . . 18

3.3 Exemplo de uma VP-tree de grau dois, cujo vantage point o $o_{11}$ é escolhido no primeiro nível com mediana igual a 3,1. No segundo nível são escolhidos os objetos $o_{7}$ e $o_{9}$, com mediana 2,9 e 4,0 , respectivamente. . . . . . . . . . 19

3.4 Como uma partição feita pelo vantage point $o_{10}$ pode ser dividida utilizando um segundo vantage point $o_{5}$, com 3 valores de cortes. . . . . . . . . . . . 20

3.5 Exemplo de uma $F Q$-tree no qual o objeto $o_{11}$ é usado como referência no primeiro nível e o objeto $o_{5}$ no segundo nível. . . . . . . . . . . . . . 21

3.6 Exemplo do primeiro nível de uma GNAT com $g=4$ [Chávez et al., 2001]. . 22 
3.7 Um exemplo do uso de dois omni-focos para gerar coordenadas em um conjunto de objetos. A consulta $R Q\left(o_{q}, r_{q}\right)$ pode descartar qualquer objeto que não esteja localizado na região escura. . . . . . . . . . . . . . .

3.8 Uso de dois representativos em uma DF-tree: um do nó, orep, e um global, para podar objetos durante as consultas. É possível descartar qualquer objeto que não esteja localizado na região mais escura da figura (região 3), através do uso da propriedade de desigualdade triangular e dos dois objetos representativos.

3.9 Estrutura lógica dos nós (a) índice (indexNode) e (b) folha (leafNode) da Slim-tree [Traina et al., 2002b].

3.10 Exemplo da estrutura lógica de uma Slim-tree contendo 7 cadeias de caracteres com a função de distância $L_{E d i t}$. . . . . . . . . . . . . . . . . . .

3.11 Representação de uma Slim-tree contendo 17 objetos em (a), e sua correspondente estrutura lógica em (b). Os círculos brancos em (a) representam os nós folhas, enquanto os de cor cinza representam os nós índice. Os pontos pequenos dos objetos, preenchidos de cor preta, representam os objetos representativos do nó. . . . . . . . . . . . . . . . . . . .

3.12 Exemplificação do mecanismo de quebra de nós segundo a política $M S T$ (Minimal Spanning Tree) em um conjunto de objetos: (a) estrutura do nó antes da divisão; (b) MST construída sobre os objetos do nó; (c) organização dos objetos depois da divisão do nó.

3.13 Exemplo da aplicação do algoritmo Slim-Down em três nós folhas. Em (a) estão os três nós antes da otimização, e uma consulta $R Q\left(o_{q}, r_{q}\right)$ localizada na região de sobreposição. Em (b) é ilustrada a nova configuração dos nós depois da execução do Slim-Down. A troca de apenas três objetos entre os nós foi suficiente para diminuir quase toda a sobreposição entre eles. As linhas interligando os objetos ao representativo de cada nó indicam a que nó eles pertencem.

3.14 Duas imagens geradas pelo MAMView apresentando uma Slim-tree carregada com um conjunto de dados contendo 150 objetos com 4 dimensões. (a) visualização da estrutura com o raio de cobertura dos nós. (b) uma outra visualização da mesma estrutura sem o raio de cobertura dos nós. . .

4.1 Estrutura do nó da DBM-tree. Este nó é capaz de armazenar $C$ entradas do tipo subárvore ou objeto. As entradas do tipo subárvore armazenam as informações referentes às subárvores enquanto as do tipo objeto armazenam os objetos que não são cobertos pelas subárvores. As informações referentes ao objeto representativo e o raio de uma subárvore estão sempre armazenadas no nível imediatamente superior. . . . . . . . . . . . . . . . 
4.2 Exemplo da estrutura lógica de uma DBM-tree contendo 8 cadeias de caracteres com a função de distância $L_{\text {Edit }}$. O objeto "alex" não é coberto pelas subárvores representadas pelos objetos "jose" e "maria". . . . . . . . . 36

4.3 Representação de uma DBM-tree contendo 16 objetos em (a), e sua correspondente estrutura lógica em (b). Os círculos em (a) representam os raios dos respectivos nós da estrutura. Os objetos $o_{19}$ e $o_{18}$ não são cobertos por nenhuma subárvore no nó em que estão armazenados. . . . . . . . . . . . .

4.4 Visualização da estrutura DBM-tree criada pelo MAMView para o conjunto de 5507 cidades brasileiras. Em (a) é mostrado todos os níveis da estrutura com os raios de cobertura dos nós; em (b) é mostrado apenas os níveis 5 , 6 e 7 da estrutura, também com os raios de cobertura dos nós. É possível verificar através das figuras que a profundidade é maior em regiões mais densas (região sudeste e costa leste do Brasil). . . . . . . . . . . . . . .

4.5 Alguns quadros da animação de uma $R Q$ realizada na $D B M$-tree carregada com o conjunto de 5507 cidades brasileiras. O objeto de consulta está representado pela estrela preta, o raio de abrangência pelo círculo preto, e os objetos pertencentes ao conjunto resposta pelos pontos pretos contidos no círculo preto (raio de abrangência). O primeiro quadro da animação é representado por (a), e a último por (f). Os quadros (b), (c), (d) e (e) representam visualizações intermediárias entre o quadro (a) e (f). . . . . .

5.1 Resultados das consultas $k N N Q$ (gráficos (a), (b) e (c)) e $R Q$ (gráficos (d), (e) e (f)), comparando o número médio de cálculos de distância (gráficos (a) e (d)), número médio de acessos a disco (gráficos (b) e (e)) e tempo total de processamento (gráficos (c) e (f)) para 500 consultas utilizando a DBM-tree, Slim-tree e M-tree no conjunto Cidades. . . . . . . . . . . .

5.2 Resultados das consultas $k N N Q$ (gráficos (a), (b) e (c)) e $R Q$ (gráficos (d), (e) e (f)), comparando o número médio de cálculos de distância (gráficos (a) e (d)), número médio de acessos a disco (gráficos (b) e (e)) e tempo total de processamento (gráficos (c) e (f)) para 500 consultas utilizando a DBM-tree, Slim-tree e M-tree no conjunto CorelHisto. . . . . . . . . . . . .

5.3 Resultados das consultas $k N N Q$ (gráficos (a), (b) e (c)) e $R Q$ (gráficos (d), (e) e (f)), comparando o número médio de cálculos de distância (gráficos (a) e (d)), número médio de acessos a disco (gráficos (b) e (e)) e tempo total de processamento (gráficos (c) e (f)) para 500 consultas utilizando a DBM-tree, Slim-tree e M-tree no conjunto Histogramas. . . . . . . . . . . . 56 
5.4 Resultados das consultas kNNQ (gráficos (a), (b) e (c)) e RQ (gráficos (d), (e) e (f)), comparando o número médio de cálculos de distância (gráficos (a) e (d)), número médio de acessos a disco (gráficos (b) e (e)) e tempo total de processamento (gráficos (c) e (f)) para 500 consultas utilizando a DBM-tree, Slim-tree e M-tree no conjunto Sintético2D. . . . . . . . . . . . 56

5.5 Resultados das consultas $k N N Q$ (gráficos (a), (b) e (c)) e $R Q$ (gráficos (d), (e) e (f)), comparando o número médio de cálculos de distância (gráficos (a) e (d)), número médio de acessos a disco (gráficos (b) e (e)) e tempo total de processamento (gráficos (c) e (f)) para 500 consultas utilizando a DBM-tree, Slim-tree e M-tree no conjunto Sintético6D.

5.6 Resultados das consultas $k N N Q$ (gráficos (a), (b) e (c)) e $R Q$ (gráficos (d), (e) e (f)), comparando o número médio de cálculos de distância (gráficos (a) e (d)), número médio de acessos a disco (gráficos (b) e (e)) e tempo total de processamento (gráficos (c) e (f)) para 500 consultas utilizando a DBM-tree, Slim-tree e M-tree no conjunto Sintético16D. . . . . . . . . . . . 57

5.7 Resultados das consultas $k N N Q$ (gráficos (a), (b) e (c)) e $R Q$ (gráficos (d), (e) e (f)), comparando o número médio de cálculos de distância (gráficos (a) e (d)), número médio de acessos a disco (gráficos (b) e (e)) e tempo total de processamento (gráficos (c) e (f)) para 500 consultas utilizando a DBM-tree, Slim-tree e M-tree no conjunto Sintético256D. . . . . . . . . . .

5.8 Resultados das consultas $k N N Q$ (gráficos (a), (b) e (c)) e $R Q$ (gráficos (d), (e) e (f)), comparando o número médio de cálculos de distância (gráficos (a) e (d)), número médio de acessos a disco (gráficos (b) e (e)) e tempo total de processamento (gráficos (c) e (f)) para 500 consultas utilizando a DBM-tree no conjunto Sintético16D. Os gráficos apresentam a comparação da $D B M-M M$ e da $D B M-G M M$ antes e depois da execução do algoritmo DBM-Slim-Down. . . . . . . . . . . . . . . . .

5.9 Escalabilidade da $D B M$-tree em relação ao tamanho do conjunto durante as consultas $k N N Q$ (gráficos (a), (b) e (c)) e $R Q$ (gráficos (d), (e) e (f)). Avaliando as medidas de: média de cálculos de distância (gráficos (a) e (d)); média de acessos a disco (gráficos (b) e (e)); e tempo total (gráficos (c) e (f)). O conjunto indexado foi o Sintético16D com 100.000 objetos. . .

A.1 Exemplo de árvores com dados numéricos: (a) árvore de cardinalidade 4 e grau 5; (b) árvore binária.

A.2 Exemplo de uma árvore $B$-tree de grau 5 e cardinalidade 4 contendo dados numéricos. . . . . . . . . . . . . . . . . . . . 72

A.3 Divisão do espaço de uma $B$-tree em regiões disjuntas. . . . . . . . . . . 73

A.4 Uma $B^{+}$-tree com seus nós internos (como uma $B$-tree) e folhas (conjunto seqüencial - interligado como uma lista ligada). 
A.5 Exemplo da estrutura lógica de uma $k$ - $d$-B-tree. Os pontos são simbolizados por $p i$ e a dimensão do espaço bidimensional por $x i$ e $y i$ [Gaede \& Günther, 1998]. . . . . . . . . . . . . . . . . . . . . 75

A.6 Exemplo da árvore $R$-tree: (a) representação dos nós em MBR; (b) representação da estrutura lógica da árvore. . . . . . . . . . . . . . . . . . . . 77

B.1 Arquitetura da biblioteca Arboretum e suas principais classes/interfaces de cada camada. As setas representam as interações entre as camadas. . . . . 81 


\section{Lista de Tabelas}

5.1 Descrição dos conjuntos de dados reais e sintéticos utilizados nos experimentos. . . . . . . . . . . . . . . . . . 50 50

5.2 Configuração da $M$-tree, Slim-tree e DBM-tree para os experimentos. . . . 52

5.3 Altura máxima das árvores para os conjunto de dados testados. . . . . . . 53

5.4 Tempo total de construção para os diversos conjuntos de testes, em s. . . . 53 


\section{Siglas}

$A E S A$

Approximating and Eliminating Search Algorithm.

DBM-tree

Density-Based Metric tree.

DF-tree

Distance Fields tree.

FQ-tree

Fixed Queries tree.

GBDI-ICMC-USP Grupo de Bases de Dados e Imagens - Instituto de Ciências Matemáticas e de Computação - USP.

GH-tree

Generalized Hyperplane Decomposition tree.

GNAT

Geometric Near-Neighbor Access Tree.

$k N N Q$

LAESA

$\mathrm{MA}$

Consulta aos $k$-Vizinhos mais próximos ( $k$-Nearest Neighbors Query).

MAE

Linear AESA.

Método de Acesso.

Método de Acesso Espacial.

MAENP

Método de Acesso Espacial Não-Pontual.

MAEP

Método de Acesso Espacial Pontual.

MAM

Método de Acesso Métrico.

MASI

Método de Acesso Seqüencial Indexado.

MBR

Minimum Bounding Rectangle (retângulo mínimo que envolve um objeto). 
Minimal Spanning Tree (Árvore de Caminho Mínimo - um dos método de divisão da Slim-tree).

MVP-tree

OId

$R Q$

SA-tree

SGBD

SS-tree

VP-tree
Multi-Vantage Point tree.

Object Identification (código de identificação do objetos).

Consulta por Abrangência (Range Query).

Spatial Approximation tree.

Sistema de Gerenciamento de Bases de Dados.

Sphere-Rectangle tree.

Vantage Point tree. 


\section{Tabelas de Símbolos}

C

$\mathfrak{D}$

$d\left(o_{1}, o_{2}\right)$

Ent $_{i}$

$k$ $k N N Q\left(o_{q}, k\right)$

$L_{E d i t}\left(o_{1}, o_{2}\right)$

$L_{p}$

$\mathrm{M}$

$O$

$o_{i}$

$o_{q}$
Cardinalidade ou capacidade máxima do nó.

Um domínio de objetos.

Função de distância métrica. $d\left(o_{1}, o_{2}\right)$, nos quais $\left\{o_{1}, o_{2}\right\} \in \mathfrak{D}$, representa a distância (similaridade) entre $o_{1}$ e $o_{2}$.

Número de objetos contidos na subárvore apontada pela entrada $i$ de um nó.

Quantidade de objetos que se deseja recuperar em uma $k N N Q$.

Representa uma consulta aos $k$-vizinhos mais próximos, cujo objeto de consulta é dado por $o_{q}$ e a quantidade de vizinhos por $k$.

Função de distância métrica (Levenshtein). A distância $L_{E d i t}\left(o_{1}, o_{2}\right)$ retorna o número mínimo de operações de edições (inserções, remoções e substituições de caracteres) necessárias para transformar a cadeia de caracteres $O_{1}$ na cadeia $O_{2}$.

Função de distância métrica (Minkowski).

Espaço métrico definido pelo par $<\mathfrak{D}, d()>$.

Subconjunto de $\mathfrak{D}$.

Elemento de $O$. Quando indicado, $o_{i}$ é usado de forma restrita, representando um objeto de um subconjunto $o_{i} \in O \subseteq \mathfrak{D}$.

Objeto de consulta pertencente a $\mathfrak{D}$. 
$o_{\text {rep }}$

$\operatorname{Ptr}_{i}$

$R_{i}$

$r_{q}$

$R Q\left(o_{q}, r_{q}\right)$
Objeto representativo de uma subárvore.

Ponteiro para o nó raiz da subárvore apontada pela entra $i$ de um nó. Raio de cobertura da subárvore apontada pela entrada $i$ de um nó. Raio de busca em uma $R Q$.

Representa uma consulta por abrangência cujo objeto de consulta é dado por $o_{q}$ e o raio por $r_{q}$. 


\section{Sumário}

Resumo

Abstract

iii

Lista de Figuras

iv

Lista de Tabelas

ix

Lista de Abreviaturas

$\mathrm{x}$

Siglas

$\mathrm{x}$

Lista de Símbolos

xii

Tabelas de Símbolos

xii

1 Introdução 1

1.1 Considerações Iniciais . . . . . . . . . . . . . . . . . . . . . . . . 1

1.2 Definição do Problema . . . . . . . . . . . . . . . . . . . 3

1.3 Organização do Documento . . . . . . . . . . . . . 5

2 Consultas por Similaridade e Espaço Métrico $\quad 7$

2.1 Introdução . . . . . . . . . . . . . . . . . . . . . 7

2.2 Tipos de Consulta por Similaridade . . . . . . . . . . . . . . . . . . 8

2.3 Espaço Métrico . . . . . . . . . . . . . . . . . . . . . . . . . . . . . . . 10

2.3 .1 Espaço Vetorial . . . . . . . . . . . . . . . . 11

2.4 Conclusão . . . . . . . . . . . . . . . . . . . . . . . . 12

3 Métodos de Acesso Métricos $\quad 14$

3.1 Introdução . . . . . . . . . . . . . . . . . . . . . 14 
3.2 Dados em Domínios Métricos . . . . . . . . . . . . . . . . 15

3.2.1 Principais Métodos de Acesso Métricos . . . . . . . . . . . . . 16

3.2 .2 O MAM dinâmico Slim-tree . . . . . . . . . . . . . . . . 24

3.2 .3 Visualizando Estruturas Métricas . . . . . . . . . . . . . . 31

3.3 Conclusão . . . . . . . . . . . . . . . . . . . . . . . . . . . . . 32

4 O Método de Acesso DBM-tree $\quad 34$

4.1 Introdução . . . . . . . . . . . . . . . . . . . . . . . . . . 34

4.2 Visão Geral do MAM DBM-tree . . . . . . . . . . . . . . . . 35

4.3 Organização da estrutura . . . . . . . . . . . . . . . . . . . 35

4.4 Construção da DBM-tree . . . . . . . . . . . . . . . . . . . . 36

4.5 Executando Consultas por Similaridade . . . . . . . . . . . . . . . . 42

4.6 Otimizando a Estrutura . . . . . . . . . . . . . . . . . . . . . . 43

4.7 Remoção de objetos . . . . . . . . . . . . . . . . . . . . . 45

4.8 Visualizando a Estrutura . . . . . . . . . . . . . . . . . . . . 46

4.9 Conclusão . . . . . . . . . . . . . . . . . . . . . . . 46

5 Experimentos $\quad 49$

5.1 Introdução . . . . . . . . . . . . . . . . . . . . . . . . . . . . . . . . 49

5.2 Materiais e Métodos . . . . . . . . . . . . . . . . 50

5.3 Resultados e Discussão . . . . . . . . . . . . . . . . . . . . . 52

5.3 .1 Altura Máxima . . . . . . . . . . . . . . . . . . . 52

5.3 .2 Tempo de Construção . . . . . . . . . . . . . . . . . . 53

5.3 .3 Consultas por Similaridade . . . . . . . . . . . . . 53

5.3 .4 Otimização da Estrutura . . . . . . . . . . . . . . . . . 58

5.3 .5 Escalabilidade . . . . . . . . . . . . . . . . . . 59

5.4 Conclusão . . . . . . . . . . . . . . . . . . . . . . . . . . 59

6 Conclusão $\quad 62$

6.1 Considerações Finais . . . . . . . . . . . . . . . . . . . . . . 62

6.2 Principais Contribuições deste Trabalho . . . . . . . . . . . . . . 63

6.3 Proposta para Trabalhos Futuros . . . . . . . . . . . . . . . 63

$\begin{array}{ll}\text { Referências Bibliográficas } & 65\end{array}$

A Métodos de Acesso para Domínios de Dados com Relação de Ordem 70

A.1 Introdução . . . . . . . . . . . . . . . . . . . . . . . . . . . 70

A.2 Definições sobre Árvores . . . . . . . . . . . . . . . . . . . . . 70

A.3 Dados em Domínios com Relação de Ordem Total . . . . . . . . . . . . . . 71

A.4 Dados Multidimensionais . . . . . . . . . . . . . . . . . . . . . 74

A.4.1 k-d-B-tree . . . . . . . . . . . . . . . . 75 
A.4.2 R-tree ........................... 76

A.4.3 Utilizando MAEs para indexar dados multimídia . . . . . . . . 78

B A Biblioteca de MAMs Arboretum $\quad 80$

B.1 Introdução . . . . . . . . . . . . . . . . . . . . . 80

B.2 Arquitetura da biblioteca de MAMs Arboretum . . . . . . . . . . 80

B.2.1 Interfaces e Classes da biblioteca Arboretum . . . . . . . . . . . . . 81

C Usando a Desigualdade Triangular $\quad 84$ 


\subsection{Considerações Iniciais}

O volume de dados armazenado e manipulado pelos Sistemas de Gerenciamento de Bases de Dados (SGBDs) vem crescendo muito nos últimos anos. Além disso, novos tipos de dados, mais complexos que os convencionais, estão sendo incorporados aos SGBDs. Estes novos tipos de dados incluem dados multimídia (imagem, áudio, vídeo e texto longo), informações geo-referenciadas, séries temporais, dados de telemetria, dados de engenharia e estatísticos, impressões digitais, dados genômicos e seqüências de proteínas.

A principal técnica utilizada para acelerar a busca de dados nos SGBDs é a indexação dos dados através de Métodos de Acesso (MAs), adaptados a cada domínio dos dados. Os domínios de dados em bases de dados tradicionais, tal como números e pequenas cadeias de caracteres, têm a relação de ordem total, o que permite o desenvolvimento dos SGBDs tradicionais para responder eficientemente às consultas, tais como consulta por igualdade e por intervalo. Os MAs mais utilizados em SGBDs são o B-tree e seus variantes.

Entretanto, a maioria dos domínios de dados complexos não define a relação de ordem total necessária para que consultas por intervalo possam ser realizadas, e as consultas por igualdade têm aplicação muito limitada. Porém, para estes dados, é possível estabelecer relações de similaridade entre pares de objetos, permitindo a realização de consultas por similaridade, mais natural a esses domínios de dados. Estas consultas retornam os objetos do conjunto de dados que atendem a certos critérios de similaridade em relação a um objeto de referência, também chamado de objeto central da consulta. Os MAs tradicionais não podem ser utilizados para indexar estes dados complexos, nem 
responder consultas por similaridade. Este fato levou ao desenvolvimento de MAs capazes de realizar tais consultas.

Usualmente os Métodos de Acesso Métricos (MAMs) são utilizados para indexar esses dados complexos, usando apenas os objetos e as distâncias (medida de similaridade) entre estes. A medida de distância pode ser abstraída por uma função de distância métrica capaz de quantificar a similaridade entre dois objetos (detalhada melhor no Capítulo 2). Domínios de dados que apresentam tal função são chamados domínios (ou espaços) métricos. Entre os mais importantes MAMs encontrados na literatura estão o M-tree [Ciaccia et al., 1997] e o Slim-tree [Traina et al., 2000] (detalhados melhor no Capítulo 3).

Em geral, estas estruturas são mantidas balanceadas pois isto minimiza a altura, e, teoricamente, o número de acessos a disco necessários para responder às consultas. No entanto, na maioria dos MAMs dinâmicos o número de acessos a disco não depende exclusivamente da altura das estruturas pois as regiões definidas pelos nós de um mesmo nível da estrutura pode não ser disjunta. Quer dizer, pode haver sobreposição das regiões definidas pelos nós em um mesmo nível nessas estruturas. Uma conseqüência imediata deste fato é que consultas localizadas em regiões onde ocorrem sobreposições fazem com que todos os nós que cobrem parte ou toda esta região necessitem ser analisados. Isso faz com que as árvores sejam percorridas tanto em largura quanto em profundidade.

Esta pesquisa partiu do princípio que o balanceamento da estrutura diminui o custo do acesso em profundidade da árvore, mas não controla o acesso em largura nos métodos que sofrem do efeito de sobreposição. Assim, o objetivo deste projeto foi criar um método que controla o acesso tanto em largura quanto em profundidade, procurando usar ambos os recursos para minimizar o número de acessos a disco e o número de cálculos de distância.

Assim, este projeto desenvolveu um novo MAM dinâmico, capaz de diminuir a taxa de sobreposição entre os nós através da flexibilização do balanceamento da estrutura, aproveitando a distribuição dos objetos no espaço. Essa flexibilização é ajustada durante a criação da estrutura e é rigidamente controlada para que a estrutura não se degenere.

O termo "método de acesso" pode ser encontrado ao longo do texto, possuindo o significado de conceito, a idéia em si, incorporando os algoritmos e a estrutura de dados que o implementa. Já o termo "índice" tem diferente significado de "método", significando uma instância da estrutura de dados gerada por um "método", a partir de um conjunto de dados de entrada. Já para os métodos específicos, eles estão no gênero feminino quando indicarem a instância da "estrutura" ou "árvore", e masculino para "método de acesso". Por exemplo, a Slim-tree (a instância da estrutura/árvore) e o Slim-tree (o método de acesso).

Outro esclarecimento a ser feito é que, ao longo do texto, os exemplos de conjuntos de dados complexos presentes em quase todas as figuras apenas apresentam objetos pontuais em duas dimensões por causa da facilidade de representá-los graficamente. Po- 
rém, a menos quando ressaltado, as explicações e exemplos poderão ser generalizados para quaisquer dimensões e quaisquer tipos de dados complexos.

\subsection{Definição do Problema}

Um Método de Acesso (MA) é um dos principais recursos dos SGBDs para conseguir um bom desempenho na recuperação dos dados armazenados. O conceito fundamental que embasa um MA é o uso de determinadas propriedades entre os objetos indexados. Através dessas propriedades é possível descartar um subconjunto dos dados indexados sem compará-los entre si, utilizando somente a comparação entre um dos objetos indexados e o objeto de consulta. Por exemplo, considere dados numéricos mantidos de maneira ordenada: neste caso a propriedade utilizada é a relação de ordem numérica entre os números (o número 5 é menor que 7, que por sua vez é menor que 10). Qualquer número indexado separa um subconjunto em duas partes: os que são menores e os que são maiores ao número indexado. Quando se deseja procurar por um determinado número, compará-lo com qualquer número indexado permite descartar uma das partes que o número indexado define.

Uma classe importante de MA é aquela na qual os métodos são baseados em estrutura hierárquica, também chamada de árvore, que adota um processo recursivo para a indexação dos dados. Nesta classe os objetos são divididos em blocos, usualmente chamados de nós, onde para cada nó é escolhido um objeto que pode ser utilizado para indexar todos os objetos do nó. Os nós que armazenam os objetos originais são chamados de nós folhas. Os objetos que são utilizados para indexar os demais são por sua vez agrupados em outros nós, chamados de nós internos da árvore. De cada nó interno é escolhido também um objeto para indexar, criando-se um novo nível (ou camada) de nós internos, e assim sucessivamente novos níveis vão sendo acrescentados, até que em um determinado nível apenas um nó seja necessário. Este nó é então chamado de nó raiz, e o processo de construção termina. Quando for necessário empreender uma busca nessa estrutura, compara-se o objeto de busca com os objetos da raiz, e com isso determinam-se as subárvores que precisam ser analisadas para prosseguir o processo de busca.

Note que se for possível estabelecer uma relação de ordem total entre os objetos, através da propriedade adotada para a comparação entre pares de objetos, apenas uma subárvore precisa ser avaliada em cada nível nas buscas. Caso a propriedade estabeleça uma relação de ordem parcial, então pode ser necessário avaliar mais de uma subárvore em cada nível. Por exemplo, a relação de ordem numérica em domínios numéricos, ou a relação de ordem lexicográfica em domínios de cadeias de caracteres são relações de ordem total, e, portanto, árvores criadas usando essas propriedades são navegadas avaliando apenas um nó em cada nível da estrutura. Já árvores construídas usando como propriedade a relação de ordem entre cada uma das coordenadas de um domínio espacial não possui uma relação de ordem total entre seus dados, e por isso pode ser necessário avaliar mais 
do que uma subárvore em cada nível da estrutura.

Existem diversas possíveis variações para a criação de árvores. Por exemplo, quando se escolhe um objeto para indexar um nó, esse objeto pode ou não ser mantido no nó onde ele já estava (e ser replicado no nó do nível seguinte). Caso ele seja mantido no nó original, todos os objetos indexados estarão nas folhas, caso contrário a recuperação de todos os objetos obriga a busca por todos os nós da árvore. Outra possível variação é permitir que as subárvores de um determinado nó tenham alturas diferentes. A altura de um nó é o número máximo de níveis que o separa do nó raiz. As árvores que têm todas as subárvores de cada nó sempre com a mesma altura são ditas balanceadas em altura, caso contrário são chamadas de não balanceadas ou desbalanceadas.

Quando utilizadas como MA em SGBDs, as árvores armazenam os nós como registros em disco, todos com um tamanho fixo pré-determinado. Isso faz com que a capacidade de cada nó também seja pré-determinada, e todos os nós internos e o nó raiz tenham a mesma capacidade de armazenamento de objetos. Os nós folhas também possuem uma mesma capacidade, que pode ou não ser igual àquela dos nós internos. Armazenar os nós como registros em disco é importante, pois permite a persistência e o suporte a um grande número de objetos, porém o acesso aos registros torna-se mais lento, obrigando os MAs a tentar reduzir ao máximo o número de acessos a disco para responder cada consulta. Caso uma árvore tenha muitos níveis, são necessários mais acessos a disco para percorrê-la, portanto é importante mantê-la com menor altura possível. Uma árvore não balanceada leva a diferentes quantidades de acessos a disco, dependendo de quais subárvores precisem ser avaliadas. Quando se permite que uma árvore seja não balanceada, é possível que o não balanceamento degenere completamente a árvore, pois em geral não se tem controle sobre como, ou quanto, a árvore fica desbalanceada. Por isso, apenas árvores balanceadas têm sido amplamente empregadas nos SGBDs.

Já em árvores métricas (MAMs baseados em estrutura hierárquica) que admitem sobreposição, o nível de sobreposição dos agrupamentos é tão ou mais influente no número de acessos a disco do que a altura. Por isto, este trabalho estudou a viabilidade de se criar uma árvore não balanceada para dados em domínios métricos, porém mantendo controle sobre o grau de desbalanceamento. Domínios métricos permitem calcular a distância entre quaisquer pares de objetos, portanto é possível identificar agrupamentos de objetos que estão próximos. As consultas em árvores métricas têm custo diferente das árvores que indexam dados em domínios ordenáveis, mesmo que elas sejam balanceadas, pois pode ser necessário avaliar mais do que uma subárvore de cada nó. Nesse caso, a minimização do número de subárvores que não podem ser descartadas em uma consulta pode ser mais importante do que manter a árvore balanceada.

Este trabalho apresenta um novo MAM dinâmico, chamado de DBM-tree (DensityBased Metric tree), que permite flexibilizar o balanceamento da estrutura, minimizando o grau de sobreposição entre os nós em regiões densas e, conseqüentemente, aumentando o seu desempenho para responder às consultas. A profundidade da árvore é maior em 
regiões de alta densidade, procurando um equilíbrio entre o número de acessos a disco para avaliar múltiplas subárvores e a busca em profundidade em cada subárvore.

Este trabalho também apresenta um algoritmo de otimização, chamado de $D B M$ Slim-Down, que melhora o desempenho das árvores através da reorganização de elementos entre os seus nós, e a visualização da estrutura e de consultas por similaridade (consulta por abrangência e aos $k$-vizinhos mais próximos) na $D B M$-tree.

Os experimentos feitos com dados reais e sintéticos mostram que a DBM-tree supera em desempenho os MAMs tradicionais (M-tree e Slim-tree). Ela é, em média, 50\% mais rápida que os MAMs tradicionais e reduz o número médio de acessos a disco e cálculos de distância em até $50 \%$ para responder consultas por similaridade. Depois de executado o algoritmo DBM-Slim-Down, o seu desempenho melhorou em até $30 \%$ para as consultas por abrangência e aos $k$-vizinhos mais próximos em relação ao número médio de acesso a disco. Ainda, a DBM-tree é escalável considerando o tempo total de processamento, o número de acessos a disco e de cálculos de distância em relação ao tamanho do conjunto de dados indexado.

\subsection{Organização do Documento}

Este documento apresenta a seguinte organização:

- No Capítulo 2 são formalizados e exemplificados os dois tipos mais comuns de consultas por similaridade: Consulta por abrangência e aos $k$-vizinhos mais próximos. Em seguida, são apresentadas as definições de espaço métrico e exemplificados algumas funções de distância métricas;

- No Capítulo 3 são apresentados as definições e exemplos dos principais MAMs encontrados na literatura;

- No Capítulo 4 é apresentado o MAM DBM-tree, seu princípio de funcionamento, algoritmos de consultas e otimização da estrutura, e a visualização da estrutura;

- No Capítulo 5 são apresentados os resultados experimentais obtidos usando a $D B M$-tree com dados reais e sintéticos, comparando-os com os MAMs $M$-tree e Slim-tree;

- O Capítulo 6 encerra esta dissertação, apresentando as considerações finais, principais contribuições e propostas para trabalhos futuros.

Este documento possui ainda 3 apêndices que trazem informações complementares ao entendimento deste trabalho:

- O Apêndice A apresenta os mais importantes métodos de acesso para dados em domínios com relação de ordem total e para dados multidimensionais; 
- O Apêndice B apresenta alguns detalhes sobre a implementação do DBM-tree e da biblioteca de árvore métricas Arboretum;

- Por fim, o Apêndice C ilustra o uso da desigualdade triangular no descarte (poda) de objetos e subárvores em árvores métricas. 


\section{Capítulo \\ 2 \\ Consultas por Similaridade e Espaço Métrico}

\subsection{Introdução}

Os Métodos de Acesso (MAs) dos Sistemas de Gerenciamento de Bases de Dados (SGBDs) tradicionais realizam buscas sobre os dados através das relações de igualdade e de ordem existentes nos dados armazenados (números e textos curtos). Porém, quando se utilizam SGBDs para armazenar dados multimídia, tais como imagens, sons e outras informações mais complexas, as buscas por igualdade ou por intervalo não se aplicam, ou simplesmente são de pouca serventia. Ou seja, dificilmente a tomografia ${ }^{1}$ do cérebro de um paciente onde se encontra um tumor é idêntica à de outro paciente, mesmo que apenas a região do tumor esteja destacada e que os tumores sejam do mesmo tipo. Neste caso, o grau de similaridade entre os dados é o fator mais importante.

Esse tipo de busca, denominada Consulta por Similaridade, consiste em procurar por objetos em um conjunto que, segundo algum critério de similaridade, sejam mais "parecidos" ou mais "distintos" com/de um determinado objeto. Em outras palavras, estas são consultas que consistem em comparar todos os objetos do conjunto com um objeto escolhido, selecionando apenas os elementos que atendam a um certo critério de similaridade. Por exemplo, procurando dar um diagnóstico mais preciso sobre o tumor no cérebro de um paciente, e até mesmo tentando encontrar subsídios para decidir como encaminhar o tratamento, um médico estaria interessado em encontrar as tomografias de

\footnotetext{
${ }^{1}$ tomografia é considerada como qualquer exame radiológico que permita visualizar as estruturas anatômicas na forma de cortes [Houaiss \& Villar, 2001]
} 
cérebro que apresentem um tumor semelhante àquele em estudo. Esse tipo de consulta, que leva em consideração a informação inerente ao objeto de referência, é chamado de Consulta Baseada em Conteúdo (Content-Based Query). Ou seja, a consulta é feita a partir do significado do conteúdo do objeto, e não a partir de informações descritivas associadas aos mesmos.

Para se determinar a similaridade entre os objetos, eles podem ser comparados diretamente ou a partir de vetores de características extraídos dos mesmos. Nos dois casos, uma função de distância $d()$ é definida para calcular o grau de similaridade, retornando um valor numérico que quantifica o quão similares estes objetos são. Por definição, esses valores são sempre maiores ou iguais a zero, tendo valores próximos de zero para objetos muito similares (zero para objetos iguais) e valores maiores para objetos menos similares. Esta função é chamada de função de dissimilaridade ou de função de distância e deveria ser sempre definida por um especialista no domínio em questão.

$\mathrm{Na}$ realidade, a função de distância indica a dissimilaridade entre dois objetos, e convém colocar que a similaridade é medida pelo seu inverso. Para simplificar a compreensão do texto, muitas vezes os autores estabelecem que a função de distância indica a similaridade, já que esta é facilmente obtida pela dissimilaridade.

Existem vários tipos de consultas por similaridade, sendo a consulta por abrangência e a consulta aos $k$-vizinhos mais próximos as mais comuns. Esses dois tipos de consultas são detalhadas a seguir.

\subsection{Tipos de Consulta por Similaridade}

Considere um conjunto de objetos $O=\left\{o_{1}, o_{2}, o_{3}, \ldots, o_{n}\right\}$ pertencentes a um domínio $\mathfrak{D}$, uma função de distância $d()$, os tipos mais comuns de consultas por similaridade são:

1. Consulta por Abrangência (Range Query - $R Q): R Q\left(o_{q}, r_{q}\right)$ é uma consulta por abrangência que visa recuperar objetos que se encontram a uma distância máxima $r_{q}$ (raio de busca), a partir do objeto de referência $o_{q}$ (objeto de busca), onde $o_{q} \in \mathfrak{D}$. Formalmente, pretende-se encontrar o subconjunto $A \subseteq O$ que atenda:

$$
R Q\left(o_{q}, r_{q}\right)=A=\left\{a \mid a \in O, d\left(o_{q}, a\right) \leq r_{q}\right\}
$$

A Figura 2.1(a) ilustra um exemplo de uma consulta por abrangência com a função de distância Euclidiana $L_{2}$. Os objetos contidos na circunferência (cor cinza) pertencem ao subconjunto $\boldsymbol{A}$.

Um exemplo de $R Q()$ seria: "Selecione as proteínas que difiram da proteína $\boldsymbol{P}$ por até 5 bases purínicas", no qual $o_{q}$ é a proteína $\boldsymbol{P}$, o universo $\mathfrak{D}$ é o conjunto de proteínas, o subconjunto $O \subseteq \mathfrak{D}$ é uma base de dados contendo as proteínas 

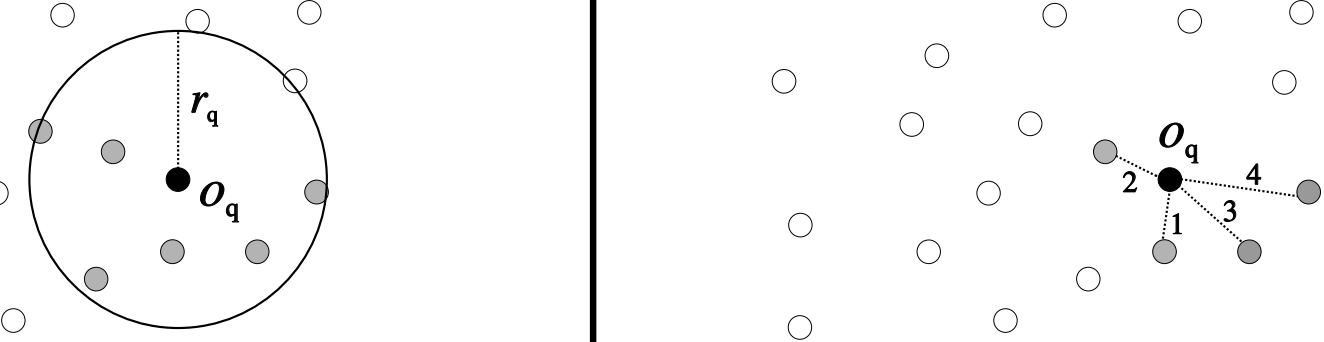

Figura 2.1: Exemplo de consultas por similaridade utilizando a função de distância $L_{2}$. O objeto $o_{q}$ é o objeto de busca enquanto os objetos cinza constituem os objetos do conjunto resposta $\boldsymbol{A}$. (a) Ilustra uma consulta por abrangência - $R Q\left(o_{q}, r_{q}\right)$ e (b) ilustra uma consulta aos $k$-vizinhos mais próximos - $k N N Q\left(o_{q}, 4\right)$.

conhecidas, o raio de busca $r_{q}=5$ bases purínicas e a métrica $d() \equiv L_{E d i t}$. Ou seja, $R Q(\boldsymbol{P}, 5)$.

2. Consulta aos k-Vizinhos Mais Próximos ( $k$-Nearest Neighbor Query - kNNQ): $k N N Q\left(o_{q}, k\right)$ é uma consulta aos $k$-vizinhos mais próximos que visa recuperar os $k$ objetos mais próximos ao objeto de referência $o_{q}$, no qual $o_{q} \in \mathfrak{D}$. Formalmente, pretende-se encontrar o subconjunto $A \subseteq O$ que atenda a:

$$
k N N Q\left(o_{q}, k\right)=A=\left\{a\left|a \in O, \forall o_{i} \in O-A, d\left(o_{q}, a\right) \leq d\left(o_{q}, o_{i}\right),\right| A \mid=k\right\}
$$

A Figura 2.1(b) ilustra um exemplo de uma consulta aos $k$-vizinhos mais próximos com a função de distância Euclidiana $L_{2}$. Os objetos conectados por uma linha ao objeto de consulta pertencem ao conjunto resposta.

Usando as mesmas definições para proteínas, um exemplo de $k N N Q()$ seria: "Selecione as 3 proteínas mais semelhantes à proteína $\boldsymbol{P}$ ", onde $k=3$, e é representado por $k N N Q(\boldsymbol{P}, 3)$.

Vale observar que em caso de empate, muito comum quando o domínio de $d()$ é discreto, a resposta de uma consulta $k N N Q$ pode conter muitos objetos encontrados à distância máxima, e então o número de objetos retornados pode ser maior do que $k$ (consulta com lista de empate), ou então qualquer combinação dos objetos empatados à distância máxima formando conjuntos de $k$ elementos (consulta sem lista de empate).

Uma consulta sem lista de empate pode ser interessante em algumas situações, e ela facilita a programação dos aplicativos que solicitam as consultas, pois ela sempre retorna um número definido (o número $k$ ) de objetos na resposta. No entanto ela não é uma consulta que retorna sempre os mesmos resultados, pois havendo empate, se não 
couberem todos os objetos empatados nos $k$ objetos da resposta, consultas iguais sobre a mesma base podem retornar objetos distintos dentre aqueles empatados.

Existe também a combinação destas duas consultas por similaridade, através dos operadores lógicos $\mathbf{E} / \mathbf{O U}$, gerando consultas complexas com o mesmo objeto de consulta de $R Q \wedge k N N Q$, para o operador $\mathbf{E}$, e $R Q \vee k N N Q$, para o operador $\mathbf{O U}$ [Arantes et al., 2003b].

Essas consultas por similaridade podem ser respondidas examinando todo o conjunto de dados $O$. Se não existir um índice para os dados então a busca seqüencial é a única maneira para responder às consultas. Um algoritmo de indexação é um procedimento para construir antecipadamente um índice projetado para minimizar cálculos de distâncias e acessos a disco quando consultas por similaridade são requisitadas. O índice pode ser custoso de se construir em um primeiro momento, mas seu custo pode ser amortizado com a economia de cálculos de distâncias e acessos a disco sobre várias consultas na base de dados [Chávez et al., 2001].

\subsection{Espaço Métrico}

O conceito de consulta por similaridade é bastante natural para o ser humano, porém, a elaboração de algoritmos capazes de executar este tipo de consulta exige a existência de leis algébricas para reger o comportamento do domínio dos objetos e sua relação com a função de distância. Inicialmente é apresentada a notação a ser utilizada no restante deste trabalho, que foi baseada nos trabalhos de [Ciaccia et al., 1997] e [Chávez et al., 2001].

Considere $\mathfrak{D}$ um domínio de objetos. O subconjunto finito $O \subseteq \mathfrak{D}$ representa o conjunto de objetos nas quais as consultas são efetuadas. A função $d()$ :

$$
d: \mathfrak{D} \times \mathfrak{D} \rightarrow \mathbb{R}^{+}
$$

corresponde à medida de "distância", também chamada de "similaridade", entre dois objetos. Isso significa que quanto menor a distância entre dois objetos, mais próximos ou semelhantes (similares) eles são. Se uma função de distância possuir as seguintes propriedades:

1. Simetria: $d\left(o_{1}, o_{2}\right)=d\left(o_{2}, o_{1}\right)$

2. Não negatividade: $0<d\left(o_{1}, o_{2}\right)<\infty$ se $o_{1} \neq o_{2}$ e $d\left(o_{1}, o_{1}\right)=0$

3. Desigualdade triangular: $d\left(o_{1}, o_{2}\right) \leq d\left(o_{1}, o_{3}\right)+d\left(o_{3}, o_{2}\right)$

onde $\left\{o_{1}, o_{2}, o_{3}\right\} \in \mathfrak{D}$, o espaço $\mathbb{M}$ definido pelo par $<\mathfrak{D}, d()>$ passa a ser chamado Espaço Métrico e a função de distância é chamada Função de Distância Métrica, ou simplesmente Métrica. Note que nenhuma informação geométrica, como num domínio espacial, pode ser usada em um espaço métrico. 
As funções métricas mais utilizadas são as métricas de Minkowski - $\left(L_{p}\right)$ [Wilson \& Martinez, 1997] (detalhadas na Seção 2.3.1) e de Levenshtein - $\left(L_{E d i t}\right)$ [Levenshtein, 1966], utilizada para o cálculo de similaridade entre cadeias de caracteres. A distância $L_{E d i t}\left(o_{1}, o_{2}\right)$ retorna o número mínimo de operações de edições (inserções, remoções e substituições de caracteres) necessárias para transformar a cadeia de caracteres $o_{1}$ na cadeia $O_{2}$.

As propriedades dos espaços métricos, principalmente a desigualdade triangular, permitem a elaboração de técnicas de indexação capazes de responder a consultas por similaridade de modo eficiente.

Uma característica dos espaços métricos é a possibilidade de englobar os espaços vetoriais, bem como espaços adimensionais (detalhados na Seção A.4.3 do Apêndice A), como conjuntos de imagens, palavras, sons ou dados genômicos, desde que para isto haja uma função de distância adequada. Um espaço é adimensional quando o domínio dos objetos não possue uma dimensão fixa.

\subsubsection{Espaço Vetorial}

Se os objetos do domínio $\mathfrak{D}$ correspondem a vetores de valores numéricos então o espaço é chamado Espaço Vetorial com Dimensão Finita, ou simplesmente Espaço Vetorial. Os objetos de um espaço vetorial de dimensão $n$ (ou $n$-dimensional) são representados por $n$ coordenadas de valores reais $\left\{x_{1}, \ldots, x_{k}\right\}$. Diversas métricas podem ser aplicadas para comparar os objetos de $\mathfrak{D}$, sendo as mais conhecidas as da família $L_{p}$ (ou Minkowski), definidas por:

$$
L_{p}\left(\left(x_{1}, \ldots, x_{k}\right),\left(y_{1}, \ldots, y_{k}\right)\right)=\left(\sum_{i=1}^{k}\left|x_{i}-y_{i}\right|^{p}\right)^{1 / p}
$$

A Figura 2.2(a) ilustra, para diferentes casos da família $L_{p}$, o conjunto de pontos que estão à mesma distância $r_{q}$, a partir de um centro $o_{q}$. No exemplo da Figura 2.2(a), a métrica $L_{1}$, também conhecida como Bloco ou Manhattan, corresponde ao somatório do módulo das diferenças entre as coordenadas. Nesse caso, o conjunto de pontos de mesma distância $r_{q}$ forma um losango com os diâmetros paralelos aos eixos das coordenadas. A métrica $L_{2}$, mais conhecida como distância Euclidiana, corresponde à função usual para distância entre vetores. O conjunto de pontos de mesma distância para $L_{2}$ forma uma circunferência. Calculando-se o limite da métrica 2.4 quando $p$ tende ao infinito, obtém-se a métrica $L_{\infty}$, também conhecida como Chebychev, dada pela métrica 2.5, no qual o conjunto de pontos com mesma distância formam um quadrado com os lados paralelos aos eixos das coordenadas.

$$
L_{\infty}\left(\left(x_{1}, \ldots, x_{k}\right),\left(y_{1}, \ldots, y_{k}\right)\right)=\max _{i=1}^{k}\left|x_{i}-y_{i}\right|
$$

A Figura 2.2(b) representa um conjunto de objetos $\left(o_{i}\right)$, um objeto de consulta 
a)
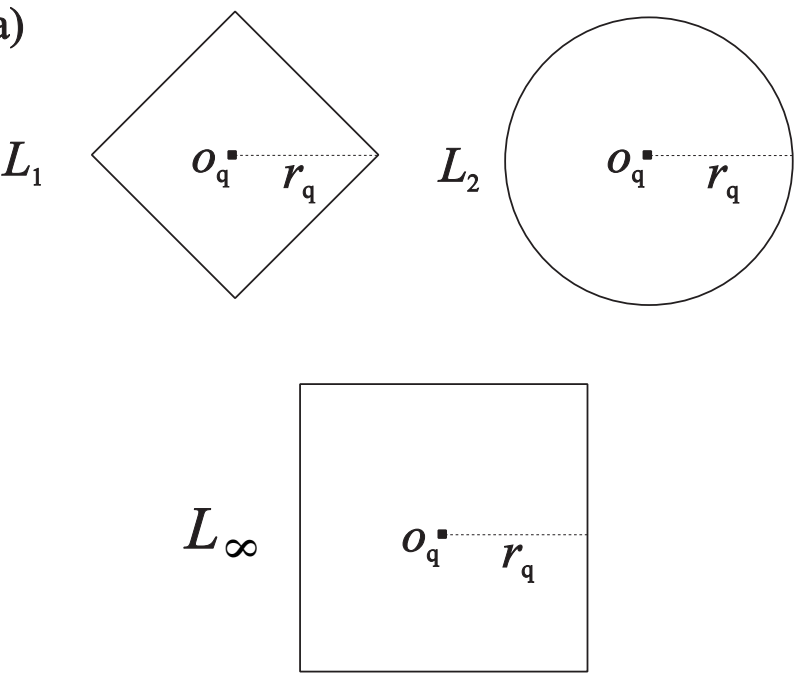

b)
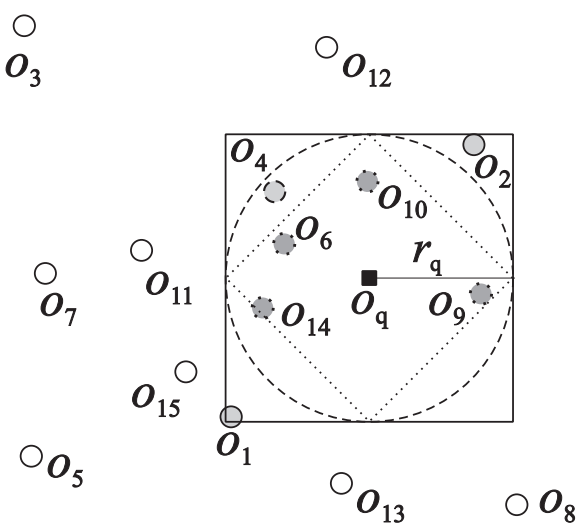

Figura 2.2: (a) Representação dos pontos situados à distância $r_{q}$ a partir do objeto $o_{q}$, considerando as diferentes métricas da família $L_{p}$. (b) Exemplos de consultas por abrangência em um conjunto de objetos: $R Q\left(o_{q}, r_{q}\right)$ sobre $<\mathfrak{D}, L_{1}>=\left\{o_{6}, o_{9}, o_{10}, o_{14}\right\}$; $R Q\left(o_{q}, r_{q}\right)$ sobre $<\mathfrak{D}, L_{2}>=\left\{o_{4}, o_{6}, o_{9}, o_{10}, o_{14}\right\} ;$ e $R Q\left(o_{q}, r_{q}\right)$ sobre $<\mathfrak{D}, L_{\infty}>=$ $\left\{o_{1}, o_{2}, o_{4}, o_{6}, o_{9}, o_{10}, o_{14}\right\}$.

$o_{q}$, o raio de consulta $r_{q}$ e três métricas utilizadas: $L_{1}, L_{2}$ e $L_{\infty}$. O conjunto de objetos $\left\{o_{6}, o_{9}, o_{10}, o_{14}\right\}$ contido no losango de consulta da Figura 2.2(b) faz parte do conjunto resposta para a métrica $L_{1} ;\left\{o_{4}, o_{6}, o_{9}, o_{10}, o_{14}\right\}$ contido na circunferência de consulta da Figura 2.2(b) faz parte do conjunto resposta para a métrica $L_{2}$; e $\left\{o_{1}, o_{2}, o_{4}, o_{6}, o_{9}, o_{10}, o_{14}\right\}$ contido no quadrado de consulta da Figura 2.2(b) faz parte do conjunto resposta para a métrica $L_{\infty}$.

As três componentes citadas anteriormente foram escolhidas por serem muito utilizadas em consultas por similaridade. Em um espaço vetorial é possível utilizar propriedades geométricas tais como ângulos, áreas, além das informações a respeito de distâncias.

\subsection{Conclusão}

Com o crescente uso de SGBDs para armazenar e recuperar dados complexos surgiu a necessidade deles responderem a consultas baseada no conteúdo dos dados, podendo ser respondidas através do uso de similaridade entre os dados. Entre os diversos tipos de consultas por similaridade, as mais utilizadas são as por abrangência e aos $k$-vizinhos mais próximos.

Os espaços métricos constituem a formulação matemática mais apropriada para abordar consultas por similaridade, pois para eles estas são operações naturais. Baseandose apenas em uma função de distância métrica e em suas propriedades é possível elaborar técnicas de indexação eficientes capazes de responder a essas consultas. Porém, a definição de uma função de distância apropriada não é uma tarefa simples.

A principal técnica utilizada para responder a consultas por similaridade é o uso 
dos chamados Métodos de Acesso Métricos (MAMs), que indexam os objetos apenas em função do valor de distância entre eles. Esses métodos não utilizam posições espaciais para indexar os dados, apenas de posições relativas entre eles. Os MAMs são detalhados melhor no próximo capítulo. 


\section{Métodos de Acesso Métricos}

\subsection{Introdução}

Uma das principais técnicas dos SGBDs para recuperar informações de maneira mais eficiente é o uso de Métodos de Acesso (MAs). Eles permitem acesso eficiente aos registros de dados pelos campos de indexação (chaves) que são usados para construir o índice. Através deles é possível localizar um dado de interesse armazenado em um determinado registro examinando apenas uma pequena fração do volume de dados total disponível.

Existe uma grande variedade de MAs, cada qual com sua particularidade e voltado para um domínio de dados específico. Os mais importantes são os métodos hierárquicos, mais conhecidos como árvores ( $B$-tree, $k$ - $d$-B-tree, $R$-tree, Slim-tree, e outros). As primeiras propostas foram desenvolvidas para trabalhar sobre dados numéricos e pequenas cadeias de caracteres, típicos dos SGBDs relacionais tradicionais, cujos domínios possuem a relação de ordem total entre os dados.

Com a necessidade dos SGBDs suportarem domínios de dados mais complexos, tais como dados geográficos, multimídia, biológicos, de engenharia e estatísticos, surge também a necessidade de desenvolver MAs mais adequados para esses novos domínios de dados. Portanto, foram propostos novos MAs para dar suporte a dados espaciais, inicialmente suportando baixas dimensões. Esses métodos são chamados de Métodos de Acesso Multidimensionais, também conhecidos como Métodos de Acesso Espaciais (MAEs). Uma explicação mais detalhada desses MAs encontra-se no Apêndice A.

Já para dados multimídia foram propostos os Métodos de Acesso Métricos (MAMs) suportando consultas por similaridade, na qual a similaridade entre os objetos 
é definida através de uma função de distância métrica. A abordagem dos MAMs assume que os objetos estão em um espaço métrico e relaciona os objetos apenas por suas relações de similaridade. Este capítulo apresenta uma revisão bibliográfica sobre os principais MAMs.

\subsection{Dados em Domínios Métricos}

Dados complexos, tais como dados multimídia, dados genômicos e cadeias de proteínas, entre outros, são geralmente comparados por similaridade, pois a comparação por igualdade não é muito usual, como os dados em domínios com relação de ordem total, ou por operações espaciais, como os dados multidimensionais. Esses dados podem ser naturalmente abstraídos por um espaço métrico, sendo por isto chamados de Dados em Domínios Métricos. Estes podem também comportar dados multidimensionais e adimensionais, desde que para isto seja definida uma função de distância métrica.

Dados em domínios métricos podem ser indexados através dos Métodos de Acesso Métricos (MAMs). A idéia geral da maioria dos MAMs consiste em selecionar um ou mais objetos e colocá-los como objetos representativos do conjunto. Quando um objeto $o_{i}$ é inserido, as distâncias entre ele e cada um dos representativos são calculadas e armazenadas junto com seus dados. Os MAMs são diferenciados: pela forma como os representativos são escolhidos; como os objetos são dispostos em relação aos representativos; e se podem sofrer inserções e remoções de objetos sem degenerar a estrutura, uma vez a estrutura já criada (dinâmicos ou estáticos). A Seção 3.2.1 faz um levantamento dos mais importantes MAMs encontrados na literatura.

Como as distâncias entre todos os objetos armazenados e cada um dos objetos representativos são conhecidas, a propriedade de desigualdade triangular pode ser usada durante uma consulta por similaridade para descartar objetos que, com certeza, não fazem parte do conjunto resposta. A vantagem é que o descarte pode ser feito sem a necessidade de calcular as distâncias entre os objetos armazenados e o objeto de consulta. Dessa forma, a quantidade de cálculos de distância em uma consulta é reduzida, proporcionando um bom desempenho para responder a consultas.

O descarte por desigualdade triangular é feito da seguinte forma: dados o espaço métrico $\mathbb{M}=\left\langle\mathfrak{D}, d()>\right.$, o conjunto de objetos $O \subseteq \mathfrak{D}$, o objeto de consulta $o_{q} \in \mathfrak{D}$, o raio de consulta $r_{q}$ e um objeto representativo $o_{r e p}$, um objeto $o_{i} \in O$ poderá ser descartado se, e somente se, uma das duas condições a seguir forem satisfeitas:

$$
\begin{aligned}
& d\left(o_{\text {rep }}, o_{i}\right)<d\left(o_{\text {rep }}, o_{q}\right)-r_{q} \\
& d\left(o_{\text {rep }}, o_{i}\right)>d\left(o_{\text {rep }}, o_{q}\right)+r_{q}
\end{aligned}
$$




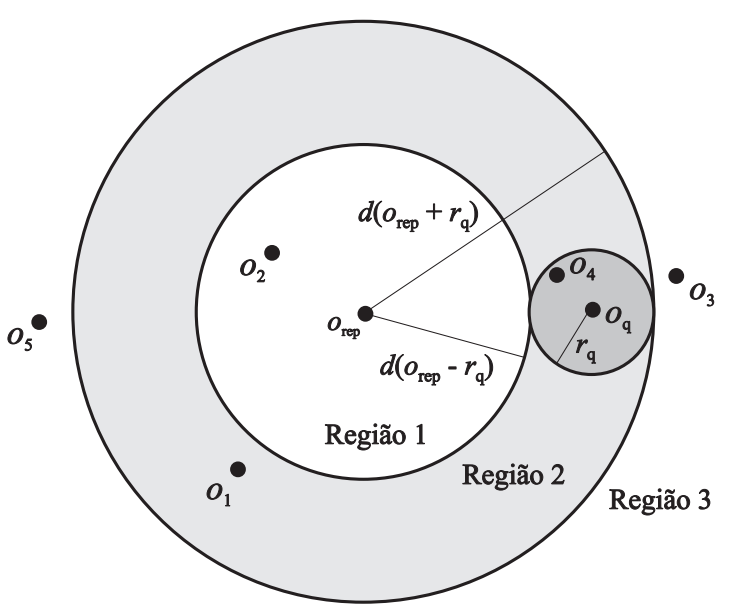

Figura 3.1: Através da propriedade de desigualdade triangular é possível descartar qualquer objeto que esteja na região 1 ou 3, sem mesmo calcular a distância entre os objetos contidos nestas regiões e o objeto de consulta. Já os objetos que estiverem na região 2 não podem ser descartados apenas com o uso da desigualdade triangular.

Note que $d\left(o_{r e p}, o_{i}\right)$ foi previamente obtida e armazenada com $o_{i}$ na estrutura de indexação. Na Figura 3.1, a região 1 equivale à condição 3.1 e a região 3 à condição 3.2 . Qualquer objeto que estiver na região 1 ou 3 pode ser descartado através da propriedade de desigualdade triangular sem calcular sua distância com o objeto da consulta. Já na região 2, há a necessidade de se calcular a distância entre o objeto de consulta e os objetos pertencentes a região.

Os objetos $\left\{o_{1}, o_{2}, o_{3}, o_{4}, o_{5}\right\}$ pertencem ao conjunto $O$. Os objetos $\left\{o_{2}, o_{3}, o_{5}\right\}$ podem ser descartados sem nenhum cálculo de distância adicional; o objeto $o_{1}$ não pode ser descartado, mas não faz parte do conjunto resposta; e $o_{4}$ não pode ser descartado e faz parte do conjunto resposta. A prova do descarte utilizando a desigualdade triangular pode ser obtida no Apêndice C ou em [Burkhard \& Keller, 1973].

\subsubsection{Principais Métodos de Acesso Métricos}

Para as definições dadas a seguir, considere o espaço métrico $\mathbb{M}$ definido pelo par $<\mathfrak{D}, d()>$ e o conjunto de objetos $O \subseteq \mathfrak{D}$. Esta seção se destina a apresentar, resumidamente, os principais MAMs encontrados na literatura. O trabalho de Chávez et al. em [Chávez et al., 2001] e de Hjaltason e Samet em [Hjaltason \& Samet, 2003] são boas referências para estudos que requeiram uma abordagem mais detalhada e abrangente.

Existem vários trabalhos de pesquisas voltados a estudar como responder a consultas por similaridade de forma eficiente. O primeiro trabalho encontrado na literatura envolvendo a indexação de dados em domínios métricos é o de Burkhard e Keller [Burkhard \& Keller, 1973]. Nele são propostas três técnicas para particionar o espaço métrico dos dados em uma maneira recursiva, no qual o processo recursivo é materializado através de árvores. Elas são adequadas para funções de distância que retornem valores discretos: 
- A primeira técnica é uma decomposição hierárquica multivias. No primeiro nível é escolhido arbitrariamente um objeto representativo do domínio e os demais objetos são agrupados conforme a sua distância ao representativo. Os objetos que possuem uma mesma distância são agrupados em um mesmo grupo. Isso só é possível porque os valores das distâncias são sempre discretos. A mesma composição hierárquica segue em todos os outros grupos recursivamente, criando uma estrutura hierárquica multivias;

- A segunda técnica divide o espaço dos dados em função de um número fixo de objetos representativos. Para cada partição é escolhido arbitrariamente um objeto representativo, e o raio é calculado segundo a distância máxima entre o objeto representativo e qualquer outro objeto do conjunto. Os objetos em cada partição são divididos da mesma maneira recursivamente, criando uma estrutura hierárquica multivias. Cada nó da estrutura guarda os objetos representativos, os raios e ligações para os conjuntos de objetos indexados. Para que um objeto faça parte de um subconjunto específico, sua distância ao objeto representativo tem que ser menor ou igual ao respectivo raio máximo;

- A terceira técnica é similar à segunda, apenas com o requisito adicional que a distância máxima entre quaisquer dois objetos em um mesmo grupo não seja maior que uma dada constante $\boldsymbol{c}$, cujo valor de $\boldsymbol{c}$ é diferente para cada nível da estrutura. O grupo satisfazendo esse critério é chamado de clique. A escolha do valor de $\boldsymbol{c}$ tem que garantir que todos os objetos do espaço estejam em pelo menos um dos cliques, podendo um objeto aparecer em mais que um clique. Em seguida, um objeto arbitrário de cada clique é escolhido como seu representativo.

Os objetos representativos que aparecem nas três técnicas anteriores são utilizados para descartar objetos e subárvores durante uma dada consulta.

Em uma outra abordagem, Shasha e Wang [Shasha \& Wang., 1990] sugerem o uso de distâncias pré-computadas entre alguns pares de objetos selecionados para aumentar o descarte durante a fase de consulta e estimar distâncias entre objetos. O objetivo dessa abordagem é a minimização do número de cálculos de distância ao máximo possível, pois eles são muito custosos. Essa técnica de armazenagem e uso de distâncias précomputadas para estimar distâncias entre objetos pode ser eficiente para um conjunto de dados pequeno (poucos objetos). Porém, se o conjunto de dados for muito grande, o espaço para armazenar a matriz de distâncias torna-se inviável. As técnicas $A E S A$ (Approximating and Eliminating Search Algorithm) [Vidal Ruiz, 1994] e LAESA (Linear $A E S A)$ [Micó et al., 1994] são semelhantes à de Shasha e Wang.

A seguir serão detalhados os principais MAMs em forma de estrutura hierárquica, que estão agrupados em estáticos e dinâmicos. 


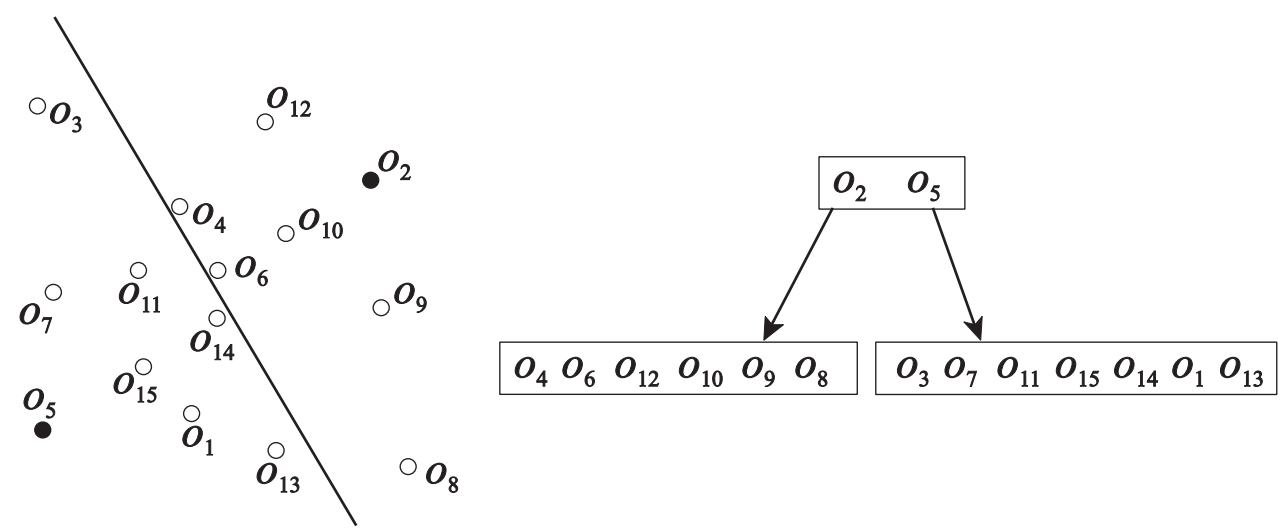

Figura 3.2: Exemplo do primeiro nível de uma GH-tree [Chávez et al., 2001].

\subsubsection{MAMs Estáticos}

Em [Uhlmann, 1991], Uhlmann introduziu dois MAMs hierárquicos para consultas por similaridade, chamados de Árvores Métricas. Esses dois métodos podem manipular valores contínuos retornados pela função de distância. O primeiro método proposto em [Uhlmann, 1991] é uma estrutura em forma de árvore binária e é referenciado por Decomposição de Hiperplanos Generalizados (Generalized Hyperplane decomposition - GH-tree), e corresponde à segunda técnica proposta em [Burkhard \& Keller, 1973]. No GH-tree, o espaço é dividido usando dois objetos diferentes, $o_{x}$ e $o_{y}$, definindo duas regiões. O hiperplano generalizado entre dois objetos é definido como o conjunto de objetos $o_{i}$ satisfazendo a equação $d\left(o_{x}, o_{i}\right)=d\left(o_{y}, o_{i}\right)$. As duas regiões, então, são definidas como o conjunto de pontos que estão mais próximos a um objeto do que a outro.

Sua construção é feita da seguinte forma: cada nó é composto por dois objetos, $o_{1}$ e $o_{2}$, escolhidos arbitrariamente; os objetos mais próximos a $o_{1}$ são armazenados na subárvore esquerda do nó; os objetos mais próximos a $o_{2}$ são armazenados na subárvore direita do nó. O processo se repete recursivamente até que todos os objetos tenham sido inseridos. Se os dois objetos escolhidos para gerar o hiperplano forem selecionados apropriadamente, a árvore tende a ser balanceada. A Figura 3.2 representa o primeiro nível de uma GH-tree, sendo os objetos $O_{2}$ e $O_{5}$ escolhidos para definir o hiperplano. Os objetos $\left\{o_{4}, o_{6}, o_{12}, o_{10}, o_{9}, o_{8}\right\}$ estão mais próximo de $o_{2}$ do que $o_{5}$, por isso estão na subárvore esquerda. Os demais estão na subárvore direita pois estão mais perto de $o_{5}$ do que $\mathrm{O}_{2}$.

O segundo método proposto por Uhlmann é referenciado como Decomposição por Bolas (Ball Decomposition), sendo similar à primeira técnica em [Burkhard \& Keller, 1973]. Nesse método, o espaço é dividido usando um único objeto $o_{i}$. As regiões associadas com os nós correspondem aos cortes em volta de $o_{i}$. Esses dois métodos propostos em [Uhlmann, 1991] originaram vários outros métodos detalhados a seguir.

Em [Yianilos, 1993] foi definido o método chamado VP-tree (Vantage Point tree), 

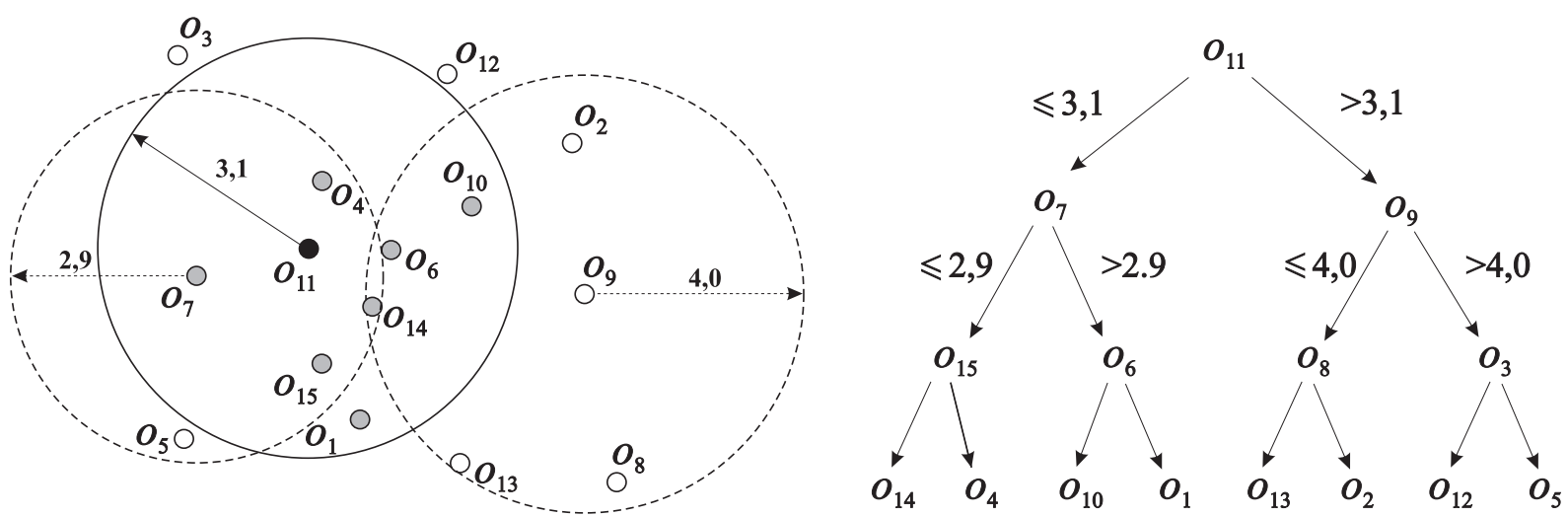

Figura 3.3: Exemplo de uma VP-tree de grau dois, cujo vantage point $o_{11}$ é escolhido no primeiro nível com mediana igual a 3,1. No segundo nível são escolhidos os objetos $O_{7}$ e $o_{9}$, com mediana 2,9 e 4,0 , respectivamente.

que é baseado no método Ball Decomposition de Uhlmann. O VP-tree basicamente divide o espaço de dados em cortes sobre um vantage point (objeto representativo) escolhido em cada nível da árvore, gerando uma VP-tree binária (ver Figura 3.3). Para uma VP-tree binária, cada nó armazena um objeto pertencente ao conjunto de dados, um raio $r_{p}$ para dividir o espaço métrico, e uma ligação para as subárvores esquerda e direita. O raio é usado como critério para decidir em qual subárvore um novo objeto deve ser inserido. Ou seja, considerando o objeto $o_{i}$ do nó raiz e um novo objeto $o_{y} \in O-\left\{o_{i}\right\}$, se $d\left(o_{i}, o_{y}\right) \leq r_{p}$ então o objeto $o_{y}$ deve ser inserido na subárvore esquerda da raiz; senão deve ser inserido na subárvore direita da raiz.

O mesmo princípio é recursivamente aplicado para os níveis inferiores da árvore, seguindo sua hierarquia (da raiz para as folhas). O valor de $r_{p}$ é definido como o valor da mediana das distâncias dos objetos restantes, procurando manter a árvore balanceada. A Figura 3.3 representa uma VP-tree binária, cujo vantage point escolhido no nível raiz é o $o_{11}$, e no segundo nível são o $o_{7}$ e o $o_{9}$. Os objetos cujas distâncias em relação a $o_{11}$ são menores ou iguais à mediana $(3,1)$, serão inseridos na subárvore esquerda, os maiores na subárvore direita. Em [Yianilos, 1993] são fornecidos resultados em VP-trees multivias e também formas de escolha dos melhores vantage points. Chiueh em [Chiueh, 1994] propôs um algoritmo para o $V P$-tree responder $k N N Q()$ e também foi proposto um novo algoritmo para a escolha dos vantage points, melhorando a estrutura para as consultas.

Em [Fu et al., 2000] foram propostas algumas melhorias na VP-tree para permitir inserções e remoções de objetos. Porém, esses algoritmos são consideravelmente complexos, podendo levar a uma reorganização completa de todo o índice. Além disso, uma árvore otimizada só pode ser obtida através de operações de carregamento em lote (bulk loading), em que todo o conjunto precisa ser conhecido no momento da construção.

Em outro trabalho [Yianilos, 1998] Yianilos propôs excluir da árvore todos os objetos próximos à região limítrofe definida pelo raio, e armazená-los em uma estrutura de diretórios (buckets). Após completar a construção da árvore, os diretórios são organiza- 


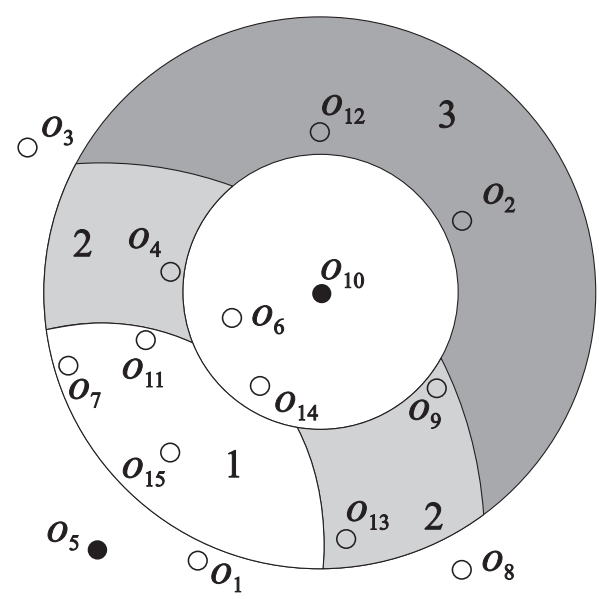

Figura 3.4: Como uma partição feita pelo vantage point $o_{10}$ pode ser dividida utilizando um segundo vantage point $o_{5}$, com 3 valores de cortes.

dos recursivamente. O processo é repetido, gerando um "floresta" de árvores. O método é chamado de Excluded Middle VP-Forest. Em [Gennaro et al., 2001] esse método foi estendido para usar uma função de hashing e organizar a floresta em páginas de disco, criando o método Similarity Hashing. Em [Dohnal et al., 2003] são mostradas outras formas de divisão do espaço para o MAM VP-tree.

Em [Bozkaya \& Özsoyoglu, 1997] e [Bozkaya \& Özsoyoglu, 1999], Bozkaya e Özsoyoglu propõem uma generalização do VP-tree chamado de MVP-tree (Multi-Vantage Point tree). Nesse MAM, o espaço é dividido usando mais do que um vantage point em cada nível, no qual informações sobre as distâncias dos objetos aos vantage points dos níveis superiores são armazenados nas folhas para descarte de objetos. Um MVP-tree é caracterizado por quatro parâmetros: o número de vantage points em cada nó (apenas 2 vantage points são considerados em [Bozkaya \& Özsoyoglu, 1997]); o número de partições criadas por cada vantage point $\boldsymbol{v}$; a capacidade máxima do nó folha; e o número de distâncias que podem ser armazenadas para os objetos no nó folha.

Em cada nó, o primeiro vantage point divide o espaço em $v$ partes usando $v-1$ valores de cortes, enquanto o vantage point seguinte divide a região resultante em mais $v$ partições, utilizando $v-1$ valores de cortes para cada partição. Na Figura 3.4 é ilustrado como uma partição feita pelo vantage point $o_{10}$ é dividida pelo segundo vantage point $o_{5}$. Para dividir o espaço em $v$ cortes, os objetos de dados são ordenados em relação a sua distância ao vantage point, e então divididos em $v$ grupos de (quase) igual cardinalidade. Os valores de distância $v-1$ usados para dividir o espaço de dados (valores de cortes) são armazenados em cada nó interno da árvore. Os $v^{2}$ grupos de objetos são, então, recursivamente indexados pelos $v^{2}$ filhos do nó raiz.

Cada nó folha armazena as distâncias entre cada entrada e os dois vantage points da folha, bem como as distâncias aos vantage points entre o caminho da raiz até o nó folha contendo a entrada. Isso permite diminuir, através da desigualdade triangular, a quantidade de cálculos de distâncias durante consultas em relação ao VP-tree. Durante 

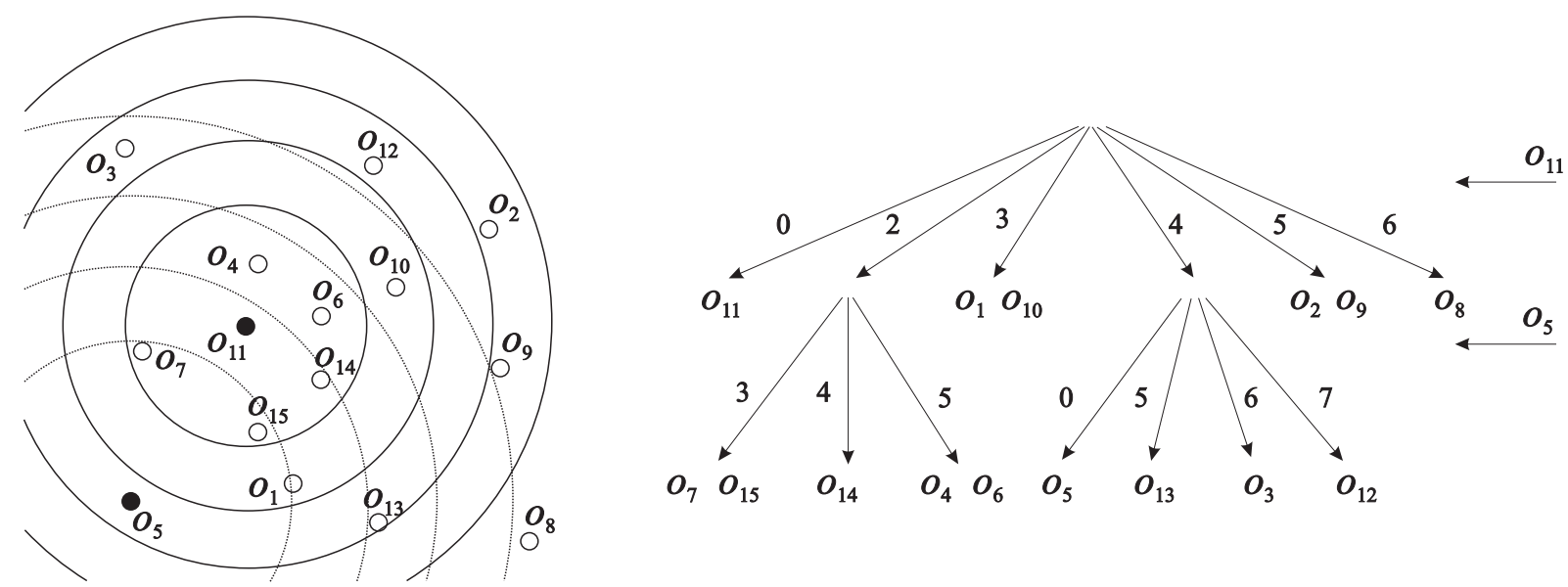

Figura 3.5: Exemplo de uma $F Q$-tree no qual o objeto $o_{11}$ é usado como referência no primeiro nível e o objeto $O_{5}$ no segundo nível.

a fase de construção, em cada nível, o primeiro vantage point é escolhido aleatoriamente, enquanto o segundo vantage point é o que tem a maior distância em relação ao primeiro vantage point. Com isso, o descarte de objetos aumenta durante a fase de consulta.

O MAM FQ-tree (Fixed-Queries tree), apresentado em [Baeza-Yates et al., 1994], é outro método em forma de árvore multivias que faz uso de objetos de referência para dividir o espaço métrico. Sua principal diferença em relação ao VP-tree é que um único objeto de referência é usado para todos os nós internos pertencentes a um mesmo nível da árvore. Portanto, o número de objetos de referência é igual à altura da árvore. A divisão do espaço na $F Q$-tree é similar à primeira técnica em [Burkhard \& Keller, 1973]. A Figura 3.5 representa uma $F Q$-tree com 2 objetos de referência: $o_{11}$ (primeiro nível) e $o_{5}$ (segundo nível). No primeiro nível os objetos são agrupados em relação à distância ao objeto de referência $O_{11}$, e no segundo nível em relação ao $O_{5}$.

Em [Brin, 1995] foi proposto o GNAT (Geometric Near-neighbor Access Tree), que é uma árvore multivias e funciona de forma semelhante a GH-tree, só que são escolhidos mais do que dois representativos por nó. A construção é feita da seguinte forma: $g$ representativos (um para cada conjunto) são escolhidos no nível superior; cada um dos objetos restantes é associado a um dos $g$ representativos, dependendo de qual representativo ele tem a menor distância; para cada representativo são guardadas as distâncias mínima e máxima aos outros representativos no nó, para que seja possível descartar objetos e conjuntos, através da desigualdade triangular, durante as consultas; a árvore é construída recursivamente para cada conjunto no nível seguinte. O número de representativos $g$ é parametrizado e escolhido para ser um valor diferente em cada nó da árvore, dependendo da sua cardinalidade. A árvore GNAT é comparada com a VP-tree binária e é mostrado em [Brin, 1995] que o tempo de construção da GNAT é mais demorado que a VP-tree, porém os algoritmos de consulta fazem menos cálculos de distância. A Figura 3.6 ilustra o primeiro nível de uma GNAT com 4 representativos: $\left\{o_{2}, o_{3}, o_{5}, o_{9}\right\}$. Em [Navarro, 2002] é mostrado uma variação do GNAT, chamado de SA-tree (Spatial Approximation tree) . 

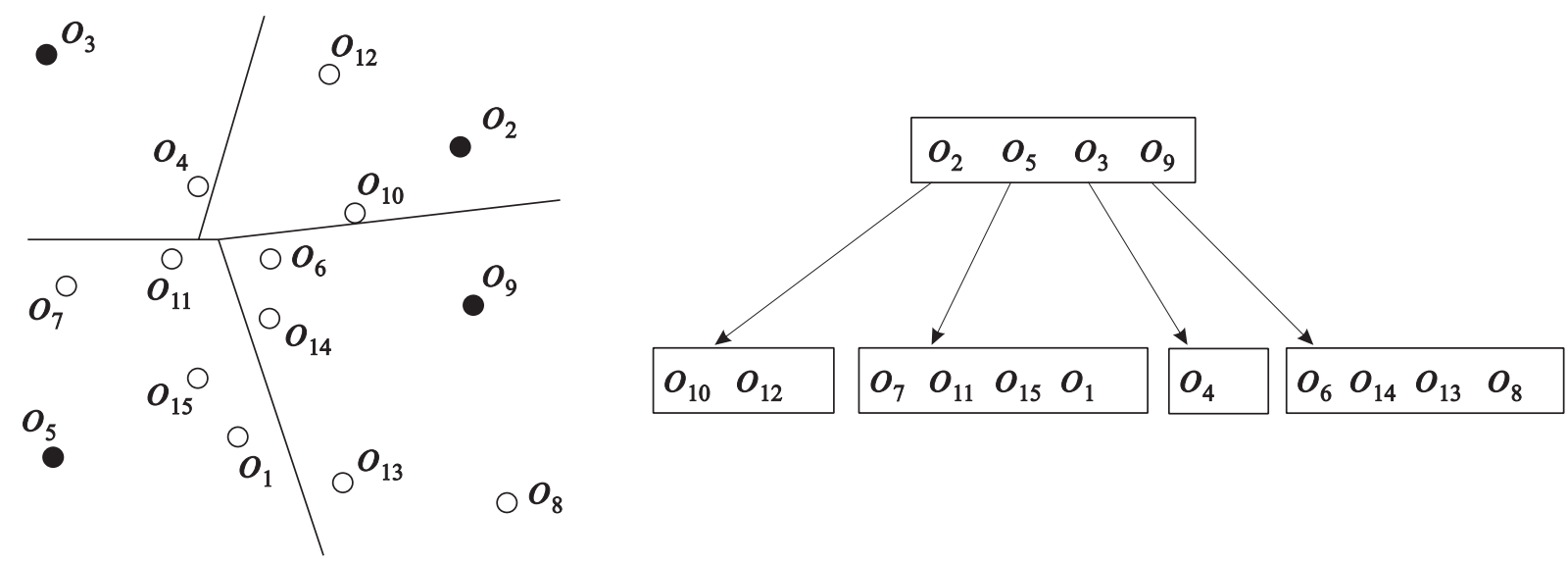

Figura 3.6: Exemplo do primeiro nível de uma GNAT com $g=4$ [Chávez et al., 2001].

Todos os MAMs em forma de árvore descritos até este ponto nesta seção são estáticos, ou seja, todos constroem a estrutura de indexação utilizando todo o conjunto de dados disponível numa única operação, limitando a sua aplicação em ambientes de bases de dados dinâmicas. Além disto, todos constroem as árvores em um processo recursivo do nível raiz em direção as folhas (top-down), por isso não há garantia de permanecerem balanceadas no caso de inserções e remoções de objetos. Conseqüentemente, elas requerem reorganizações custosas para evitar degradação do seu desempenho.

\subsubsection{MAMs Dinâmicos}

O primeiro MAM dinâmico a surgir na literatura foi apresentado por Ciaccia et al. em [Ciaccia et al., 1997] com o nome de $M$-tree. Ele pode ser visto como uma adaptação do MAE $R$-tree para indexar dados em domínios métricos. Ao contrário dos outros métodos citados, ele permite a inserção de objetos a qualquer momento, fazendo deste um método dinâmico que não exige reestruturações periódicas. Além disto, sua construção é feita de baixo para cima (bottom-up), garantindo o balanceamento da estrutura.

$\mathrm{Na} M$-tree todos os objetos são armazenados apenas nas folhas, e a interseção das regiões do espaço métrico, abrangidas por duas subárvores de um mesmo nó, pode não ser vazia. Ela armazena um dado conjunto de objetos em nós folhas de tamanho fixo, que correspondem às regiões do espaço métrico. Cada entrada do nó folha contém o identificador do objeto, os dados para o cálculo de distância, e a distância ao objeto representativo, o qual também é armazenado no nó pai. Cada entrada do nó interno armazena uma ligação para a sua subárvore (nó filho), um objeto representativo, sua distância ao objeto representativo pai (com exceção do nó raiz), e o raio da região que acomoda todos os objetos indexados pela entrada (chamado de raio de cobertura). Nas buscas, os objetos são descartados pelo uso do raio de cobertura e das distâncias dos objetos ao seus objetos representativos.

Resultados experimentais comparando a $M$-tree com a $R^{*}$-tree são mostrados em [Ciaccia et al., 1997]. Em [Ciaccia \& Patella, 1998] e [Traina et al., 1999] são mostrados 


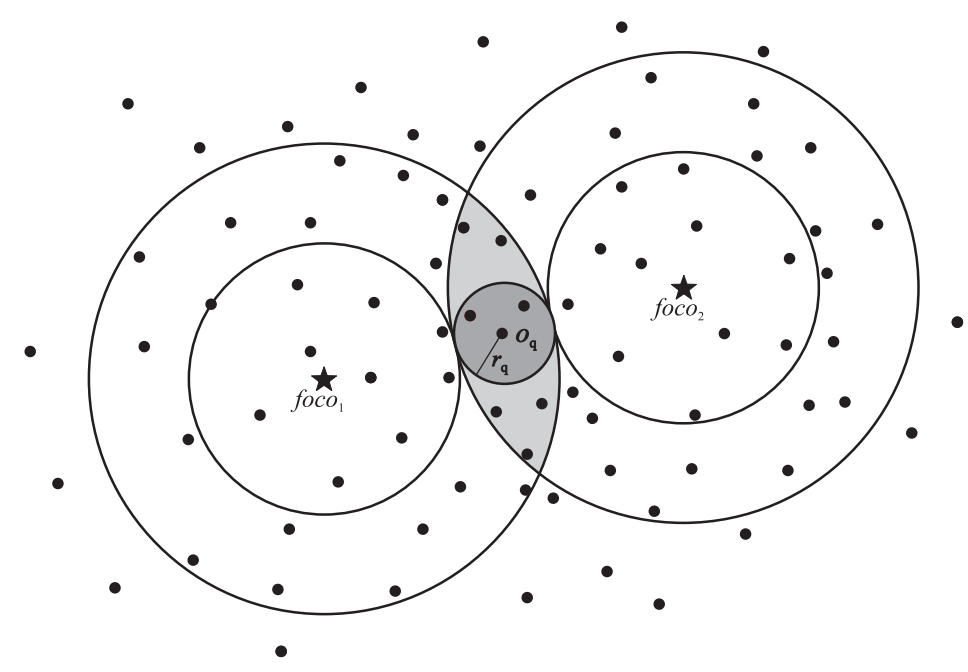

Figura 3.7: Um exemplo do uso de dois omni-focos para gerar coordenadas em um conjunto de objetos. A consulta $R Q\left(o_{q}, r_{q}\right)$ pode descartar qualquer objeto que não esteja localizado na região escura.

modelos de custos e em [Ciaccia et al., 1998] é mostrado o algoritmo de carregamento em lote (bulk loading) para a $M$-tree. O MAM $M^{+}$-tree [Zhou et al., 2003] é uma extensão do M-tree, que faz uso de dois representativos por nó para aumentar a quantidade de podas nas consultas.

Outro MAM dinâmico a surgir na literatura foi o Slim-tree [Traina et al., 2000]. Seu funcionamento é semelhante ao $M$-tree, porém possui um custo computacional menor no algoritmo de divisão, devido ao uso de um algoritmo baseado no uso de árvores de caminho mínimo (MST - Minimal Spanning Tree). Ele foi o primeiro a apresentar uma maneira de medir a sobreposição dos nós e uma técnica de redução de sobreposição de regiões que pode operar em espaços métricos. Uma descrição mais detalhada deste MAM é apresentada na Seção 3.2.2, pois ele é utilizado como referência para os experimentos deste trabalho.

Em [Santos et al., 2001] foi proposto o uso de múltiplos representativos chamados omni-focos para atuar como geradores de coordenadas para todos os objetos de um conjunto. Eles são usados para medir a distância em qualquer região do espaço ocupado por um conjunto de dados. Essas coordenadas podem ser indexadas utilizando qualquer MAM, MAE ou MASI, gerando toda uma nova "família" de MAMs, denominada Omnifamily, baseada em omni-focos. A Figura 3.7 mostra dois omni-focos sendo utilizados para dividir um conjunto de objetos. Note que com a utilização das coordenadas geradas pelos dois omni-focos, é possível descartar, para uma consulta $R Q\left(o_{q}, r_{q}\right)$ como mostrada na figura, qualquer objeto que não esteja na região escura da Figura 3.7.

Em [Traina et al., 2002c] foi apresentado mais um MAM, com a designação de DF-tree (Distance Fields-tree), cujo funcionamento é semelhante ao Slim-tree. Este MAM utiliza objetos representativos globais para a estrutura inteira, além dos representativos de cada nó, aumentando o descarte de subárvores nas consultas e, conseqüentemente, 


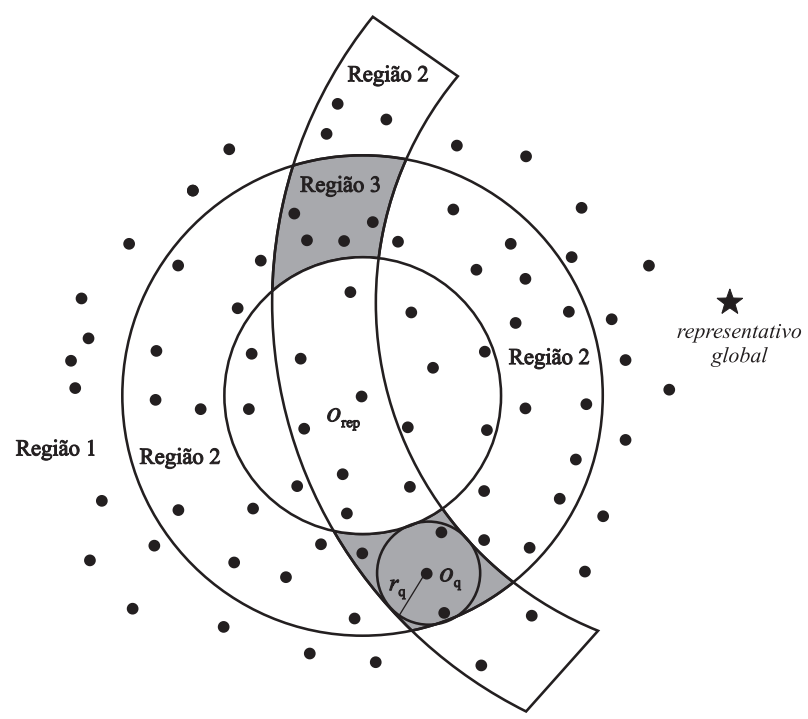

Figura 3.8: Uso de dois representativos em uma DF-tree: um do nó, orep, e um global, para podar objetos durante as consultas. É possível descartar qualquer objeto que não esteja localizado na região mais escura da figura (região 3), através do uso da propriedade de desigualdade triangular e dos dois objetos representativos.

diminuindo o número de cálculos de distância necessários para as consultas.

Outra contribuição desse trabalho é a definição de uma medida chamada "capacidade de poda" (prunability), que é uma estimativa de quantos cálculos de distância podem ser descartados em cada nível da árvore. A Figura 3.8 mostra um representativo global sendo utilizado para descartar objetos em um determinado nó da estrutura. Note que todos os objetos contidos nas regiões 1 e 2 podem ser descartados, sem ter calculado a distância deles ao objeto da consulta. Já os objetos contidos na região de cor igual à da região 3 não podem ser descartados.

\subsubsection{O MAM dinâmico Slim-tree}

O MAM Slim-tree [Traina et al., 2000] é uma evolução do M-tree. Sendo assim, a Slimtree também é uma árvore multivias balanceada pela altura, dinâmica, e que possui todos os objetos armazenados nas folhas. Outra semelhança é que a interseção das regiões definidas pelos nós de um mesmo nível pode não ser vazia. Ou seja, a divisão do espaço métrico não gera regiões disjuntas, admitindo sobreposição.

A estrutura possui ainda recursos para a avaliação do grau de sobreposição entre seus nós (Fat-Factor) e um algoritmo de pós-otimização da árvore (Slim-Down).

\subsubsection{Organização da Slim-tree}

A Slim-tree agrupa os objetos do conjunto em páginas de tamanho fixo que representam os nós da árvore. Os agrupamentos são construídos em torno de objetos especialmente selecionados, chamados de objetos representativos, que definem os centros de regiões de- 


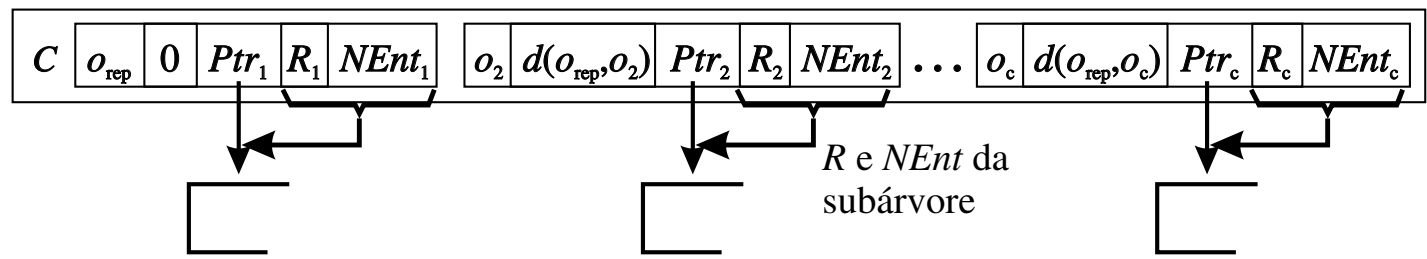

(b) leafNode

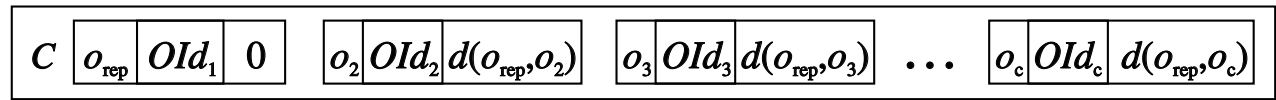

Figura 3.9: Estrutura lógica dos nós (a) índice (indexNode) e (b) folha (leafNode) da Slim-tree [Traina et al., 2002b].

limitadas por um raio de cobertura. Os objetos podem ser associados ao nó do objeto representativo se eles forem cobertos pelo raio associado ao objeto representativo em questão. Dessa forma, esta organização permite minimizar tanto o número de acessos a disco (leituras de páginas) quanto o número de cálculos de distância necessários para responder a consultas.

Os nós da Slim-tree podem ser de dois tipos: nó índice (indexNode); e nó folha (leafNode), que possuem cardinalidade igual ao seu grau. Todos os nós da estrutura, exceto o nó raiz, possuem um objeto representativo e um raio de cobertura que engloba todas as suas subárvores. A Figura 3.9 ilustra a estrutura lógica do nó índice e folha da Slim-tree.

Cada entrada no nó folha é composta pelos atributos que compõem o objeto $\left(o_{i}\right)$; pelo identificador do objeto $\left(O I d_{i}\right)$; e pelo valor da distância entre este objeto e o representativo do nó $\left(d\left(o_{r e p}, o_{i}\right)\right)$. Essa estrutura pode ser representada como:

$$
\text { leafNode [vetor } \left.[1 . . C] \text { de }<o_{i}, O I d_{i}, d\left(o_{r e p}, o_{i}\right)>\right]
$$

Cada entrada em um nó índice é composta pelo objeto $\left(o_{i}\right)$ que é o representativo (centro) da subárvore apontada por $\mathrm{Ptr}_{i}$; pelo valor da distância entre este objeto e o representativo do nó $\left(d\left(o_{r e p}, o_{i}\right)\right)$; por uma ligação para sua subárvore $\left(P t r_{i}\right)$; um raio de cobertura abrangendo toda a sua subárvore $\left(R_{i}\right)$; e pelo número de entradas $\left(N E n t_{i}\right)$ presentes na subárvore apontado por $P t_{i}$. Essa estrutura pode ser representada como:

$$
\text { indexNode [vetor [1..C] de }<o_{i}, d\left(o_{r e p}, o_{i}\right), \operatorname{Ptr}_{i}, R_{i}, N E n t_{i}>\text { ] }
$$

A Figura 3.10 ilustra a estrutura lógica de uma Slim-tree contendo 7 cadeias de caracteres, cuja função de distância é a $L_{E d i t}$.

\subsubsection{Construindo uma Slim-tree}

A Slim-tree é construída do nível folha em direção ao nível raiz (bottom-up), igual à $B$-tree. Ao contrário dos MAMs estáticos, não é necessário que todos os objetos estejam presentes 


\begin{tabular}{|l|l|l|l|l|l|l|l|l|l|l|l|}
\hline \multicolumn{1}{|c|}{$o_{1}$} & $d()$ & Ptr & $R_{1}$ & $N E n t$ & $o_{2}$ & $d()$ & Ptr & $R_{2}$ & $N E n t$ \\
2 & jose & $\mathbf{0}$ & $\mathbf{1}$ & $\mathbf{2}$ & $\mathbf{4}$ & maria & $\mathbf{0}$ & $\mathbf{2}$ & $\mathbf{1}$ & $\mathbf{3}$ \\
\hline
\end{tabular}

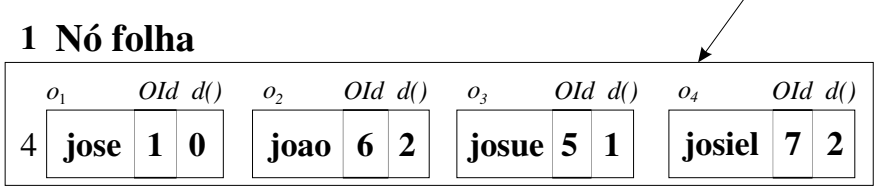

2 Nó folha
\begin{tabular}{|l|l|l|l|l|l|l|l|l|l|l|}
\hline$o_{1}$ & OId $d()$ & $o_{2}$ & OId & $d()$ & $o_{3}$ & \multicolumn{1}{l|}{ OId $d()$} \\
\hline 3 & maria & $\mathbf{2}$ & $\mathbf{0}$ & marisa & $\mathbf{3}$ & $\mathbf{1}$ & marta & $\mathbf{4}$ & $\mathbf{1}$ \\
\hline
\end{tabular}

Figura 3.10: Exemplo da estrutura lógica de uma Slim-tree contendo 7 cadeias de caracteres com a função de distância $L_{\text {Edit }}$.

para a construção da árvore. Novos objetos podem ser inseridos depois da estrutura já construída.

O algoritmo de inserção começa a partir do nó raiz, percorrendo a estrutura até encontrar um nó folha, onde a inserção do novo objeto realmente ocorre. O algoritmo tenta localizar um nó que possa receber o novo objeto sem a necessidade de aumento do raio de cobertura. Se mais de um nó pode receber o novo objeto, o algoritmo ChooseSubtree é executado para selecionar em qual deles será inserido o novo objeto. Se não existir nenhum nó que possa receber o novo objeto nestas condições, é selecionado um cujo centro está mais próximo do novo objeto. Esse processo é aplicado recursivamente para todos os níveis da árvore até chegar em um nó folha.

A Slim-tree possui três opções para o algoritmo ChooseSubtree:

- Aleatório (random): seleciona aleatoriamente um dos nós que podem receber o novo objeto sem aumento do raio de cobertura;

- Distância Mínima (minDist): seleciona, entre os nós que podem receber o novo objeto, aquele cuja distância entre seu representativo (centro) e o novo objeto for mínima;

- Ocupação Mínima (minOccup): seleciona, entre os nós que podem receber o novo objeto, aquele cujo número de objetos armazenados seja mínimo. Isso é verificado através do atributo NEnt. Esta opção é a padrão para a Slim-tree.

A escolha da opção para o algoritmo ChooseSubtree influencia bastante as características da árvore resultante. A opção minOccup do algoritmo ChooseSubtree tende a gerar árvores com maior taxa de ocupação dos nós, como explicitado em [Traina et al., 2000], resultando em árvores mais baixas, porém ao custo de um maior grau de sobreposição. A opção minDist tende a criar árvores com uma taxa de ocupação menor dos nós e com um grau menor de sobreposição, conseqüentemente as árvores resultantes são mais altas. Surpreendentemente, a opção random consegue gerar árvores quase tão boas quanto as outras duas, porém sua eficiência e resultados não são determinísticos. Este fenômeno 


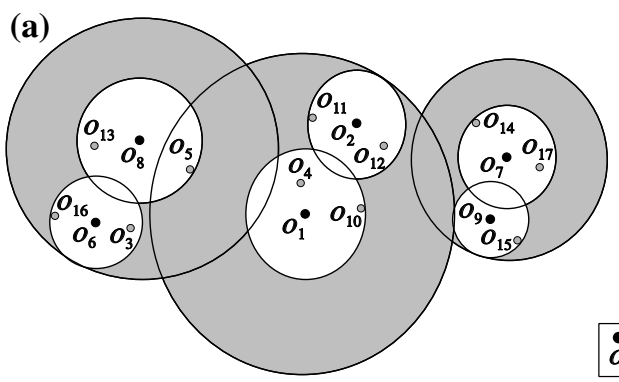

(b)

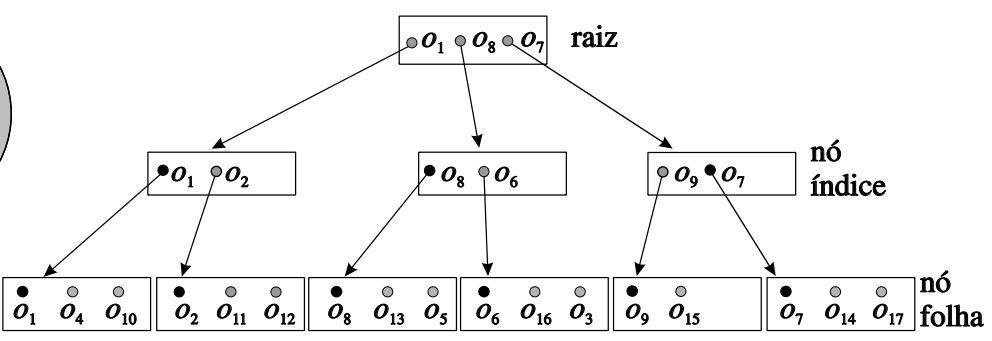

Figura 3.11: Representação de uma Slim-tree contendo 17 objetos em (a), e sua correspondente estrutura lógica em (b). Os círculos brancos em (a) representam os nós folhas, enquanto os de cor cinza representam os nós índice. Os pontos pequenos dos objetos, preenchidos de cor preta, representam os objetos representativos do nó.

pode indicar que o verdadeiro responsável pelas características da árvore seja mesmo o algoritmo de redistribuição dos objetos entre os nós.

Yamamoto em [Yamamoto et al., 2003] criou uma quarta política para o algoritmo ChooseSubtree da Slim-tree utilizando conceitos de lógica nebulosa. Esta opção é chamada de HCS (Hybrid ChooseSubtree).

A Figura 3.11(a) apresenta a disposição de 17 objetos $\left\{o_{1}, \ldots, o_{17}\right\}$ de uma Slimtree com capacidade máxima de 3 objetos por nó. Os objetos $\left\{o_{1}, o_{4}, o_{10}\right\}$ estão em um mesmo nó folha e o objeto representativo deste nó é o $o_{1}$, por isto ele aparece no nó índice do nível superior. Os círculos brancos da Figura 3.11(a) representam nós folhas, e o de cor cinza os nós índice, onde o tamanho é proporcional ao raio de cobertura e as regiões de sobreposição são indicadas pela intersecção de dois ou mais círculos. Os pontos pretos da Figura 3.11(b) representam os objetos representativos do respectivo nó. Note que o nó raiz não possui nenhum objeto representativo.

Durante o processo de inserção de um novo objeto, pode ocorrer que o nó escolhido para inserção já esteja com a sua taxa de ocupação máxima preenchida. Neste caso, deve ser alocado um novo nó e as entradas que estavam no nó anterior (com a taxa de ocupação preenchida) devem ser redistribuídos entre os dois nós, respeitando a taxa de ocupação mínima dos nós. Os dois objetos escolhidos como representativos dos dois nós (novo e antigo) e seus respectivos raios de cobertura devem ser inseridos no nó pai. O atributo NEnt também deve ser atualizado nos nós dos níveis superiores. Este processo de divisão, se necessário, pode ser repetido árvore acima. No pior caso, o processo de divisão propaga até o nó raiz e a árvore aumenta a sua altura em uma unidade.

A Slim-tree possui três políticas para efetuar a redistribuição dos objetos entre os dois nós, sendo elas:

- Aleatório (random): seleciona aleatoriamente dois objetos representativos, um para cada nó (novo e antigo), e os demais objetos são distribuídos entre os dois nós pela menor distância entre o objeto e o representativo do nó. É o mais rápido, porém seus resultados são os menos satisfatórios; 
- Mínimo dos Maiores Raios (minMax): cada possível par de objetos são considerados candidatos a representativos dos dois nós. Para cada par possível, os demais objetos são inseridos no nó cuja distância ao respectivo representativo for a menor. Serão escolhidos como representativos o par de objetos que minimizar o raio de cobertura, ou seja, o menor dos maiores raios de cobertura. A complexidade deste algoritmo é $\boldsymbol{O}\left(\boldsymbol{C}^{3}\right)$, onde $\boldsymbol{C}$ é a cardinalidade do nó, pois para cada objeto escolhe-se dentre os demais quem será seu par, e para cada par possível, verifica-se em qual dos nós centrados em um dos elementos do par cada objeto restante será armazenado. Apesar dele ser extremamente custoso, ele é apontado em [Ciaccia et al., 1998] como o que consegue obter árvores que possibilitam consultas mais eficientes;

- Minimal Spanning Tree (MST): baseado na Minimal Spanning Tree de [Kruskal, 1956]. A árvore de caminho mínimo é construída e um dos arcos mais longos da árvore é removido. Dessa forma, dois agrupamentos são obtidos e cada um é associado a um nó. O objeto representativo é o objeto central de cada agrupamento. Este algoritmo possibilita a construção de árvores praticamente equivalentes às construídas utilizando o algoritmo de quebra de nós minMax, porém com custo de processamento bem menor, resultando em um menor tempo total de construção. Isso ocorre devido à complexidade do algoritmo ser $\boldsymbol{O}\left(\boldsymbol{C}^{2} \log \boldsymbol{C}\right)$. Esta opção é a padrão para a Slim-tree redistribuir os objetos. A Figura 3.12 ilustra o mecanismo de quebra de nós utilizando o algoritmo $M S T$. Em (a) é representada a disposição dos objetos antes da divisão; em (b) é ilustrada a árvore de caminho mínimo para os objetos do nó corrente; já em (c) é ilustrada a nova distribuição para os dois novos nós.

Na opção $M S T$ não existe garantia que os nós resultantes da divisão tenham ocupação mínima de entradas, podendo até existir nós com apenas uma única entrada (apenas o objeto representativo com raio nulo para os nós folhas). Nestes casos, a probabilidade de inserção de novos objetos, para a opção minDist do algoritmo ChooseSubtree, é baixa devido ao raio do objeto representativo ser nulo.

Embora ainda não exista a implementação da remoção de objetos na Slim-tree e na $M$-tree, ela pode ser tratada de uma maneira similar como ocorre na $B^{*}$-tree, onde os objetos nos nós índices são "marcados" como removidos [Johnson \& Shasha, 1989]. Porém nesta abordagem, mesmo quando um grande número de objetos for removido, a altura da árvore continua a mesma. Além disto, há a possibilidade de existirem nós folhas com menos entradas que a capacidade mínima dos nós.

\subsubsection{Executando Consultas por Similaridade}

A Slim-tree possui diversos tipos de consultas por similaridade. As duas mais importantes são a Consulta por Abrangência $(R Q())$ e aos $k$-Vizinhos mais Próximos $(k N N Q())$. 


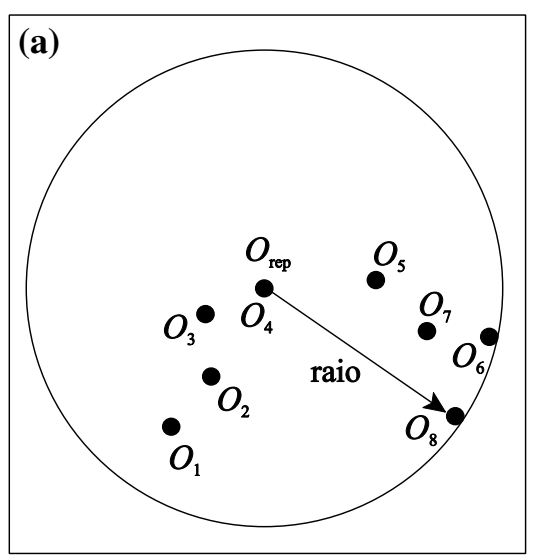

(b)

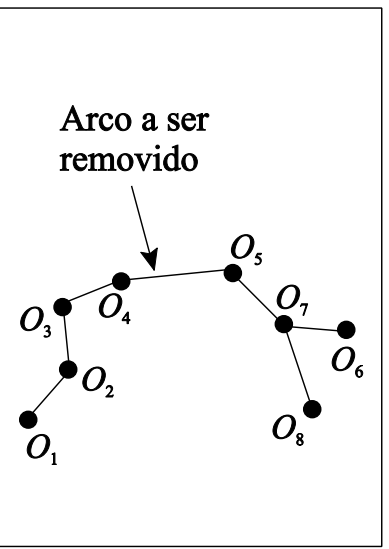

(c)

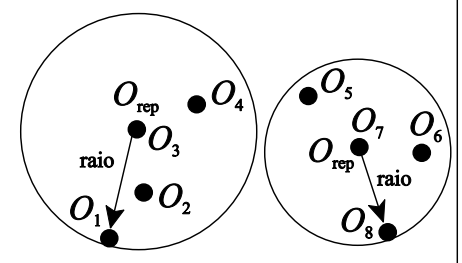

Figura 3.12: Exemplificação do mecanismo de quebra de nós segundo a política $M S T$ (Minimal Spanning Tree) em um conjunto de objetos: (a) estrutura do nó antes da divisão; (b) MST construída sobre os objetos do nó; (c) organização dos objetos depois da divisão do nó.

Os algoritmos de consulta aproveitam a organização da árvore e da propriedade de desigualdade triangular da função de distância métrica para podar subárvores e objetos. Eles começam pela raiz da árvore, comparando o objeto de busca com todos os objetos representativos do nível abaixo (que estão associados a cada uma das ligações). Apenas as subárvores que se classificarem, ou seja, cobrirem possíveis respostas, são percorridas recursivamente. Uma distância só é calculada quando não é possível descartar o objeto através da propriedade de desigualdade triangular. Com isso, é possível minimizar tanto o número de acessos a disco quanto o de cálculos de distância necessários para responder a consultas.

Este processo continua até que o algoritmo atinja um nó folha. Neste caso, todos os objetos deste nó folha são comparados com o objeto de busca, primeiramente utilizando a propriedade de desigualdade triangular, a fim de determinar quais deles podem ser descartados. Se com isto não for possível descartar o objeto, então é necessário calcular a sua distância ao objeto de consulta. Ele será incluído no conjunto resposta caso ele se qualifique segundo as condições da consulta por similaridade. O algoritmo termina quando não existirem mais subárvores que possam conter objetos que satisfaçam as condições da consulta.

Para a $R Q()$ a Slim-tree se utiliza do raio da consulta para podar subárvores e objetos. Apenas os objetos que tiverem distância ao objeto de consulta menor ou igual ao raio da consulta serão inseridos no conjunto resposta.

Já para a consulta $k N N Q()$ a abordagem é semelhante, porém existe prioridade de qual subárvore analisar primeiro. Primeiramente o raio é definido com um valor grande o suficiente para englobar todos os objetos indexados pela Slim-tree. A fila de prioridade pode conter entradas dos diversos níveis da árvore, como em [Ciaccia et al., 1997]. No momento em que $k$ objetos forem inseridos no conjunto resposta, o raio de consulta passa a ser a maior distância entre o objeto de consulta e os objetos do conjunto resposta. A 
medida que novos objetos com menores distâncias em relação ao da consulta forem sendo substituídos por objetos com distância maiores do conjunto de resposta, o raio vai sendo atualizado, e a poda de subárvores e objetos torna-se maior.

Além desses dois algoritmos de consulta por similaridade, a Slim-tree possui um outro algoritmo chamado de $k N N-F()$ [Arantes et al., 2003a], que utiliza da dimensão fractal do conjunto de dados [Traina et al., 1999] para estimar um raio ideal para recuperar os $k$ vizinhos mais próximos. A partir desta estimativa do raio, é possível executar o $k N N Q()$ com o raio estimado, aumentando a quantidade de podas. Se o raio estimado tiver sido maior que o valor necessário para recuperar os $k$ objetos, ele será "ajustado" igual ao $k N N Q()$, e se ele for subestimado, um novo algoritmo deverá ser chamado. Este novo algoritmo estima novamente o raio, a partir dos elementos retornados da primeira execução do algoritmo, fazendo apenas o "anel" restante para a recuperação dos objetos restantes para completar os $k$ objetos requisitados.

\subsubsection{O Fat-Factor e o Slim-Down}

A sobreposição entre os nós das árvores métricas é um efeito indesejável pois obriga a busca em profundidade em diversas subárvores para a localização dos objetos solicitados pelas consultas. Isso ocorre porque mais nós da árvore serão consultados (todos os que têm região se sobrepondo à região de consulta), e o descarte de subárvores fica prejudicado. Sua influência no desempenho das buscas pode ser até maior que a altura total das árvores. Para ilustrar, considere a Figura 3.13(a). Nela estão representados 3 nós com os seus respectivos representativos $\left\{o_{r e p 1}, o_{r e p 2}, o_{r e p 3}\right\}$, e uma consulta na região de sobreposição, no qual $o_{q}$ é o objeto de consulta e $r_{q}$ é o raio. Note que as regiões escuras são as sobreposições dos nós. Nenhum dos 3 nós podem ser descartados em uma $R Q()$, tendo que ser percorridos, mesmo que só o nó do objeto representativo $o_{\text {rep } 3}$ realmente possua objetos cobertos pela consulta.

Visando evitar essa deficiência, a Slim-tree foi desenvolvida com o objetivo de diminuir a sobreposição entre os nós da árvore, bem como oferecer mecanismos para verificação da porcentagem de sobreposição existente na árvore. Para isso, em [Traina et al., 2000], foi definido o fator de sobreposição Fat-Factor e o algoritmo de reorganização da árvore Slim-Down.

O Fat-Factor é uma medida para avaliar o grau de sobreposição entre os nós da árvore. Ela foi usada para desenvolver um algoritmo de reorganização dos nós, chamado Slim-Down. Esse algoritmo visa reduzir o grau de sobreposição entre os nós através da troca de objetos apenas entre os nós folhas. Os objetos são transferidos de um nó origem para um destino caso o nó destino tenha espaço para o armazenamento da entrada, e ainda, a inserção da entrada não cause aumento do raio de cobertura, podendo diminuir o raio de cobertura do nó origem. Esse processo é realizado até que não seja mais possível realizar trocas de objetos entre os nós envolvidos ou que passe de um certo valor limite de número 
(a)

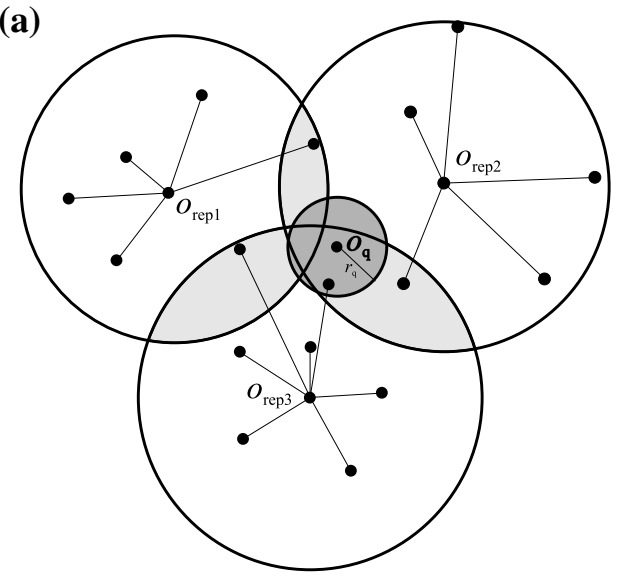

(b)

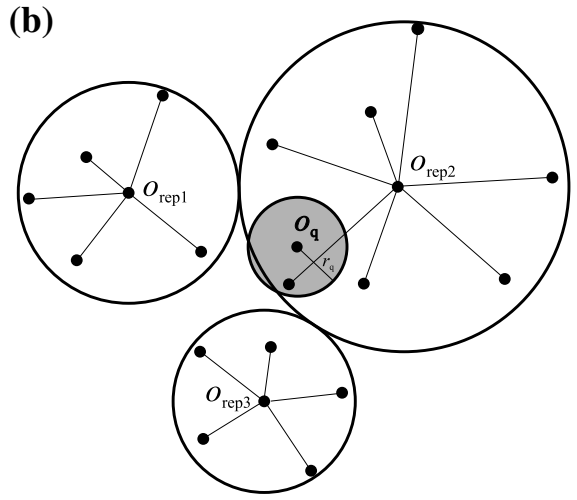

Figura 3.13: Exemplo da aplicação do algoritmo Slim-Down em três nós folhas. Em (a) estão os três nós antes da otimização, e uma consulta $R Q\left(o_{q}, r_{q}\right)$ localizada na região de sobreposição. Em (b) é ilustrada a nova configuração dos nós depois da execução do Slim-Down. A troca de apenas três objetos entre os nós foi suficiente para diminuir quase toda a sobreposição entre eles. As linhas interligando os objetos ao representativo de cada nó indicam a que nó eles pertencem.

de trocas. Este processo de reorganização das entradas pode diminuir a sobreposição dos nós e, conseqüentemente, diminuir o número de acesso a disco para responder a consultas.

Por ser um processo relativamente custoso, é recomendado que o Slim-Down seja executado apenas quando o grau de sobreposição, definido através do Fat-Factor, ultrapasse um certo limite para toda a árvore, ou que uma grande quantidade de objetos já tenha sido inserida na Slim-tree. Maiores detalhes sobre o Fat-Factor e o algoritmo SlimDown podem ser encontrados em [Traina et al., 2000] e [Traina et al., 2002b]. A Figura 3.13 representa visualmente o processo do algoritmo Slim-Down: em (a) é ilustrado a distribuição dos objetos em três nós antes do processo. Os objetos pertencentes a um nó estão interligados por uma linha com o representativo do nó em questão; e em (b) é ilustrada a nova configuração dos nós depois da execução do algoritmo Slim-Down. Note que a sobreposição entre os nós diminuiu, proporcionando que consultas localizadas nestas regiões, como a $R Q\left(o_{q}, r_{q}\right)$ da figura, precisem analisar menos nós que anteriormente.

Através desses conceitos, o MAM Slim-tree permite realizar consultas por similaridade minimizando tanto o número de cálculos de distâncias quanto o de acessos a disco. O MAM Slim-tree e o $M$-tree, por serem referência de comparação de novos MAMs e utilizarem apenas um representativo por nó, são utilizados como referências para as comparações de desempenho em relação ao método desenvolvido nesta dissertação, o DBM-tree.

\subsubsection{Visualizando Estruturas Métricas}

A visualização de árvore métricas é uma ferramenta valiosa tanto para o seu desenvolvimento quanto para o seu aprendizado. A primeira ferramenta proposta para visualização de uma árvore métrica foi apresentada em [Traina et al., 2002b]. Esta ferramenta cria 
uma representação geométrica da árvore de forma a exibir as relações de distância entre os objetos, permitindo ao usuário avaliar a distribuição dos objetos, os raios de cobertura de cada nó e o nível de sobreposição entre as regiões.

Esta ferramenta utiliza o algoritmo FastMap [Faloutsos \& Lin, 1995] para criar um mapeamento dos objetos da árvore, que habitam em um espaço métrico arbitrário, para um espaço euclidiano de 2 ou 3 dimensões. Para cada objeto, o algoritmo gera pontos no espaço euclidiano, chamados de imagem do objeto, de modo a preservar o máximo possível as distâncias existentes no espaço métrico original, condensando assim a informação relativa às distâncias entre os objetos na distribuição espacial das imagens. Além da distribuição dos objetos, o sistema extrai informações sobre a organização da árvore, como os raios de cobertura e outras informações estruturais.

Embora esta ferramenta tenha sido muito útil na fase de desenvolvimento da Slimtree, permitindo ao seus autores acompanhar o comportamento da árvore, identificar características adicionais da estrutura e problemas de implementação com o uso de inspeção visual, ela possui algumas limitações, sendo a principal delas a incapacidade de apresentar o comportamento da estrutura.

O sistema MAMView, proposto por Chino em [Chino, 2004], visa suprir as limitações da ferramenta de visualização proposta em [Traina et al., 2002b]. Ela permite a exibição de representações dinâmicas das estruturas, ou seja, o funcionamento de seus algoritmos, tanto de construção quanto de consultas por similaridade. O sistema MAMView ainda é capaz de gerar representações de outras estruturas métricas, além da Slim-tree. Como a ferramenta de visualização anterior, ela também utiliza o algoritmo FastMap para mapear os objetos.

O sistema MAMView também foi utilizado pelo MAM DBM-tree durante a fase de seu desenvolvimento, tanto para o seu aprimoramento quanto para o seu entendimento. A visualização da $D B M$-tree através do sistema MAMView é mostrada no Capítulo 4.

A Figura 3.14 ilustra duas telas do sistema MAMView de uma Slim-tree para um conjunto de dados contendo 150 objetos de 4 dimensões. Na Figura 3.14(a) é mostrado a estrutura com os seus representativos e raios de cobertura, além dos identificadores dos representativos, que é único para cada representativo. O modelo representado na Figura 3.14(a) está no espaço tridimensional, sendo possível interagir no modelo e navegar nos diversos níveis da estrutura. A coluna à direita do modelo indica as cores usadas em cada nível da estrutura.

Já a Figura 3.14(b) mostra a mesma estrutura só que sem os raios de cobertura dos nós. As linhas ligando os objetos indicam a que representativo ele está associado.

\subsection{Conclusão}

Responder às consultas por similaridade em SGBDs exige a elaboração de métodos de indexação capazes de respondê-las de modo eficiente. Surgem então várias abordagens, 
(a)

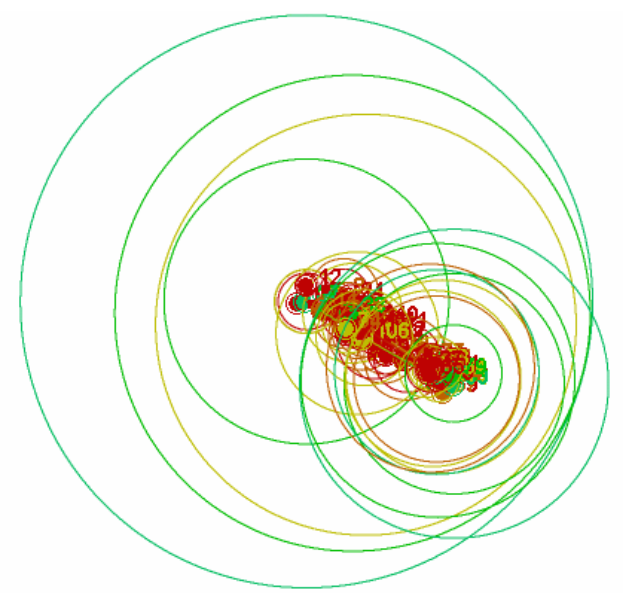

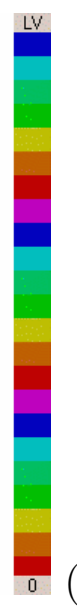

(b)

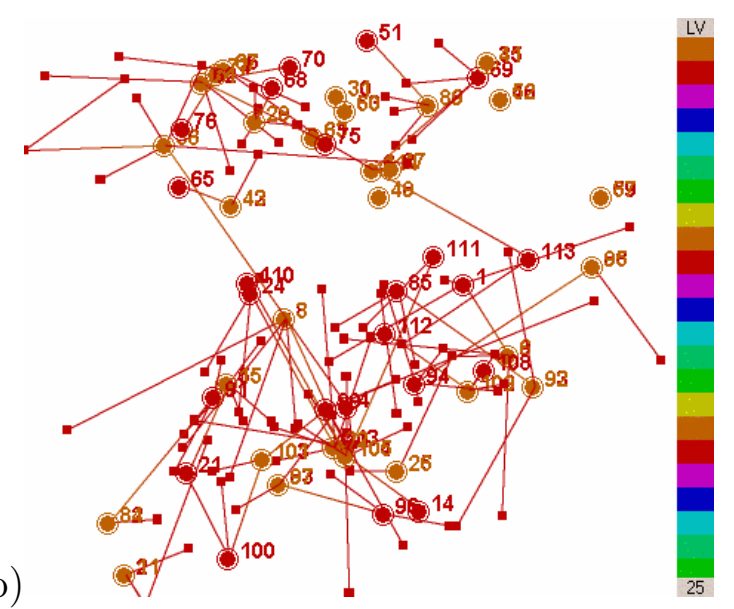

Figura 3.14: Duas imagens geradas pelo MAMView apresentando uma Slim-tree carregada com um conjunto de dados contendo 150 objetos com 4 dimensões. (a) visualização da estrutura com o raio de cobertura dos nós. (b) uma outra visualização da mesma estrutura sem o raio de cobertura dos nós.

entre as quais as mais promissoras são os Métodos de Acesso Métricos (MAMs). Dentre os diversos MAMs propostos, o Slim-tree é um dos mais eficientes, sendo uma estrutura dinâmica, balanceada pela altura, e que possui meios para avaliar e diminuir o grau de sobreposição entre os nós.

Para os MAMs tratados neste capítulo, que são balanceados, ou pelo menos tentam manter o balanceamento, a altura dessas estruturas tende a ser mínima e dependente do número de objetos nela contida. Mas como pode existir sobreposição do espaço coberto pelos nós de um mesmo nível nos MAMs dinâmicos, possivelmente uma consulta fará com que várias subárvores precisem ser avaliadas para respondê-la. Portanto, o número de acessos a disco não apenas dependerá da altura da árvore, mas também dependerá da taxa de sobreposição existente entre os nós.

O MAM DBM-tree, proposto por este trabalho, visa a diminuição da sobreposição do espaço coberto pelos nós em um mesmo nível, através da flexibilização do balanceamento da árvore em regiões densas. Esta flexibilização é rigorosamente controlada para que não haja a degeneração do desempenho da estrutura devido à sua altura. O próximo capítulo apresenta as características e o funcionamento deste novo MAM. O Capítulo 5 mostra os resultados experimentais obtidos da comparação dele com o Slim-tree e o M-tree. 
Capítulo

4

\section{O Método de Acesso DBM-tree}

\subsection{Introdução}

A sobreposição das regiões definidas pelos nós nos MAMs dinâmicos é um efeito indesejável pois faz com que a estrutura seja percorrida tanto em profundidade como em largura nas consultas. Esta característica ocorre em MAMs em que os nós definem regiões não disjuntas. Na prática, verifica-se que um dos fatores que determina a sobreposição nestes MAMs é a densidade local de objetos no espaço métrico: quanto mais densa for a região, maior a possibilidade de haver sobreposição entre os nós que definem estas regiões. Uma maneira de amenizar isto é fazer com que a estrutura seja mais profunda em regiões onde exista densidade maior de objetos.

O MAM DBM-tree (Density-Based Metric tree) permite que a estrutura seja mais profunda em regiões do espaço mais densas. Isto é possível através da flexibilização do balanceamento da estrutura, de modo que a altura da estrutura é maior em regiões com maior densidade de objetos, minimizando tanto o número de comparações entre objetos (cálculo de função de distância) quanto o número de acessos a disco para responder às consultas.

Este capítulo introduz as características e o funcionamento do MAM DBM-tree, os respectivos algoritmos de consultas por similaridade, o algoritmo para otimização da estrutura, a sua visualização através do sistema MAMView, e uma proposta de remoção de objetos na DBM-tree. 


\subsection{Visão Geral do MAM DBM-tree}

Assim como a Slim-tree, a DBM-tree é uma árvore multivias que divide o espaço em regiões não disjuntas (representadas por cada subárvore), definidas por um objeto representativo $\left(o_{r e p}\right)$ e um raio. Este objeto representativo é utilizado como referência para os demais objetos da subárvore.

Ela também permite atualizações na estrutura, armazenamento dos dados em disco, e a sua construção se dá dos níveis inferiores em direção ao nível raiz (bottomup).

O grande diferencial desta estrutura em relação às demais é o uso de um balanceamento flexível como meio para diminuir a sobreposição entre subárvores. A DBM-tree permite que subárvores sejam mais profundas em regiões do espaço onde a densidade de objetos é maior. Isto aumenta consideravelmente as possibilidades de construção das estruturas, permitindo que estas assumam configurações que resultem em menores taxas de sobreposição que estruturas balanceadas podem conseguir.

A flexibilização do balanceamento da estrutura é controlada para evitar que os algoritmos de construção gerem árvores degeneradas. Este nível de variação pode ser controlado pelos usuários no momento da criação da estrutura.

A primeira vista, o número de acessos a disco necessários para uma busca deveria ser maior na $D B M$-tree que em outras estruturas balanceadas devido à maior profundidade das subárvores. Porém, a diminuição do grau de sobreposição entre as subárvores tende a minimizar o uso das buscas em largura na estrutura, consideravelmente mais numerosas em estruturas balanceadas cujo grau de sobreposição é maior. Com isso, o número de acessos a disco feito pela Slim-tree e pela DBM-tree tende a ser equivalente em conjuntos de dados que não apresentem agrupamentos, e tende a ser menor na DBM-tree em conjuntos de dados com muitos agrupamentos. Nos testes realizados, a DBM-tree chegou a fazer, em média, $40 \%$ menos acessos a disco que a Slim-tree (depois de executado o algoritmo Slim-Down) para dados que possuem agrupamentos.

\subsection{Organização da estrutura}

A DBM-tree agrupa os objetos do conjunto a ser indexado em páginas de tamanho fixo que constituem os nós da árvore. Os agrupamentos são construídos em torno de objetos representativos, que definem os centros de regiões delimitadas por um raio de cobertura. Os objetos podem ser associados ao nó de um objeto representativo se eles forem cobertos pelo raio de cobertura associado ao objeto representativo em questão.

De maneira distinta do que ocorre na Slim-tree e $M$-tree, existe apenas um tipo de nó na $D B M$-tree, ilustrado na Figura 4.1, não existindo distinção entre nós folhas e nós internos. Cada nó é composto por $C$ entradas que podem ser do tipo subárvore ou 


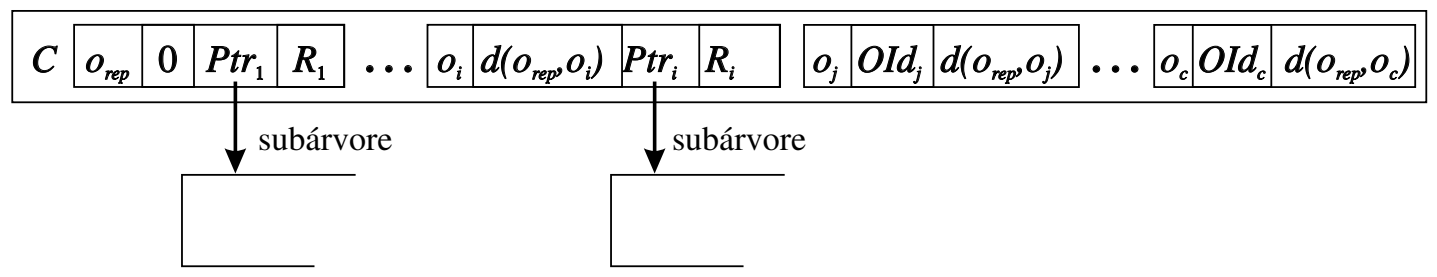

Figura 4.1: Estrutura do nó da DBM-tree. Este nó é capaz de armazenar $C$ entradas do tipo subárvore ou objeto. As entradas do tipo subárvore armazenam as informações referentes às subárvores enquanto as do tipo objeto armazenam os objetos que não são cobertos pelas subárvores. As informações referentes ao objeto representativo e o raio de uma subárvore estão sempre armazenadas no nível imediatamente superior.

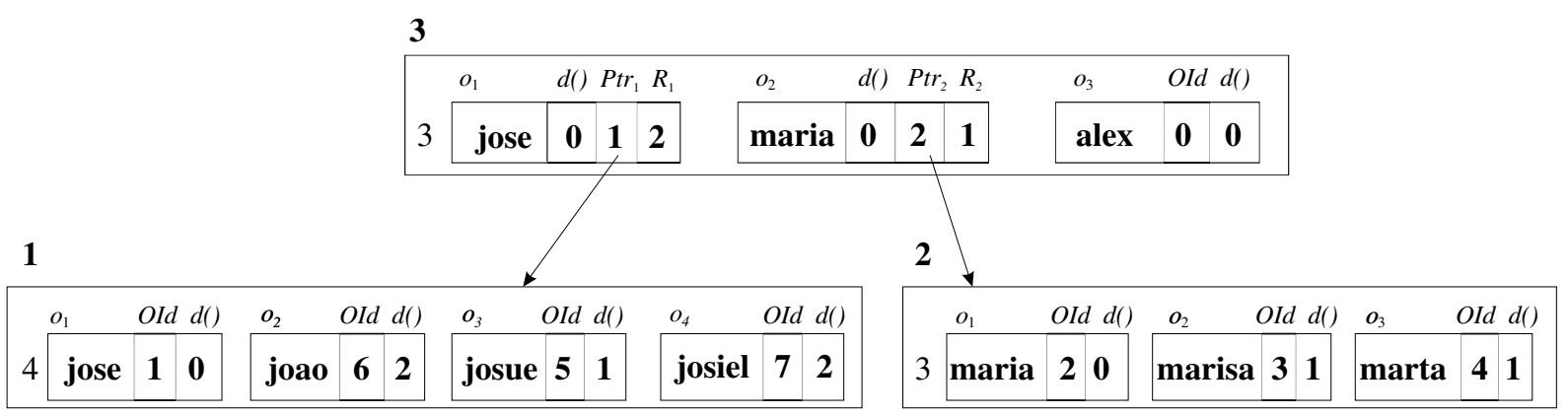

Figura 4.2: Exemplo da estrutura lógica de uma DBM-tree contendo 8 cadeias de caracteres com a função de distância $L_{E d i t}$. O objeto "alex" não é coberto pelas subárvores representadas pelos objetos "jose" e "maria".

objeto. As entradas do tipo objeto não são cobertas por nenhuma das subárvores do nó em questão.

As entradas do tipo subárvore contêm um objeto representativo $o_{i}$ que é o representativo da subárvore, a distância ao objeto representativo do nó $d\left(o_{r e p}, o_{i}\right)$, a ligação para a sua subárvore $\left(P t r_{i}\right)$ e o raio de cobertura da subárvore $R_{i}$. Já as entradas do tipo objeto contêm as informações do objeto $o_{j}$, o identificador do objeto $O I d_{j}$ e a distância ao objeto representativo do nó $d\left(o_{r e p}, o_{j}\right)$. Essa estrutura pode ser representada como:

Node [vetor $[1 . . C]$ de $<o_{i}, d\left(o_{r e p}, o_{i}\right), P t r_{i}, R_{i}>$ ou $<o_{i}, O I d_{i}, d\left(o_{r e p}, o_{i}\right)>$ ]

A Figura 4.2 mostra a estrutura lógica de uma DBM-tree contendo 8 cadeias de caracteres, usando a função de distância $L_{E d i t}$. Note que o objeto "alex" não é coberto pelas subárvores definidas pelos objetos representativos "jose" e "maria", por isto ele está armazenado no nó 3.

\subsection{Construção da DBM-tree}

Assim como a Slim-tree, a DBM-tree é uma estrutura dinâmica, capaz de receber novos objetos uma vez a estrutura já criada. Ao receber um novo objeto para ser incluído, os algoritmos de construção procuram na estrutura um nó capaz de abrigá-lo. 
O algoritmo de inserção de objetos (chamado de $A d d$ e descrito no Algoritmo 4.4.3) começa a partir do nó raiz, percorrendo a estrutura recursivamente até que não mais exista uma subárvore que se qualifique. A inserção pode ocorrer em qualquer nível da estrutura. Em cada nó, o algoritmo de inserção utiliza o algoritmo ChooseSubtree, que retorna a subárvore que melhor se qualifica para a inserção do novo objeto. Caso não exista nenhuma subárvore que se qualifique, o novo objeto é inserido no nó atual. Existem 2 políticas de funcionamento para o algoritmo ChooseSubtree:

- Menor Distância com Cobertura (minDist): entre as subárvores que englobam o novo objeto, escolhe aquela que tenha a menor distância entre o representativo e o novo objeto. Nesta opção existe a possibilidade de nenhuma subárvore ser escolhida, neste caso o objeto é inserido no nó atual;

- Menor Incremento do Raio de Cobertura (minGDist): entre as subárvores que englobam o novo objeto, escolhe aquela que tenha a menor distância em relação ao novo objeto. Caso nenhuma se qualifique englobando o novo objeto, é escolhida aquela que tiver a menor distância em relação ao novo objeto, produzindo um menor aumento no raio de cobertura. Nesta opção sempre que o nó tiver subárvores, uma será escolhida para inserir o novo objeto.

Foram testadas outras políticas para o algoritmo ChooseSubtree, porém sem resultados satisfatórios. A escolha da opção para o algoritmo ChooseSubtree influencia bastante nas características da árvore resultante. A opção minDist tende a criar árvores com uma taxa de sobreposição menor entre os nós, podendo gerar árvores mais altas que a opção minGDist. Já a opção minGDist tende a criar árvores mais baixas, porém ao custo de um maior grau de sobreposição. Isto ocorre pois na inserção de um novo objeto, a subárvore escolhida pode aumentar seu raio de cobertura para englobar o novo objeto, sendo que as inserções sempre ocorrem nos últimos níveis da estrutura.

O algoritmo ChooseSubtree é mostrado no Algoritmo 4.4.1. Os parâmetros de entrada são o novo objeto a ser inserido e o nó que é escolhido ser a melhor subárvore para a inserção do novo objeto. Este algoritmo irá retornar a melhor subárvore, segundo a política minDist ou minGDist, para ser inserido o novo objeto, ou um índice inválido para indicar que o novo objeto deve ser inserido no atual nó.

A política do ChooseSubtree é verificada na linha 1 do Algoritmo 4.4.1. A linha 2 até a 4 é para a opção minDist, e linha 7 até a 12 para a minGDist. Na opção minDist é procurada entre todas as subárvores do Nó (linha 2) uma que englobe o novo objeto e que também tenha a menor distância em relação ao novo objeto (linha 3). O índice da subárvore é armazenado na variável índiceSubárvore para retorno da função ChooseSubtree (linha 4). Caso nenhuma subárvore englobe o novo objeto, é retornado um índice inválido (-1) indicando que nenhuma subárvore se qualificou para receber o novo objeto. Neste caso, o novo objeto deve ser inserido no atual nó. 


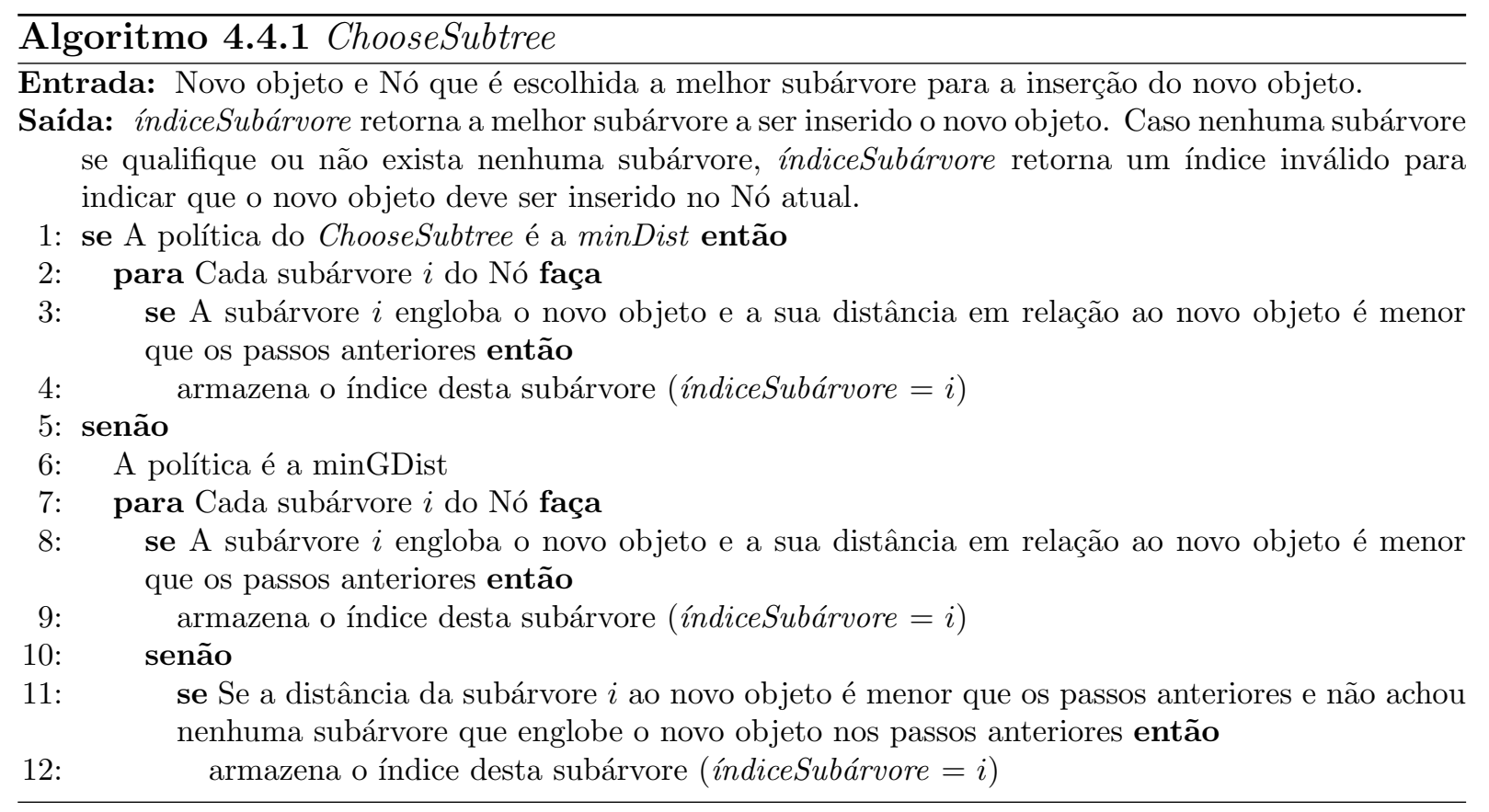

Já a política minGDist escolhe uma subárvore que englobe o novo objeto e que tem a menor distância entre o objeto representativo e o novo objeto (linha 8). Porém, se nenhuma subárvore engloba o novo objeto, é retornada a que tem a menor distância em relação ao novo objeto (linhas 11 e 12).

A Figura 4.3(a) mostra a disposição de 16 objetos de uma DBM-tree com capacidade máxima de 4 objetos por nó. Os objetos $\left\{o_{1}, o_{4}, o_{10}\right\}$ estão em um mesmo nó e o objeto representativo deste nó é o $o_{1}$, por isto ele aparece no nó do nível superior. O tamanho do círculo na Figura 4.3(a) é proporcional ao raio de cobertura, e as regiões de sobreposição são indicadas pela intersecção de dois ou mais círculos. Os pontos centrais dos círculos da Figura 4.3(b) representam os objetos representativos do respectivo círculo. Note que o nó raiz não possui nenhum objeto representativo, e possui três subárvores $\left\{o_{1}, o_{6}, o_{7}\right\}$ e um objeto $o_{19}$. O objeto $o_{19}$ pertence ao nó raiz, pois não existe nenhuma subárvore que o engloba. Já o objeto $o_{18}$ está armazenado no filho do nó raiz, também não possuindo subárvores que o englobem no nível que está armazenado. Note que a subárvore representada por $o_{6}$ é menos profunda que as representadas pelos objetos $o_{1}$ e $O_{7}$.

Pode ocorrer que o nó escolhido para a inserção do novo objeto não tenha espaço suficiente para o seu armazenamento (esteja com a sua ocupação máxima preenchida). Neste caso, todas as entradas do nó mais o novo objeto devem ser redistribuídos em um ou mais nós, dependendo da política de redistribuição. O algoritmo que faz este processo é chamado de SplitNode, e é descrito pelo Algoritmo 4.4.2. Os representativos dos nós criados com a nova configuração de entradas mais o conjunto de entradas não inseridas nos nós (entradas não cobertas por nenhum nó depois da redistribuição, podendo ser vazio este conjunto) devem ser promovidos para serem inseridos no nó pai.

Foram testadas inúmeras políticas de escolha dos representativos para o algoritmo 
(a)

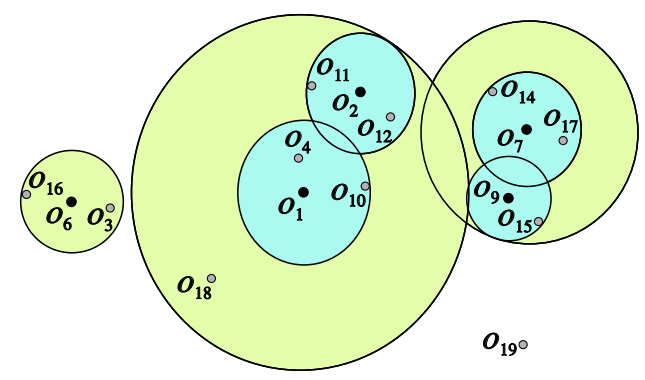

(b)

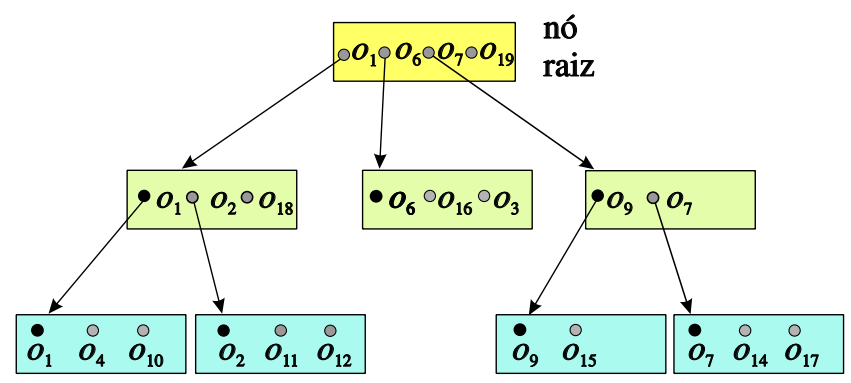

Figura 4.3: Representação de uma DBM-tree contendo 16 objetos em (a), e sua correspondente estrutura lógica em (b). Os círculos em (a) representam os raios dos respectivos nós da estrutura. Os objetos $o_{19}$ e $o_{18}$ não são cobertos por nenhuma subárvore no nó em que estão armazenados.

SplitNode, porém apenas as 3 melhores são mostradas aqui, sendo elas:

- Mínimo dos Maiores Raios ( $\min M a x)$ : esta opção gera, no máximo, dois nós com os seus respectivos representativos e um conjunto de entradas não cobertas por estes nós (este conjunto pode ser vazio). Cada par de objetos é considerado candidato a representativo dos nós. Para cada par, os demais objetos são inseridos no nó cuja distância ao respectivo representativo seja a menor. Serão escolhidos como representativos o par de objetos que minimizar o maior raio de cobertura. A complexidade deste algoritmo é $\boldsymbol{O}\left(\boldsymbol{C}^{3}\right)$, como a opção minMax do Slim-tree, onde $\boldsymbol{C}$ indica a quantidade de objetos no nó antes da divisão mais o novo objeto;

- Mínima Soma dos Raios (minSum): semelhante ao minMax, porém, são escolhidos dois representativos cuja soma dos dois raios for a menor possível;

- $\boldsymbol{N}$-Agrupamentos ( $N$-Clusters $)$ : neste algoritmo é feito no máximo $N$ agrupamentos de objetos, onde $N$ é um valor inteiro parametrizado no momento da criação da estrutura. Estes agrupamentos são gerados de acordo com as distâncias entre os objetos. O primeiro passo desse algoritmo é a criação de $C$ agrupamentos, cada um com apenas uma entrada. O segundo passo é, para cada agrupamento C, juntar ele com o que tem a menor distância em relação a ele. No final deste passo, são obtidos $N$ agrupamentos (linha 2 do Algoritmo 4.4.2). No próximo passo o algoritmo tenta a fusão dos $N$ agrupamentos, um a um, desde que com isto a sobreposição entre os agrupamentos não aumente. Se isto for possível, eles serão fundidos e o número final de agrupamentos será diminuído (linha 3). Este passo gera no mínimo 2 agrupamentos. No quarto passo os agrupamentos unitários são inseridos no conjunto para inserção no nível superior (linha 4), não sendo criados os nós para o seu armazenamento. Para cada agrupamento restante é escolhido o seu objeto representativo (linha 5) e criado os nós para o armazenamento dos seus agrupamentos (linha 6). Estes representativos são promovidos para a inserção no nível superior da estrutura (linha 7). Este algoritmo funciona de forma semelhante ao MST da 
Slim-tree quando o número de agrupamentos for ajustado em 2. A única diferença é que para os agrupamentos unitários há a promoção deles para o nível superior, o que não ocorre no $M S T^{1}$. Nesta opção não se tem garantia que a sobreposição entre os nós seja mínima, pois tem a restrição de formação de no mínimo $N$ agrupamentos nas divisões. A complexidade deste algoritmo é $\boldsymbol{O}\left(\boldsymbol{C}^{2} \log \boldsymbol{C}\right)$, igual ao $M S T$ da Slim-tree.

A taxa de ocupação mínima dos nós é utilizada pelo algoritmo SplitNode apenas nas políticas minMax e minSum. Esta taxa mínima não é utilizada na política $N$-Clusters, podendo existir nós com apenas duas entradas após a redistribuição das entradas entre os nós.

A taxa de ocupação mínima dos nós é ajustada na criação da estrutura, podendo ter valores entre 1 até a metade da capacidade máxima do nó. Nos casos em que ela é ajustada para ser a metade da capacidade máxima do nó (linha 12 do Algoritmo 4.4.2), todas as $C$ entradas devem ser redistribuídas entre os dois nós. Primeiro é adicionado o objeto representativo em cada nó (linha 11), depois as demais entradas é adicionado no nó que tiver a menor distância em relação ao seu representativo (linha 13). Nos casos em que um nó, depois da escolha final dos representativos, tiver apenas o objeto representativo (apenas uma entrada) (linha 22), o nó não será criado (linha 23), e esta entrada deverá ser inserida no nó do nível superior, juntamente com as suas informações (linha 26). Baseado em experimentos e na literatura [Ciaccia et al., 1997], divisões de forma não balanceada (em número de entradas) são melhores para minimizar a sobreposição do que as balanceadas (mesmo número de entradas em cada nó). Este mesmo princípio é aplicado a opção minMax da M-tree e da Slim-tree.

Já para os casos em que a ocupação mínima é ajustada com valores entre 1 até menos que a metade das entradas (linha 14), cada nó é obrigatoriamente preenchido com a ocupação mínima de entradas (linha 16). As demais entradas somente serão inseridas nos nós se não aumentar a sobreposição existente entre eles (linha 17). As entradas não inseridas em nenhum dos dois representativos são inseridas em PromoSet para a inserção no nível superior da estrutura (linha 18).

Depois de testadas todas as possibilidades de representativos dentre as $C$ entradas, serão escolhidos os representativos que geraram a melhor configuração para a opção minMax ou para a minSum (linha 21).

Pode ocorrer que depois da propagação de divisão para os níveis superiores, ou a atualização do raio do representativo, outras entradas sejam cobertas pela entrada que sofreu a atualização. Neste caso, estas entradas são removidas do nó atual onde elas estão e em seguida são inseridas no nível inferior da entrada que as cobre.

O algoritmo de inserção de novos objetos é mostrado, de maneira sucinta, no Algoritmo 4.4.3, incluindo as chamadas para os algoritmos ChooseSubtree e SplitNode.

\footnotetext{
${ }^{1} \mathrm{O}$ algoritmo $M S T$ da Slim-tree pode gerar nós com uma única entrada, e no caso dos nós folhas, com raio nulo, tendo baixas chances de novos objetos serem inseridos nestes nós.
} 


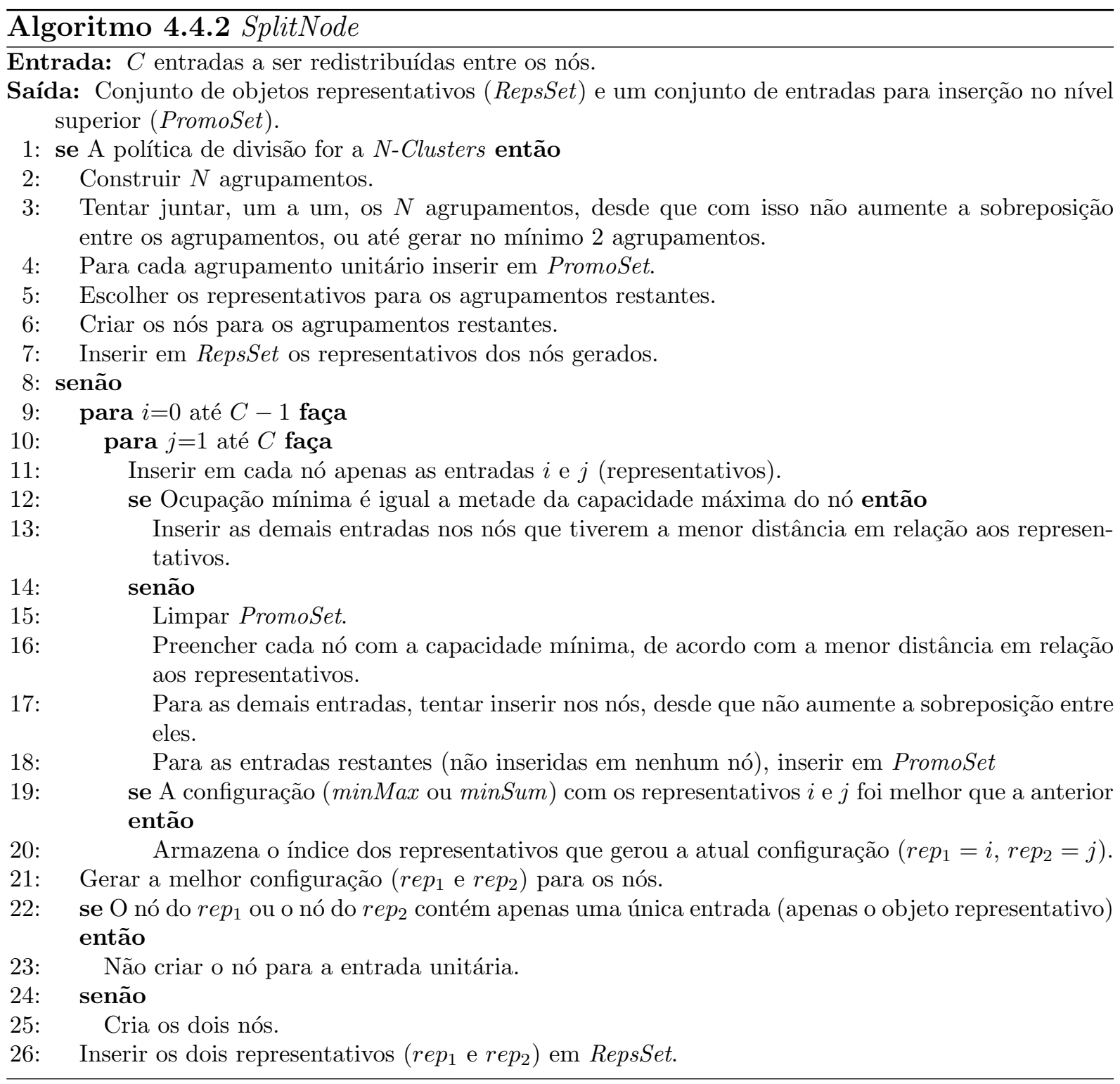

O algoritmo recebe como parâmetros de entrada o novo objeto $o_{n}$ e a árvore $\operatorname{Ptr}_{t}$ onde ele será inserido. A escolha da melhor subárvore de $P t r_{t}$ onde $o_{n}$ irá ser inserido ocorre na linha 1. Se este algoritmo retornar uma subárvore válida (linha 2), então o processo para adicionar o novo objeto $o_{n}$ é chamado recursivamente (linha 3), senão o objeto é adicionado no nó Ptr $_{t}$ (linha 11). Caso não haja espaço para armazenar $o_{n}$ em Ptr $_{t}$, ocorre uma divisão (linha 13). Ocorrendo uma divisão nos níveis inferiores da estrutura (linha 4), a entrada Ptr $_{i}$ necessita ser atualizada no retorno da recursão, e se houver novos representativos (linha 5) ou entradas promovidas dos níveis inferiores (linha 6), adicionálos no nó $\mathrm{Ptr}_{t}$. Depois é verificado se outras entradas são cobertas pela atualização (linha 7). Em caso positivo elas serão movidas para o nível inferior da entrada que as cobre (linha 8). 


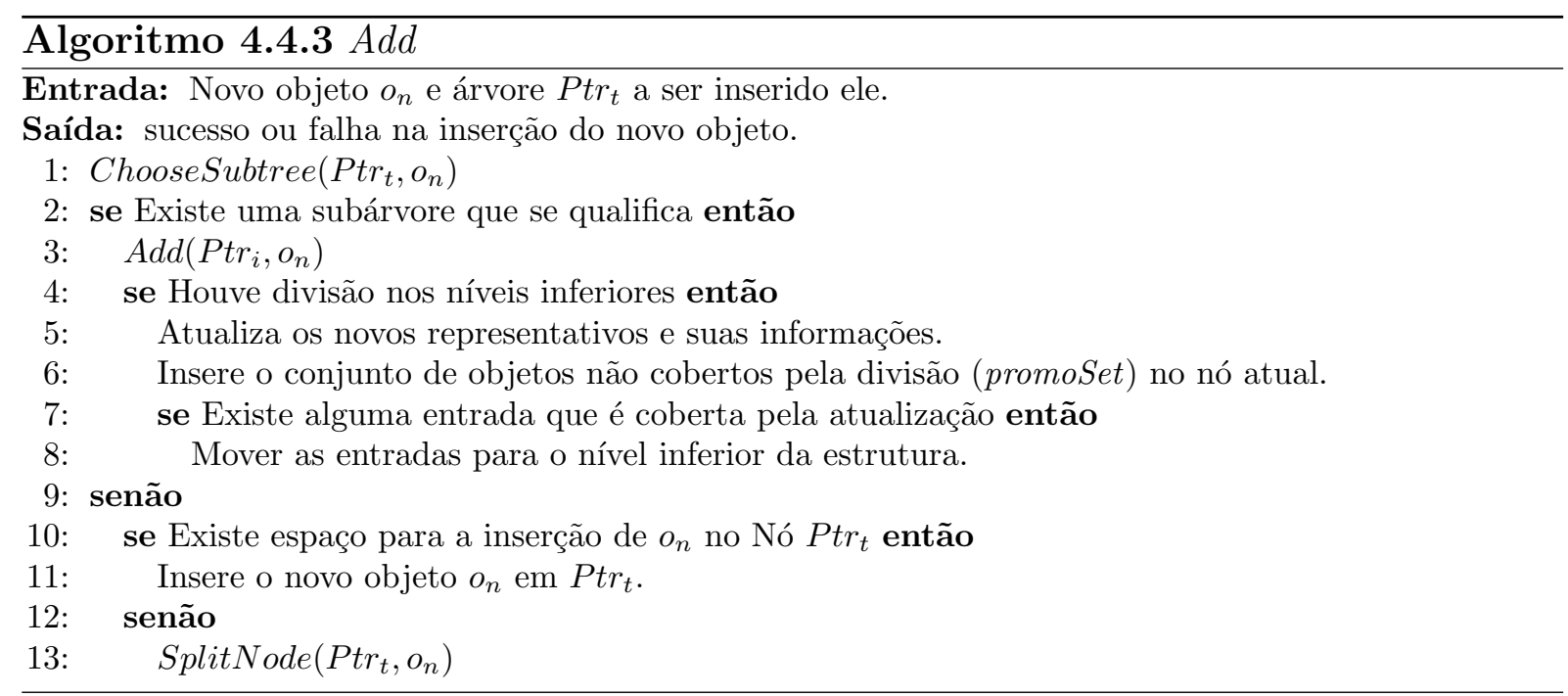

\subsection{Executando Consultas por Similaridade}

A DBM-tree pode executar as duas principais consultas por similaridade: Consulta por Abrangência $(R Q)$ e aos $\boldsymbol{k}$-Vizinhos Mais Próximos $(k N N Q)$. Seus algoritmos de consultas por similaridade são semelhantes aos da Slim-tree (vide Seção 3.2.2.3).

O algoritmo $R Q()$ da $D B M$-tree é ilustrado no Algoritmo 4.5.1. Ele recebe como parâmetros de entrada um nó da árvore $P t r_{t}$, o objeto de consulta $o_{q}$ e o raio de abrangência $r_{q}$. Todas as entradas do nó $P t_{t}$ são verificadas se possuem objetos que satisfazem as condições da consulta (linha 1). A desigualdade triangular (linha 2) é utilizada para podar subárvores e objetos que não possuam regiões de intersecção com a região definida pela consulta. Caso não seja possível descartar com o uso da desigualdade triangular, é necessário calcular a distância da entrada $i$ ao objeto de consulta (linha 3). É testado se a entrada possui intersecção com a região definida pela busca (linha 4). Em caso afirmativo, é verificado se a entrada $i$ é uma subárvore (linha 5), que neste caso é analisada recursivamente pelo algoritmo $R Q($ ) (linha 6). Sendo a entrada $i$ um objeto, ele é adicionado no conjunto resposta (linha 8). Ao final deste processo é retornado o conjunto resposta contendo todos os objetos indexados pela $D B M$-tree que satisfazem os critérios de consulta, ordenados pela distância.

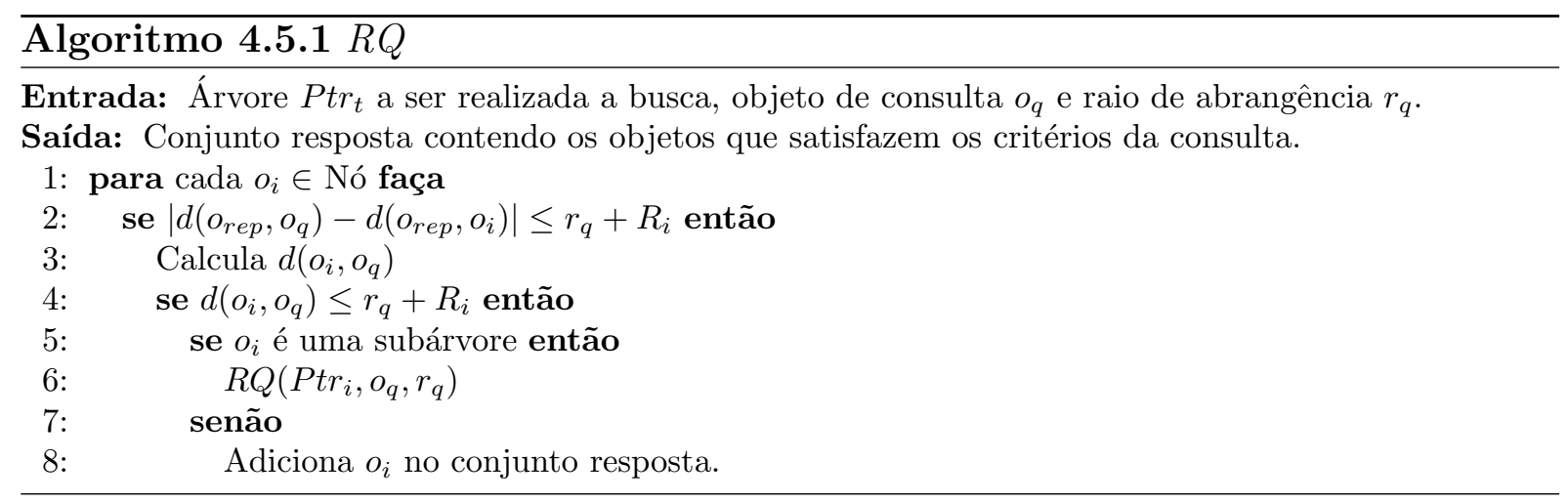


O algoritmo $k N N Q()$, ilustrado no Algoritmo 4.5.2, recebe como parâmetros de entrada o objeto de consulta $o_{q}$, o número de objetos requisitados $k$, e se a lista de empate deve ser retornada no conjunto resposta. O retorno deste algoritmo é o conjunto resposta contendo todos os objetos indexados pela $D B M$-tree que satisfazem os critérios de consulta, ordenados pela distância. O primeiro passo do algoritmo é ajustar o raio dinâmico $r_{k}$ (linha 1) e adicionar o nó raiz na lista de prioridade (linha 2). Enquanto tiver subárvores para analisar na lista de prioridade que contenham região de intersecção com a da busca (linha 3), o algoritmo irá analisar as suas entradas. Para cada nó, primeiro é analisado os objetos (linha 4), depois as suas subárvores (linha 12). Para cada objeto (linha 5), é verificado se é possível descartá-lo pela desigualdade triangular (linha 6). Caso não seja possível, é calculado a sua distância em relação ao objeto de consulta (linha 7). Se ele é coberto pela região definida da consulta (linha 8), então ele é adicionado no conjunto resposta (linha 9). Caso o conjunto resposta tenha mais do que $k$ objetos (linha 10), é ajustado o valor de $k$ (de acordo com a lista de empate) e do raio dinâmico $r_{k}$ (com o maior valor de distância do conjunto resposta) (linha 11). Para cada subárvore do nó (linha 13) é calculado a sua distância ao objeto de consulta (linha 15), depois de tentar podar ela pela desigualdade triangular (linha 14). Se a subárvore contem intersecção com a região definida pela busca (linha 16), a sua subárvore é inserida na lista de prioridade (linha 17) para ser analisada.

O funcionamento do algoritmo $k N N Q()$ é semelhante ao $R Q()$. Ele utiliza um raio dinâmico $r_{k}$, que inicialmente tem um valor que engloba todos os objetos indexados pela árvore (linha 1), e que vai se ajustando a medida que o conjunto resposta for preenchido com os $k$ objetos requisitados (linha 11). Outra diferença em relação ao $R Q($ ) é que existe prioridade para a análise das subárvores (subárvores com menores distâncias ao objeto de consulta são analisadas primeiro (linha 3)) e das entradas nos nós (primeiro acontece a análise dos objetos (linha 4 à 11), depois das subárvores do nó (linha 12 à 17)). Isto é feito para o ajuste do raio dinâmico ocorrer mais rapidamente, o que permite aumentar a quantidade de podas.

\subsection{Otimizando a Estrutura}

A DBM-tree também possui um algoritmo para otimização da estrutura, chamado de DBM-Slim-Down, semelhante ao Slim-Down. Ele recebeu este nome pois seu funcionamento é semelhante ao Slim-Down, provocando um "emagrecimento" da árvore. Ele funciona para qualquer estrutura que possua apenas um tipo de nó, como a DBM-tree.

O algoritmo DBM-Slim-Down pode ser executado diversas vezes durante a evolução de uma árvore (inserções de novos objetos). Porém, por ser um processo relativamente custoso, a sua execução é apenas recomendada quando uma grande quantidade de objetos já tenha sido inserida na DBM-tree.

O processo de otimização do DBM-Slim-Down é feito em todos os nós da estrutura, 


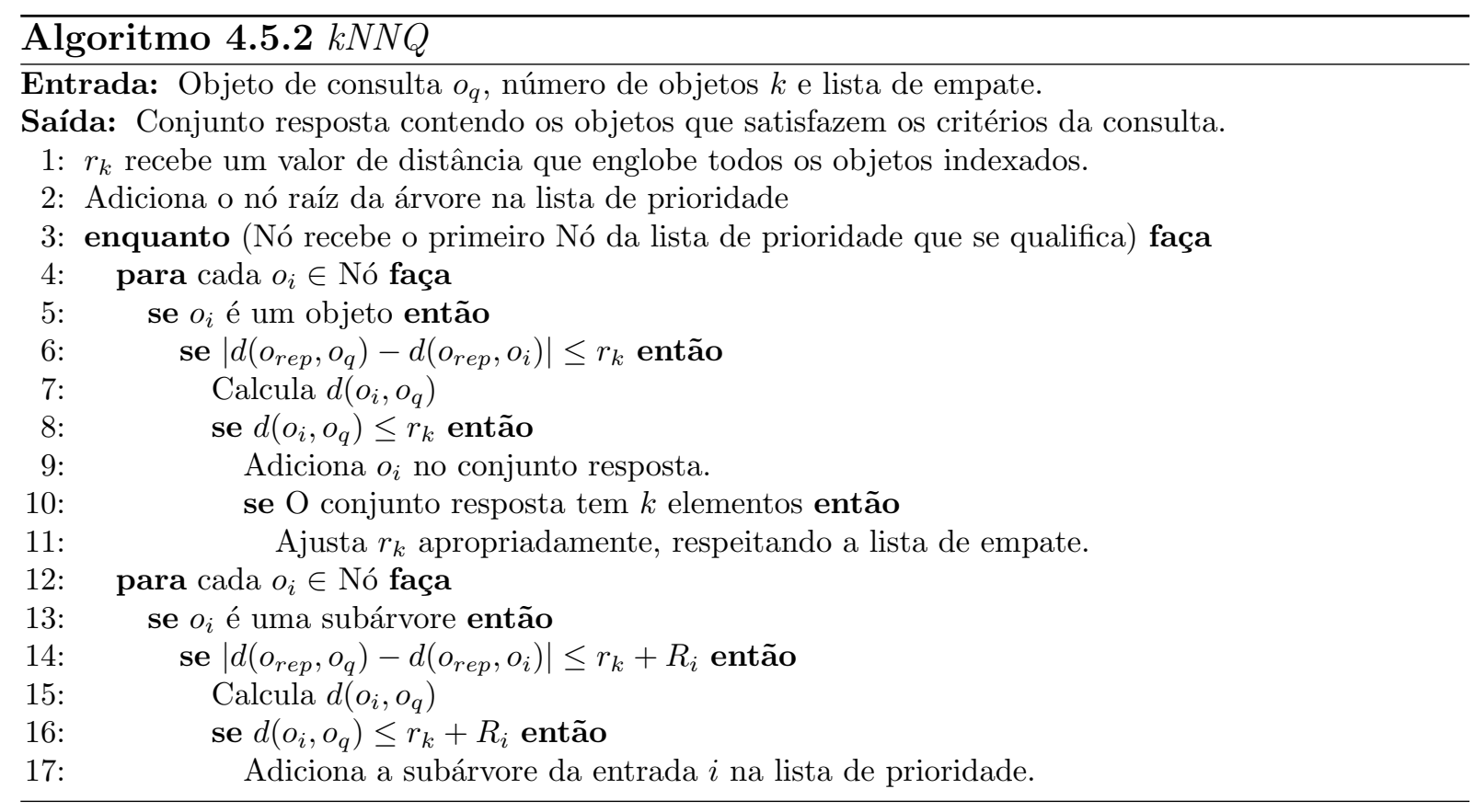

pois não existe distinção entre nó folha e interno. Além disto, os nós que possuem apenas uma única entrada são removidos da estrutura, ajustando devidamente suas informações. Por essas otimizações que o DBM-Slim-Down é mais custoso que o Slim-Down, mas produz uma melhoria mais intensa da estrutura para responder a consultas.

Este algoritmo proporciona melhorias significativas nas árvores que são refletidas na diminuição do número de cálculos de distância, tempo total de processamento e, principalmente, número de acessos a disco para responder às consultas $R Q$ e $k N N Q$. Estas melhorias são mostradas na Seção 5.3.4 do próximo capítulo.

O algoritmo DBM-Slim-Down é mostrado, de forma sucinta, no Algoritmo 4.6.1. Este algoritmo é executado para todos os nós da estrutura. Ele recebe como entrada uma árvore $\mathrm{Ptr}_{t}$ a ser otimizada e retorna ela mesma, otimizada. A condição de parada (linha 1) deste algoritmo pode ocorrer em dois casos: quando não é feito nenhuma troca de entradas entre os nós em uma interação; ou quando o número de trocas excede um valor limite de trocas (3 vezes o tamanho de entradas do Nó $P t r_{t}$ - quantidade igual ao Slim-Down). Para cada entrada $A$ do nó Ptr $_{t}$ (linha 2) encontre a entrada que tem a maior distância (linha 3). Encontre uma outra entrada do nó $\operatorname{Ptr}_{t}$ (linhas 4 e 5 ) que possa receber a entrada $i$ (linha 6). Em caso positivo, remova a entrada $i$ do Nó $A$ e insira no nó $B$ (linha 7). Se o processo de troca de entradas do nó $A$ fizer com que ele fique com nenhuma entrada (linha 8), o nó $A$ e a entrada no nó $P t r_{t}$ deverão ser eliminados (linha 9). Caso não gere nó vazio, é apenas necessário atualizar as informações da entrada $A$ no nó $\operatorname{Ptr}_{t}$ (linha 11).

Depois do processo de trocas de entradas entre os nós, é verificado para todas as entradas do nó $\operatorname{Ptr}_{t}$ (linha 12) se alguma ficou com entrada única (linha 13). Em caso positivo, a entrada única passará a ocupar o lugar da entrada $A$ no nó Ptr $_{t}$ (linha 15), e o seu nó removido (linha 14). 


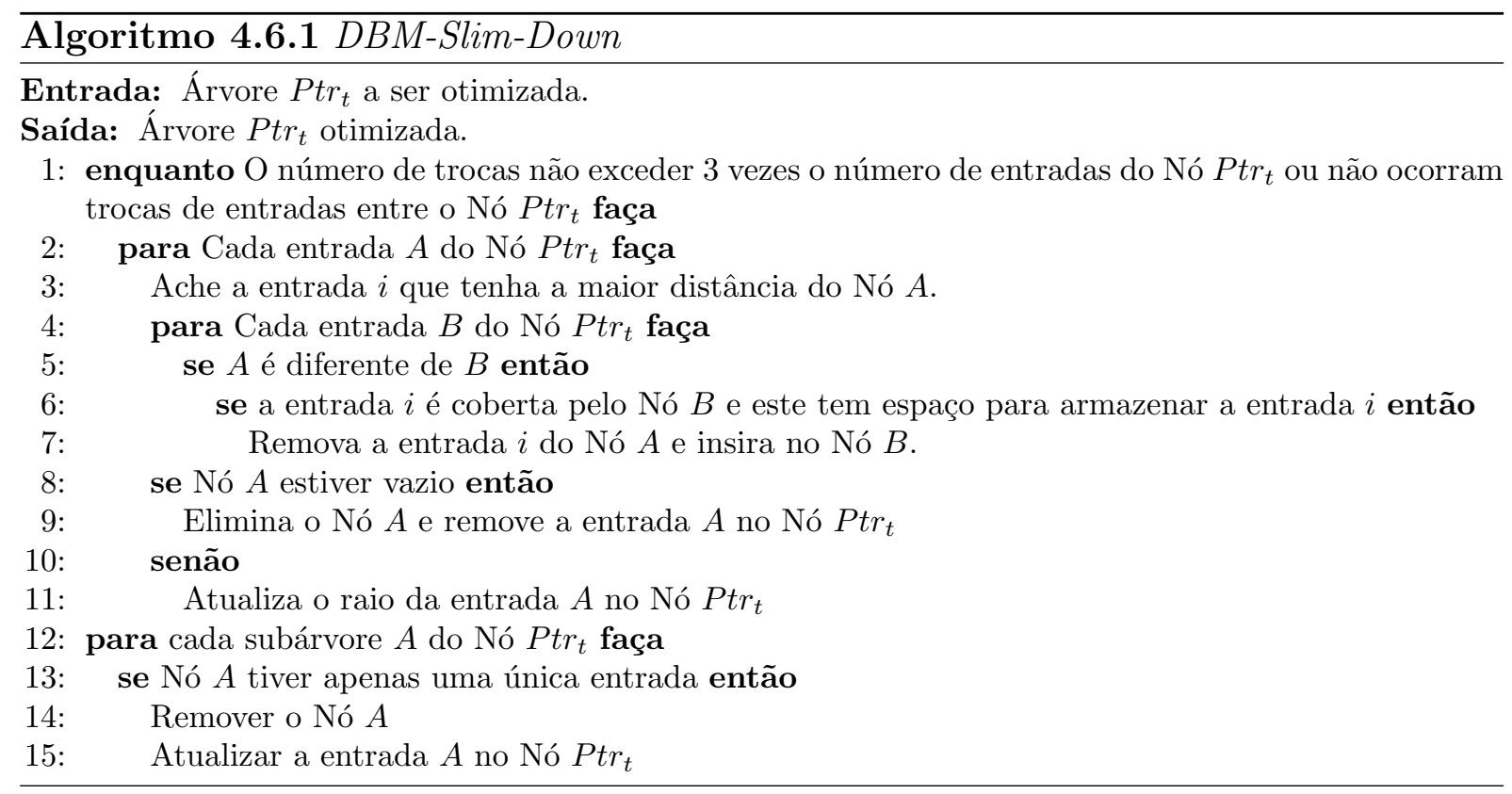

\subsection{Remoção de objetos}

A remoção de objetos é um problema que nenhuma das estruturas métricas dinâmicas existentes trata. Em [Traina et al., 2002b] foi proposta uma abordagem para remoção de objetos na Slim-tree (vide Seção 3.2.2.2). Porém, a abordagem proposta não faz diminuir a altura da árvore quando um grande número de objetos tiver sido removido da estrutura. Além disto, podem existir nós com menos entradas que a taxa de ocupação mínima dos nós.

Embora a remoção de objetos não tenha sido implementada na DBM-tree, ela é mais fácil de ser tratada do que na Slim-tree. Isto porque a $D B M$-tree não possui a restrição de manter a estrutura sempre balanceada, como ocorre na Slim-tree, e possui apenas um tipo de nó.

Uma possível abordagem para a remoção de objetos seria: procurar recursivamente pelo objeto a ser removido nos nós da estrutura; caso ele seja encontrado na estrutura, removê-lo do nó em que está armazenado; caso o objeto removido for um representativo, escolher um novo que minimize o raio de cobertura, promovendo a mudança para os níveis superiores da estrutura; nos casos em que a remoção do objeto resulte nós com menos entradas que a ocupação mínima dos nós, as entradas são reinseridas na árvore e o nó removido da estrutura; remoções que façam com que o nó raiz tenha apenas uma única entrada, faz com que a altura máxima da árvore diminua e o nó raiz passa a ser o filho dele, removendo o antigo nó raiz da estrutura; no retorno da recursão as informações das subárvores devem ser atualizadas. A abordagem descrita é semelhante a da $R$-tree [Guttman, 1984],

Note que para a implementação desta abordagem não é necessária nenhuma mudança na $D B M$-tree, nem na estrutura física, nem nos algoritmos apresentados neste ca- 
pítulo.

\subsection{Visualizando a Estrutura}

A DBM-tree possui meios para a visualização da estrutura e das consultas por similaridade ( $k N N Q$ e $R Q$ ) para qualquer conjunto de dados. Ela se utiliza do sistema MAMView (descrito na Seção 3.2.3) para gerar modelos interativos da estrutura, onde é possível navegar pelos níveis da estrutura, analisar animações das consultas $R Q$ e $k N N Q$, e fazer inspeções visuais na estrutura.

A visualização da DBM-tree foi muito importante durante a fase de desenvolvimento da estrutura. Através da visualização foi possível fazer comparações visuais das diversas opções dos algoritmos ChooseSubtree e SplitNode, contribuindo para o seu aperfeiçoamento. Além disso, a visualização das consultas por similaridade ajudou para melhorar os algoritmos $R Q$ e $k N N Q$.

A Figura 4.4 mostra a estrutura de uma DBM-tree gerada pelo MAMView com um conjunto de 5507 objetos das coordenadas geográficas das cidades brasileiras. As diferentes cores dos objetos representam os diversos níveis da estrutura. Os objetos com cores laranja e vermelho pertencem a níveis mais profundos que os de cor verde. Esta representação mostra que a profundidade é maior em regiões com maior densidade de objetos (região sudeste e costa leste do Brasil) e que estes estão armazenados em todos os níveis da estrutura, como o esperado; e ainda, a profundidade é menor em regiões menos densas (região norte e extremidades do Brasil - extremo sul e Fernando de Noronha-PE). Na Figura 4.4(a) é ilustrado todos os níveis da estrutura e na Figura 4.4(b) é mostrado apenas os níveis 5, 6 e 7 (3 últimos níveis) da mesma estrutura contendo as cidades brasileiras.

Já a Figura 4.5 ilustra a mesma estrutura com as cidades brasileiras, porém uma visualização centrada em uma determinada região do Brasil. Na figura são mostrados 6 quadros da animação de uma $R Q$ realizada na $D B M$-tree. A estrela no centro da Figura 4.5(a) representa o objeto de consulta e o círculo o raio de abrangência. Em (b), (c), (d) e (e) são mostradas as subárvores sendo navegadas e calculadas as suas distâncias com o objeto de consulta (ligações dos representativos com o objeto da consulta) e os objetos sendo adicionados no conjunto resposta (pontos pretos dentro da círculo do raio de consulta). Já na Figura 4.5(f) é mostrado o resultado final da consulta com todos os objetos do conjunto resposta e as subárvores navegadas para responder a $R Q$.

\subsection{Conclusão}

O presente capítulo apresentou o MAM DBM-tree. Ele é uma estrutura dinâmica e que permite o armazenamento dos dados em disco. Através da flexibilização do balanceamento 


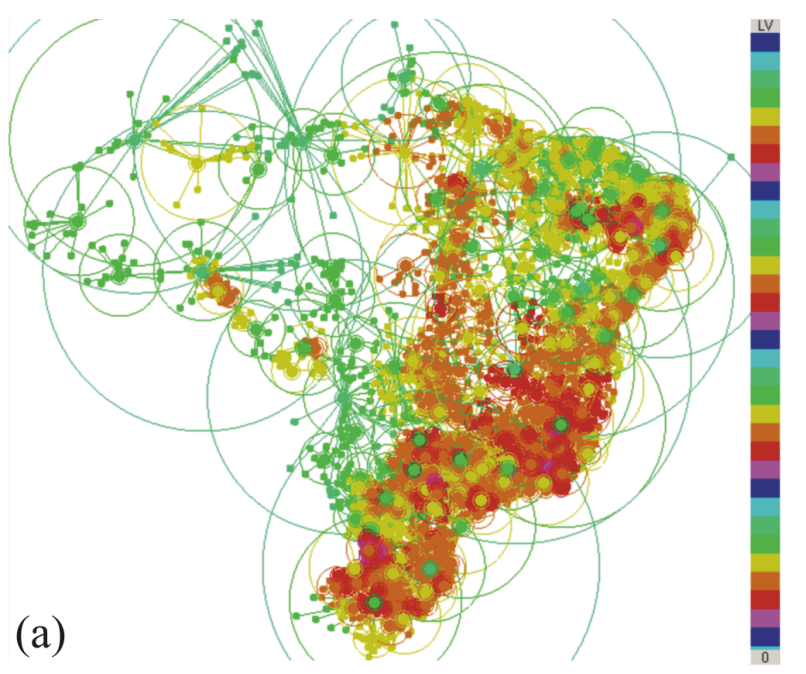

(b)

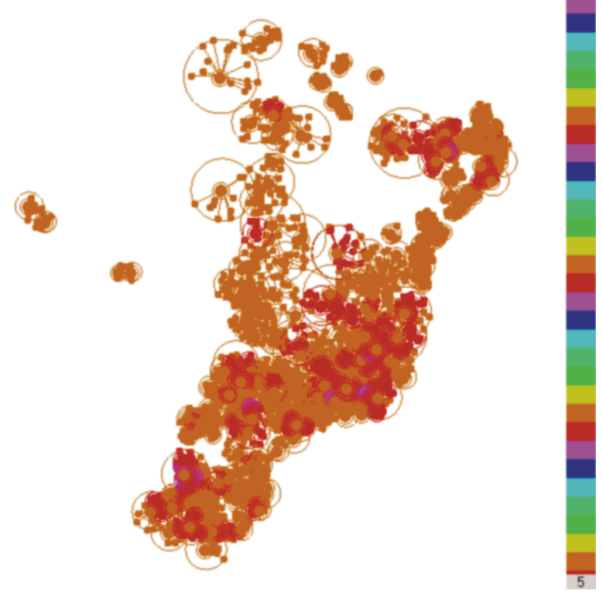

Figura 4.4: Visualização da estrutura DBM-tree criada pelo MAMView para o conjunto de 5507 cidades brasileiras. Em (a) é mostrado todos os níveis da estrutura com os raios de cobertura dos nós; em (b) é mostrado apenas os níveis 5, 6 e 7 da estrutura, também com os raios de cobertura dos nós. É possível verificar através das figuras que a profundidade é maior em regiões mais densas (região sudeste e costa leste do Brasil).
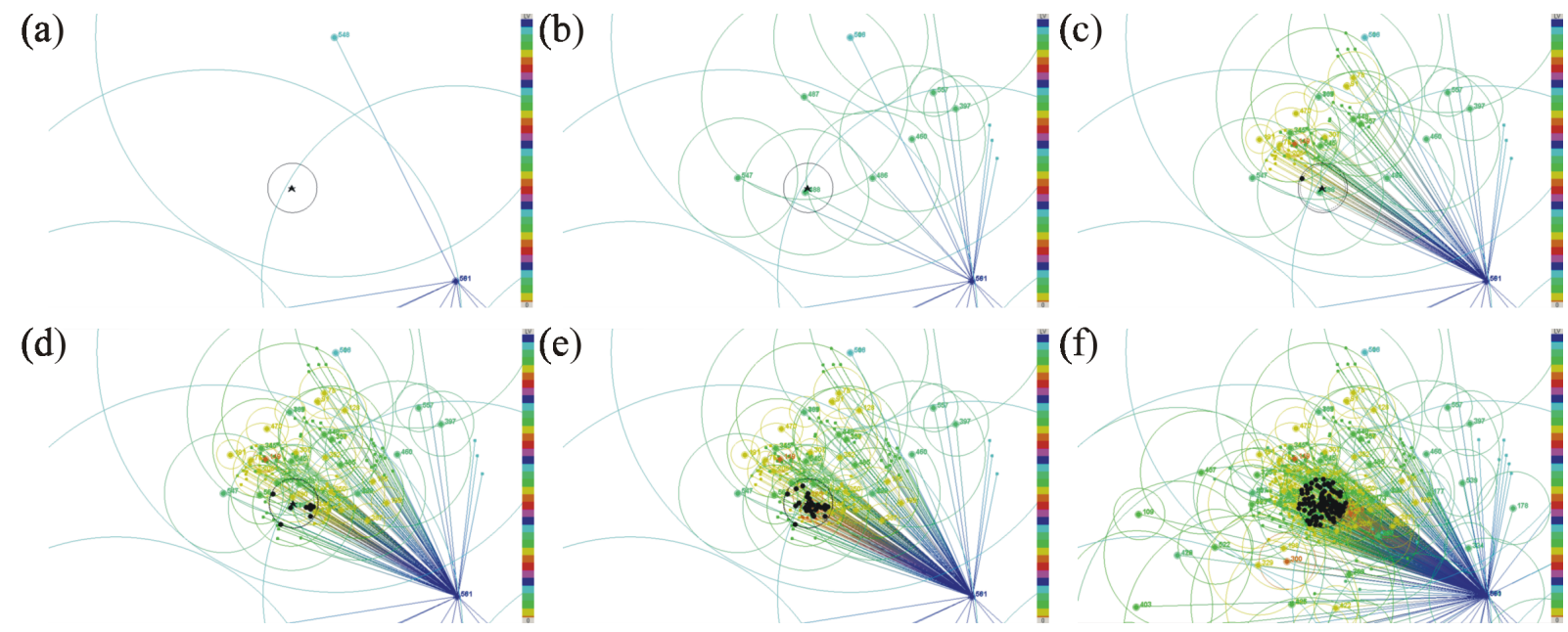

Figura 4.5: Alguns quadros da animação de uma $R Q$ realizada na $D B M$-tree carregada com o conjunto de 5507 cidades brasileiras. O objeto de consulta está representado pela estrela preta, o raio de abrangência pelo círculo preto, e os objetos pertencentes ao conjunto resposta pelos pontos pretos contidos no círculo preto (raio de abrangência). O primeiro quadro da animação é representado por (a), e a último por (f). Os quadros (b), (c), (d) e (e) representam visualizações intermediárias entre o quadro (a) e (f). 
da estrutura é possível minimizar a taxa de sobreposição entre os nós de um mesmo nível. Com isto, é possível diminuir a quantidade de buscas em largura e, conseqüentemente, melhorar o seu desempenho para responder às consultas.

Foram mostradas 2 políticas para o algoritmo ChooseSubtree (minDist e minGDist) e 3 políticas para o algoritmo SplitNode (minMax, minSum e N-Clusters). Foi proposto o algoritmo de divisão $N$-Clusters que pode gerar $N$ agrupamentos, cada um associado a um nó. Quando $N$ é igual a 2, ele funciona de forma semelhante ao MST da Slim-tree, porém não gera nós com entradas unitárias.

Também foi apresentado o algoritmo DBM-Slim-Down, que reorganiza os elementos dos nós para melhorar o desempenho nas consultas, e a extensão da DBM-tree para a visualização da sua estrutura e das consultas por similaridade ( $k N N Q$ e $R Q$ ) através do sistema MAMView. Foi também proposto uma abordagem para a DBM-tree tratar remoção de objetos, e que não necessita de mudanças nos algoritmos de construção da estrutura.

Os resultados dos experimentos feitos com a $D B M$-tree e as duas principais estruturas para indexar dados métricos encontradas na literatura, a $M$-tree e a Slim-tree, são apresentados no próximo capítulo. 


\section{Capítulo 5 \\ Experimentos}

\subsection{Introdução}

Como existem poucos trabalhos que apresentam equações de estimativa de custo para Métodos de Acesso Métricos (MAMs), é inviável compará-los analiticamente. Esta deficiência se deve à dificuldade em modelar a distribuição dos dados e à estrutura interna dos métodos. Ao contrário dos métodos de indexação tradicionais, como o B-tree, onde os nós definem regiões disjuntas, os MAMs tendem a apresentar nós com sobreposição, dificultando a modelagem de sua complexidade durante as consultas [Santos, 2003].

A experimentação é a abordagem mais freqüentemente encontrada na literatura para comparar novos MAMs com os já existentes, uma vez que seu comportamento é dependente dos dados, o que torna a análise de sua complexidade pouco realista. O processo envolve a coleta e a comparação de medidas de desempenho a partir de testes práticos com os MAMs, envolvendo: diferentes conjuntos de dados; os dois tipos de consulta por similaridade mais comuns (por abrangência e aos $k$-vizinhos mais próximos); e diferentes valores para os parâmetros destas consultas (raio e número de vizinhos $k$, respectivamente). As medidas de desempenho freqüentemente comparadas no contexto de MAMs são: número de cálculos de distância, número de acessos a disco e tempo total das consultas. É também necessário definir os objetos que serão usados como centro das regiões de busca. A técnica mais utilizada em MAMs para definir os objetos de consultas é a baseada na amostragem. 


\subsection{Materiais e Métodos}

A avaliação do desempenho da $D B M$-tree envolveu uma grande variedade de conjuntos, tanto reais quanto sintéticos, onde as principais diferenças foram a dimensão, o tamanho dos objetos e do conjunto de dados, e a distribuição dos dados no espaço métrico. A Tabela 5.1 apresenta os conjuntos de dados utilizados nos experimentos. É indicado para cada conjunto: o nome, o número total de objetos (Nro. Objs), a dimensão $(D)$, o tamanho da páginas em $\mathrm{KB}(P g)$, a métrica de comparação $(d())$ e a descrição de sua origem e composição.

Tabela 5.1: Descrição dos conjuntos de dados reais e sintéticos utilizados nos experimentos.

\begin{tabular}{|c|c|c|c|c|l|}
\hline Nome & Nro. Objs & $D$ & $P g(\mathrm{~KB})$ & $d()$ & Descrição \\
\hline Cidades & 5507 & 2 & 1 & $L_{2}$ & $\begin{array}{l}\text { Latitude, longitude e nome das cidades } \\
\text { brasileiras (www.ibge.gov.br). }\end{array}$ \\
\hline ColorHisto & 68040 & 32 & 8 & $L_{2}$ & $\begin{array}{l}\text { Histogramas de imagens coloridas obtidos do } \\
\text { repositório KDD da Universidade da } \\
\text { Califórnia - Irvine [KDD-UCI, 2004]. }\end{array}$ \\
\hline Histogramas & 4247 & - & 4 & $L_{M H}$ & $\begin{array}{l}\text { Histogramas de tons de cinza de imagens } \\
\text { médicas. Este conjunto é adimensional e } \\
\text { foi gerado pelo GBDI-ICMC-USP. Maiores } \\
\text { detalhes dos dados e da métrica utilizada, } \\
\text { vide [Traina et al., 2002a]. }\end{array}$ \\
\hline Sintético2D & 20000 & 2 & 1 & $L_{2}$ & $\begin{array}{l}\text { Vetores de dados sintéticos com distribuição } \\
\text { Gaussiana contendo 100 agrupamentos em um } \\
\text { hipercubo bidimensional. O procedimento para } \\
\text { gerar este conjunto se encontra descrito em } \\
\text { [Ciaccia et al., 1997]. }\end{array}$ \\
\hline Sintético6D & 50000 & 6 & 2 & $L_{2}$ & $\begin{array}{l}\text { Semelhante ao Sintético2D, só que para um } \\
\text { hipercubo 6-dimensional. }\end{array}$ \\
\hline Sintético16D & 10000 & 16 & 8 & $L_{2}$ & $\begin{array}{l}\text { Semelhante ao Sintético2D, só que contendo 10 } \\
\text { agrupamentos em um hipercubo 16-dimensional. }\end{array}$ \\
\hline Sintético256D & 10000 & 256 & 32 & $L_{2}$ & $\begin{array}{l}\text { Semelhante ao Sintético2D, só que para um } \\
\text { hipercubo 256-dimensional. }\end{array}$ \\
\hline
\end{tabular}

A configuração do computador usado para os testes foi: processador Intel Pentium 4 1.6GHz, com 512 MB de memória RAM e disco rígido de 40 GB. O sistema operacional foi o Microsoft Windows 2000. O MAM DBM-tree foi comparado com o Slim-tree e o $M$-tree. O código do Slim-tree e do $M$-tree foram reimplementados na biblioteca de MAMs Arboretum, utilizando a linguagem $\mathrm{C}++$. A implementação do DBM-tree também faz parte desta biblioteca (maiores detalhes da biblioteca de MAMs Arboretum e da implementação do DBM-tree, vide Apêndice B). A reimplementação destes dois MAMs foi feita para manter a comparação mais justa, uma vez que eles compartilham a mesma arquitetura e otimizações do MAM DBM-tree.

Os principais aspectos relacionados com a preparação dos testes foram:

- Os objetos de cada conjunto de dados foram "embaralhados", simulando a situação real de inserções de objetos que ocorrem em SGBDs (inserções de forma aleatória); 
- Após a primeira fase, extraiu-se uma amostra de 500 objetos, correspondendo ao conjunto de dados usados como centro da região de busca. Os objetos foram escolhidos aleatoriamente dentre todos os pertencentes ao conjunto. Metade (250) destes 500 objetos foram removidos do conjunto de dados antes de sua inserção, e a outra metade foi apenas copiado para o conjunto de busca. Portanto, metade dos objetos do conjunto de busca pertencem ao conjunto indexado pelos MAMs, e a outra metade não. A mesma amostra foi usada em todas as consultas para um mesmo conjunto de dados;

- Os números de vizinhos $k$ a serem encontrados nas consultas aos vizinhos mais próximos $(k N N Q)$ foram escolhidos de acordo com os valores freqüentemente usados em situações reais. Foram usados valores diferentes para $k$, variando de 2 a 20, em todos os testes de consultas aos $k$-vizinhos mais próximos;

- Testes preliminares foram feitos com todos os conjuntos a fim de definir os valores dos raios para as consultas por abrangência $(R Q)$. Os raios de cada consulta foram definidos em função do valor de objetos desejados por cada consulta, isto é, $k$ variando de 2 a 20 objetos. Quer dizer, o raio de uma consulta for definido para que esta consulta retornasse os $k$ objetos desejados;

- Os códigos dos métodos foram implementados para contabilizar e armazenar em arquivo texto, no padrão do GNUPlot ${ }^{1}$, as seguintes medidas (considerando as 500 consultas): número médio de cálculos de distância; número médio de acessos a disco, incluindo acessos ao nó raiz dos índices; e tempo total de consulta;

- As opções de construção da $M$-tree são as que obtêm os melhores resultados segundo [Ciaccia et al., 1997], e estão sumarizadas na Tabela 5.2;

- Considerando os resultados para a Slim-tree, todas as medições foram feitas após a execução do algoritmo de pós-otimização Slim-Down (ver seção 3.2.2.4). A opção MST e minOccup também foi testada, porém os resultados com o minMax e minDist sempre obtiveram os melhores resultados para as consultas em todos os conjuntos testados. Portanto, apenas a melhor opção da Slim-tree é mostrada, e que está sumarizada na Tabela 5.2. A ocupação mínima dos nós da Slim-tree e da M-tree foi de $25 \%$ da capacidade máxima dos nós, que é a padrão dessas estruturas. Elas não funcionam para valores menores de ocupação mínima, e para valores maiores o desempenho dessas estruturas não são satisfatórios;

- Para a DBM-tree, todas as medições foram feitas após a execução do algoritmo de pós-otimização DBM-Slim-Down. Todas as opções de construção da DBM-tree foram analisadas, variando desde a ocupação mínima dos nós quanto as configurações

\footnotetext{
${ }^{1}$ Aplicação GNU para impressão de funções (http://www.gnuplot.info/).
} 
dos algoritmos SplitNode e ChooseSubTree. Nos testes mostrados apenas as opções sumarizadas na Tabela 5.2 são descritas, pois na média, elas obtiveram os melhores resultados. A ocupação mínima para as opções minMax e minSum, ambos com a opção minDist, foram ajustados em 30\%, embora a DBM-tree possa funcionar com qualquer valor de ocupação mínima entre 1 entrada e metade da capacidade do nó, fato que não ocorre na $M$-tree e na Slim-tree.

Tabela 5.2: Configuração da $M$-tree, Slim-tree e DBM-tree para os experimentos.

\begin{tabular}{|c|c|c|c|}
\hline Nome & ChooseSubtree & SplitNode & Observação \\
\hline MTree & minDist & $\operatorname{minMax}$ & $\begin{array}{l}\text { Configuração padrão da } M \text {-tree e que obtêm } \\
\text { os melhores resultados para a } M \text {-tree. }\end{array}$ \\
\hline Slim-MM & minDist & $\min M a x$ & $\begin{array}{l}\text { Esta configuração obtêm os melhores resultados } \\
\text { nas consultas para a Slim-tree. }\end{array}$ \\
\hline$D B M-M M$ & minDist & $\min M a x$ & $\begin{array}{l}\text { Ocupação mínima dos nós fixado em } 30 \% \text { da } \\
\text { capacidade máxima do nó. }\end{array}$ \\
\hline$D B M-M S$ & minDist & minSum & $\begin{array}{l}\text { Ocupação mínima dos nós fixado em } 30 \% \text { da } \\
\text { capacidade máxima do nó. }\end{array}$ \\
\hline$D B M-G M M$ & minGDist & $\min M a x$ & $\begin{array}{l}\text { Ocupação mínima dos nós fixado em } 50 \% \text { da } \\
\text { capacidade máxima do nó. }\end{array}$ \\
\hline$D B M-G 2 C$ & minGDist & $N$-Clusters & $\begin{array}{l}\text { Com } N \text { igual a } 2 \text {. Nesta opção todos os objetos são } \\
\text { inseridos nos } 2 \text { nós da divisão, ou seja, nenhum } \\
\text { objeto ou subárvore é promovido para inserção } \\
\text { nos níveis superiores. Exceção aos nós que possuem } \\
\text { apenas um única entrada, que são inseridos nos } \\
\text { níveis superiores da estrutura. }\end{array}$ \\
\hline
\end{tabular}

Os resultados dos testes serão apresentados e discutidos a seguir.

\subsection{Resultados e Discussão}

\subsubsection{Altura Máxima}

Alguns dados foram extraídos das árvores resultantes, como a altura máxima, número total de nós, ocupação mínima dos nós, número médio de entradas por nó, tamanho médio dos objetos (para objetos de tamanho variável), entre outros dados. Aqui é mostrado apenas a altura máxima das árvores, pois é um dado de comparação muito interessante entre a DBM-tree e as árvores balanceadas. A altura máxima das diversas árvores testadas com os diferentes conjuntos de dados estão sumarizadas na Tabela 5.3. Elas foram obtidas depois da execução dos algoritmos de pós-otimização Slim-Down e DBM-Slim-Down.

A altura máxima para as árvores $D B M-M M$ e $D B M-M S$ foi maior que todas as outras árvores balanceadas em todos os conjuntos de dados. A maior diferença é para o conjunto Sintético256D, possuindo altura 17 em contraste com 4 para a MTree e a Slim$M M$. Porém, isto não faz aumentar o número de acessos a disco, como seria o esperado. Elas até fazem, em média, menos acessos a disco que a MTree e Slim-MM. 
Tabela 5.3: Altura máxima das árvores para os conjunto de dados testados.

\begin{tabular}{|c|c|c|c|c|c|c|}
\hline Nome & MTree & Slim-MM & $D B M-M M$ & $D B M-M S$ & $D B M-G M M$ & $D B M-G 2 C$ \\
\hline Cidades & 4 & 4 & 8 & 7 & 4 & 4 \\
\hline ColorHisto & 4 & 4 & 10 & 10 & 4 & 4 \\
\hline Histogramas & 4 & 4 & 9 & 11 & 5 & 5 \\
\hline Sintético2D & 4 & 4 & 8 & 9 & 4 & 4 \\
\hline Sintético6D & 3 & 3 & 7 & 7 & 3 & 3 \\
\hline Sintético16D & 3 & 3 & 7 & 7 & 3 & 3 \\
\hline Sintético256D & 4 & 4 & 17 & 17 & 5 & 5 \\
\hline
\end{tabular}

Já para as árvores $D B M-G M M$ e $D B M-G 2 C$, embora ela não obrigue o balanceamento, a altura máxima foi, na maioria das vezes, igual a MTree e a SlimMM, o que é um resultado interessante, e indica que o balanceamento de fato não é tão importante para os MAMs.

\subsubsection{Tempo de Construção}

Foi medido o tempo total de construção (em $s$ ) das árvores para todos os conjuntos de dados. Os resultados estão sumarizados na Tabela 5.4, não contabilizando o tempo para a execução dos algoritmos Slim-Down e DBM-Slim-Down.

Tabela 5.4: Tempo total de construção para os diversos conjuntos de testes, em $s$.

\begin{tabular}{|c|r|r|r|r|r|r|}
\hline Nome & MTree & Slim-MM & $D B M-M M$ & $D B M-M S$ & $D B M-G M M$ & $D B M-G 2 C$ \\
\hline Cidades & 2,7 & 2,7 & 2,9 & 2,9 & 2,2 & 0,5 \\
\hline ColorHisto & 328,2 & 329,0 & 186,7 & 188,7 & 71,6 & 41,9 \\
\hline Histogramas & 15,5 & 15,4 & 8,5 & 8,5 & 3,4 & 2,6 \\
\hline Sintético2D & 21,8 & 21,9 & 29,9 & 30,1 & 12,9 & 1,4 \\
\hline Sintético6D & 63,0 & 62,6 & 72,4 & 73,9 & 35,1 & 5,1 \\
\hline Sintético16D & 41,3 & 41,1 & 34,0 & 32,1 & 28,3 & 1,6 \\
\hline Sintético256D & 42,4 & 42,9 & 68,2 & 61,7 & 19,0 & 21,0 \\
\hline
\end{tabular}

O tempo total de construção das árvores $D B M-G M M$ e $D B M-G 2 C$ foi menor que todas as outras árvores para todos os conjuntos de dados. Entre si, para quase todos os conjunto, a árvore $D B M-G 2 C$ teve um tempo total de construção menor que a $D B M$ $G M M$, só para o Sintético256D ela teve um tempo pouco maior.

Já para as árvores $D B M-M M$ e $D B M-M S$, o tempo de construção delas foi semelhante entre si e equivalente aos tempos requeridos pela MTree e pela Slim-MM. Para alguns conjuntos o tempo de construção delas foi menor que a MTree e a Slim-MM, e para outros foi maior.

\subsubsection{Consultas por Similaridade}

As diversas árvores $D B M$-tree foram comparadas com a $M$-tree e a Slim-tree. A motivação foi avaliar o desempenho da $D B M$-tree em relação às duas principais consultas por 
similaridade: $k N N Q$ e $R Q$. Os gráficos de desempenho das consultas foram agrupados por conjunto de dados, e os comentários foram agrupados em função das medidas de desempenho (média de cálculos de distância, média de acessos a disco e tempo total das consultas).

\subsubsection{Média de cálculos de distância}

Os gráficos (a) e (d) das Figuras 5.1, 5.2, 5.3, 5.4, 5.5, 5.6 e 5.7 mostram, respectivamente, as médias de cálculos de distância durante as consultas $k N N Q$ e $R Q$. Em todos os gráficos, as 4 DBM-tree fizeram em média menos cálculos de distância que a MTree e a Slim-MM. Entre elas, a $D B M-M S$ e a $D B M-G M M$ obtiveram os melhores resultados para a maioria dos conjuntos. No conjunto Sintético16D, a $D B M-M M$ teve resultados melhores que todas as outras. Não teve nenhuma configuração da $D B M$-tree que fez em média mais cálculos de distância que a $M$-tree e Slim-tree, para todos os conjuntos de dados testados.

Os gráficos mostram que a DBM-tree reduz em até $35 \%$ a média de cálculos de distância para a $k N N Q$, e em até $45 \%$ para a $R Q$, quando comparada com a Slim-MM, que é a melhor das árvores balanceadas para a maioria dos conjuntos em cálculos de distância. Em comparação com a MTree, a DBM-tree reduziu em até $42 \%$ para a $k N N Q$, e em até $50 \%$ para a $R Q$. Todos estes ganhos se referem ao Sintético256D.

\subsubsection{Média de acessos a disco}

Os gráficos (b) e (e) das Figuras 5.1, 5.2, 5.3, 5.4, 5.5, 5.6 e 5.7 mostram, respectivamente, as médias de acessos a disco durante as consultas $k N N Q$ e $R Q$. Em quase todos os gráficos, as 4 DBM-tree fizeram em média menos acessos a disco que a MTree e a SlimMM. A única exceção é para a $D B M-G 2 C$ na consulta $k N N Q$ no conjunto Sintético2D, que perde apenas da SlimMM, mas continua ganhando da MTree.

Os gráficos mostram que a DBM-tree reduz em até $40 \%$ a média de acessos a disco para as consultas $k N N Q$ e $R Q$, quando comparada com a Slim-MM. Vale ressaltar que a Slim-tree é um método especializado em reduzir o número de acessos a disco e, ainda, suas medidas de desempenho foram tomadas após a execução do algoritmo Slim-Down. Já em relação a MTree o ganho é maior, chegando a ser $50 \%$ para as consultas $k N N Q$ e $R Q$. Todos estes ganhos se referem ao conjunto Sintético256D.

Uma observação importante dos gráficos é que o grande benefício da diminuição da taxa de sobreposição entre os nós de uma árvore é a diminuição do número de cálculos de distância. Entretanto, o número de acessos a disco em MAMs também está relacionado com a taxa de sobreposição entre os nós de uma árvore. Uma conseqüência imediata disto é que a diminuição da taxa de sobreposição entre os nós, além de beneficiar a diminuição do número de cálculos de distância, traz ainda o benefício de diminuir o número de acessos a disco para responder consultas por similaridade na DBM-tree. Ainda, estes dois benefícios tem consequiência direta no tempo total das consultas. 

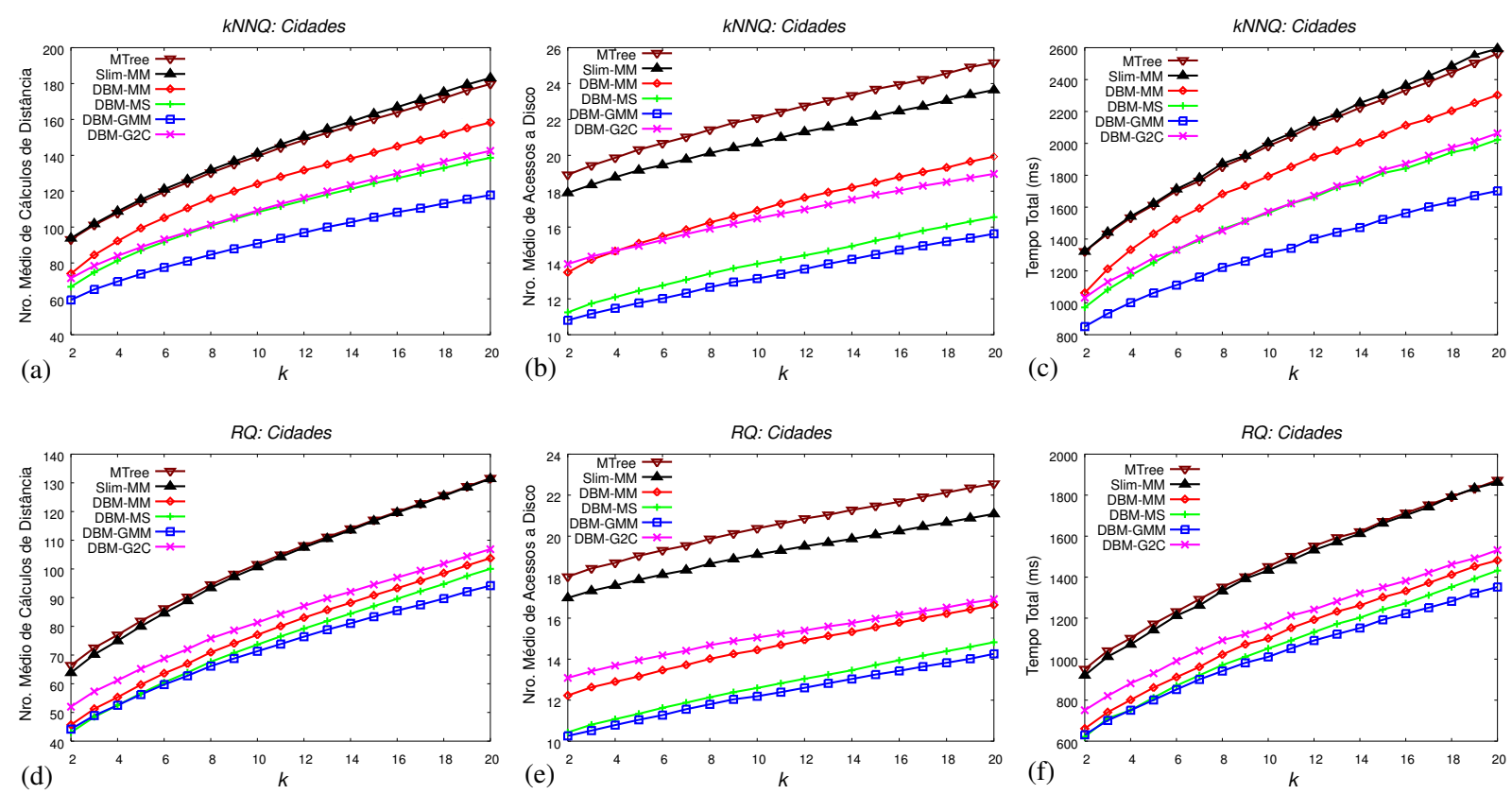

Figura 5.1: Resultados das consultas $k N N Q$ (gráficos (a), (b) e (c)) e $R Q$ (gráficos (d), (e) e (f)), comparando o número médio de cálculos de distância (gráficos (a) e (d)), número médio de acessos a disco (gráficos (b) e (e)) e tempo total de processamento (gráficos (c) e (f)) para 500 consultas utilizando a DBM-tree, Slim-tree e M-tree no conjunto Cidades.
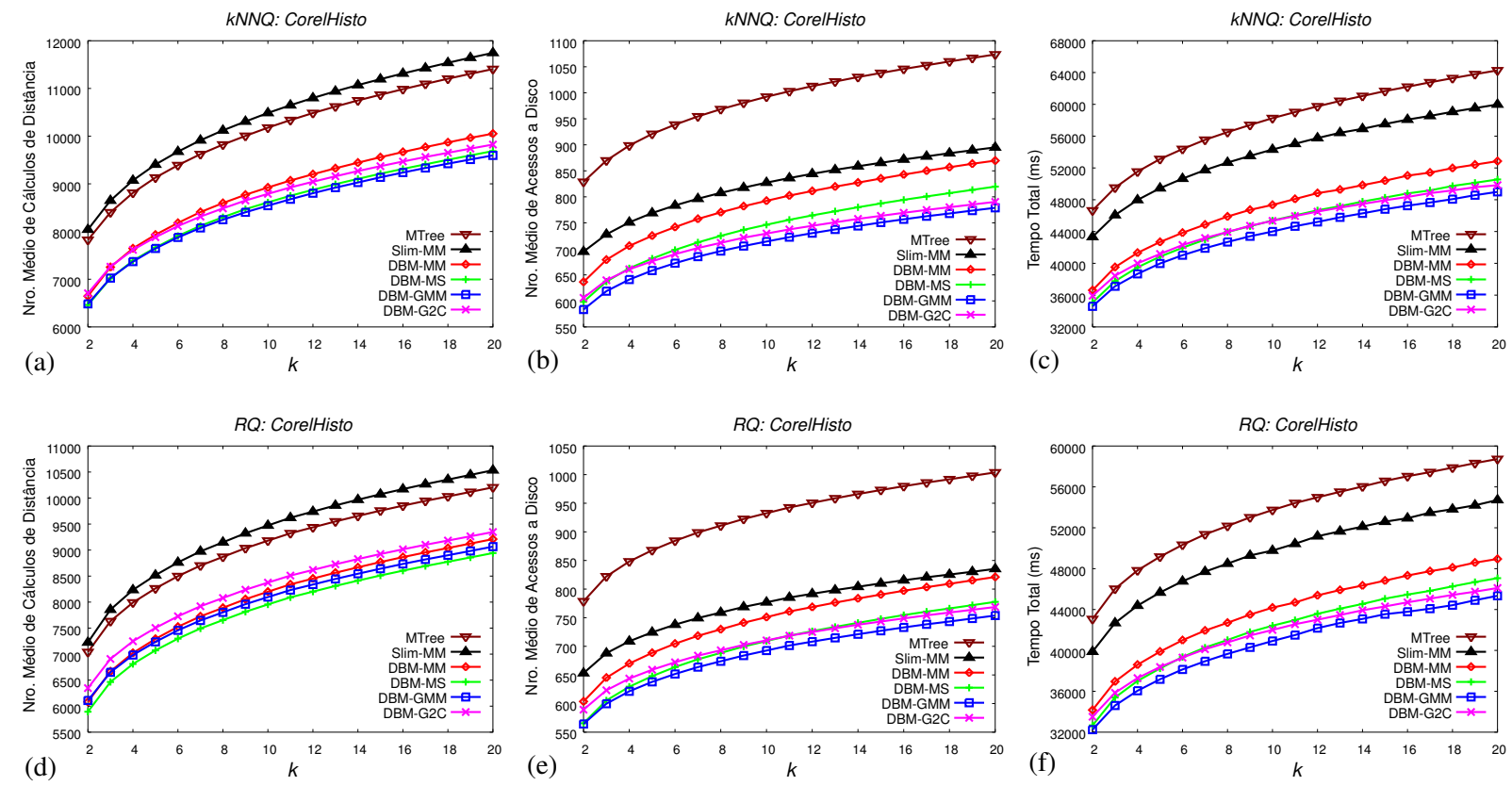

Figura 5.2: Resultados das consultas $k N N Q$ (gráficos (a), (b) e (c)) e $R Q$ (gráficos (d), (e) e (f)), comparando o número médio de cálculos de distância (gráficos (a) e (d)), número médio de acessos a disco (gráficos (b) e (e)) e tempo total de processamento (gráficos (c) e (f)) para 500 consultas utilizando a DBM-tree, Slim-tree e $M$-tree no conjunto CorelHisto. 

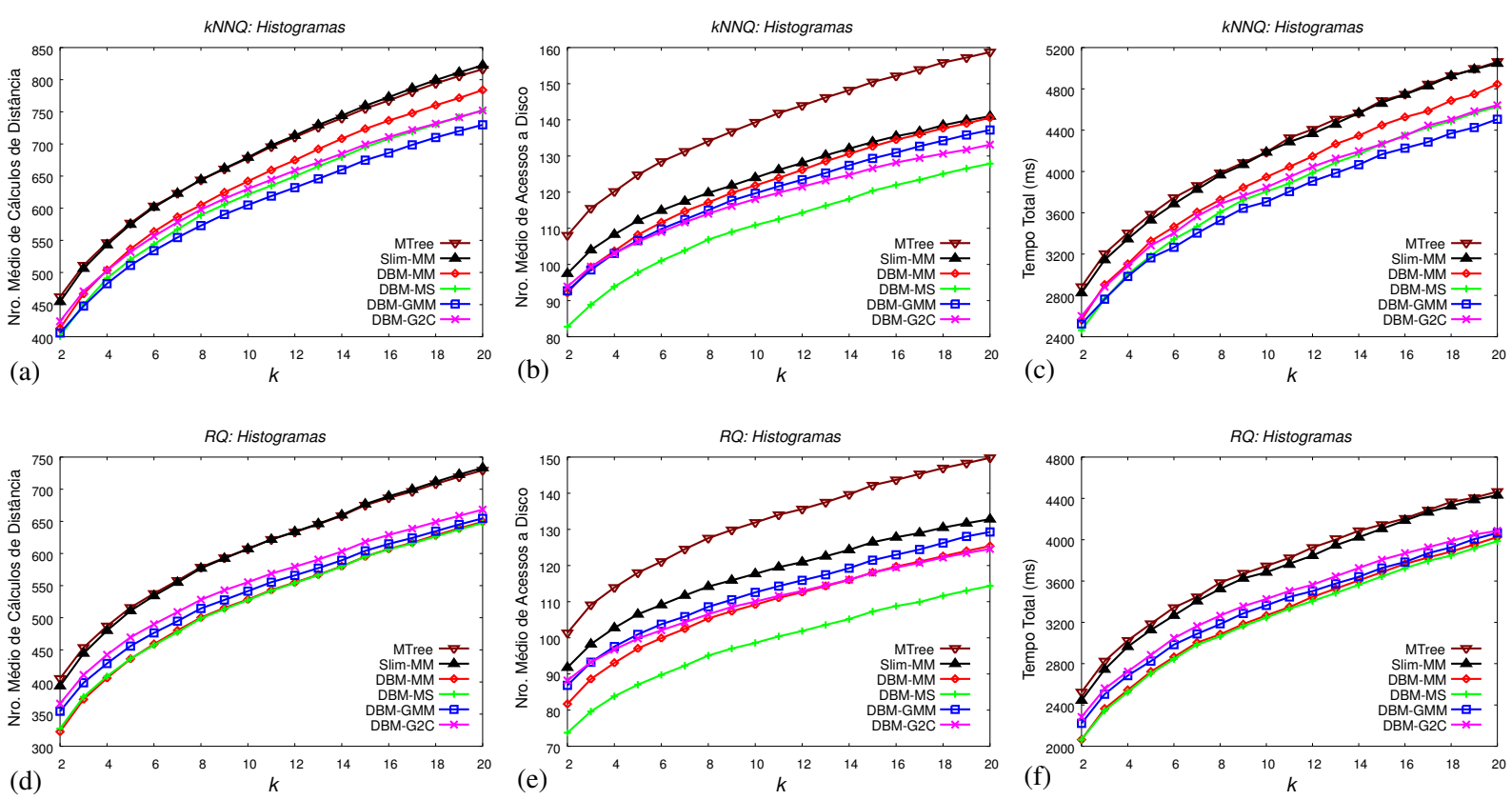

Figura 5.3: Resultados das consultas $k N N Q$ (gráficos (a), (b) e (c)) e $R Q$ (gráficos (d), (e) e (f)), comparando o número médio de cálculos de distância (gráficos (a) e (d)), número médio de acessos a disco (gráficos (b) e (e)) e tempo total de processamento (gráficos (c) e (f)) para 500 consultas utilizando a DBM-tree, Slim-tree e $M$-tree no conjunto Histogramas.
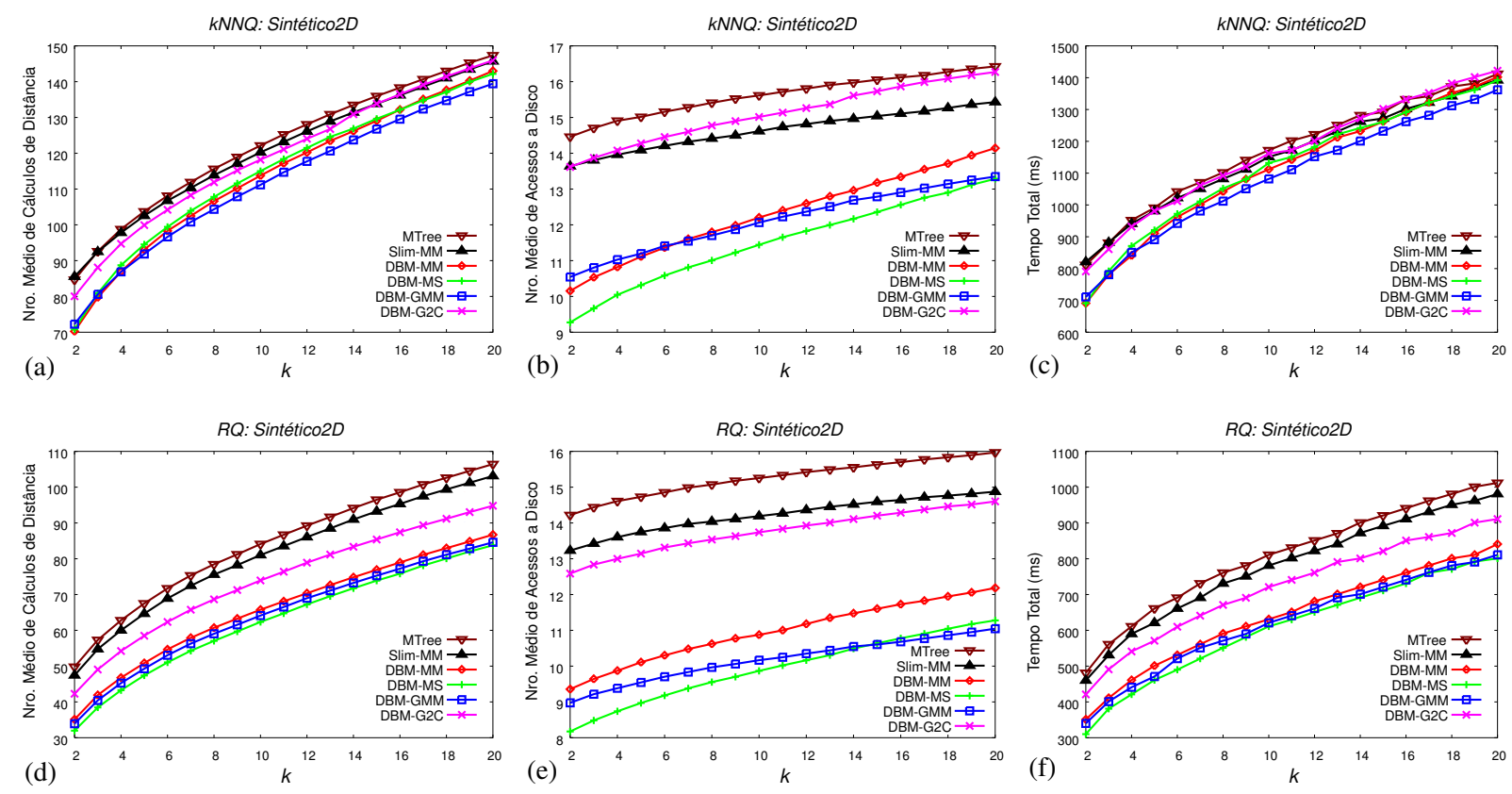

Figura 5.4: Resultados das consultas $k N N Q$ (gráficos (a), (b) e (c)) e $R Q$ (gráficos (d), (e) e (f)), comparando o número médio de cálculos de distância (gráficos (a) e (d)), número médio de acessos a disco (gráficos (b) e (e)) e tempo total de processamento (gráficos (c) e (f)) para 500 consultas utilizando a DBM-tree, Slim-tree e M-tree no conjunto Sintético2D. 

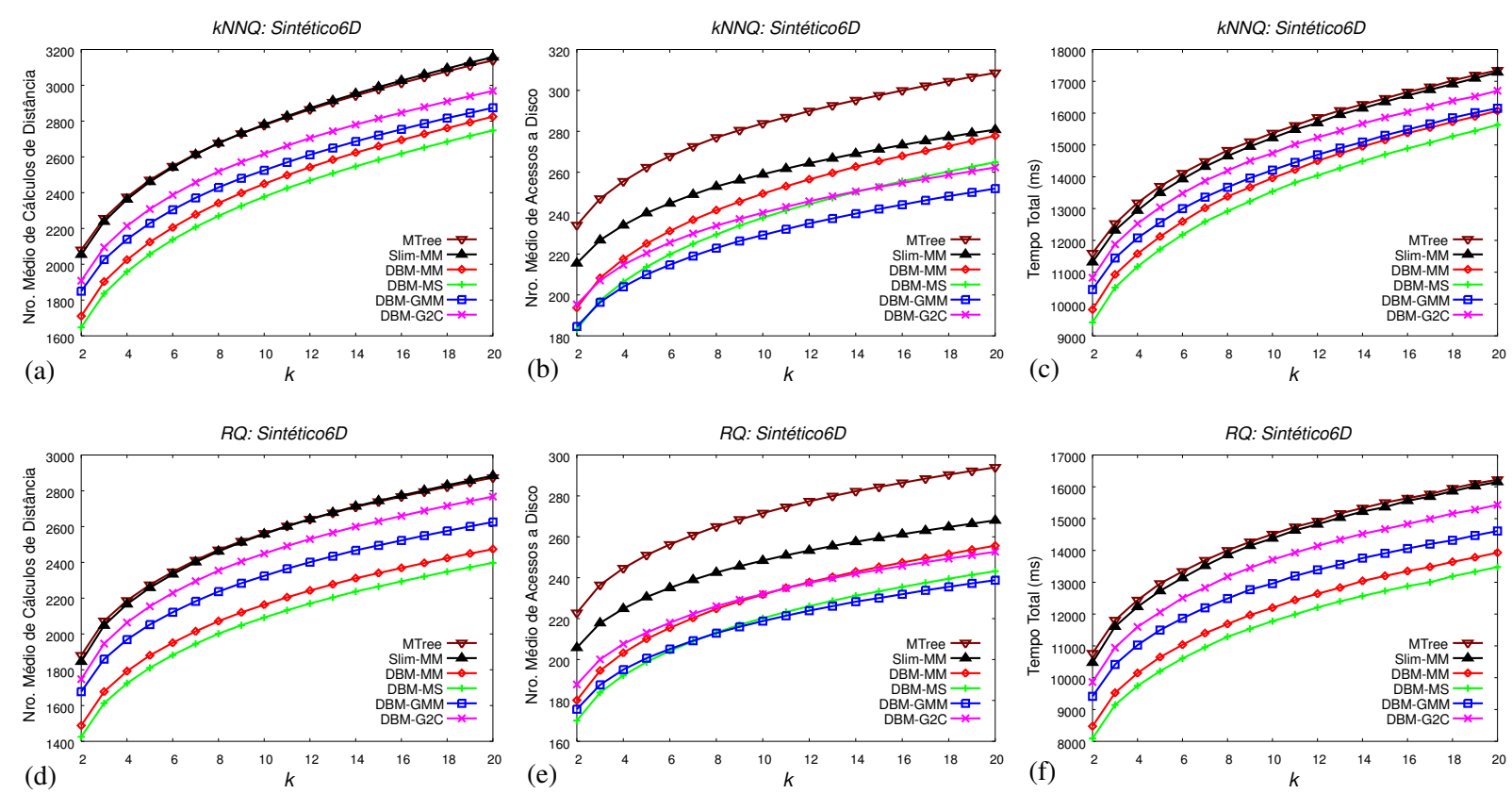

Figura 5.5: Resultados das consultas $k N N Q$ (gráficos (a), (b) e (c)) e $R Q$ (gráficos (d), (e) e (f)), comparando o número médio de cálculos de distância (gráficos (a) e (d)), número médio de acessos a disco (gráficos (b) e (e)) e tempo total de processamento (gráficos (c) e (f)) para 500 consultas utilizando a DBM-tree, Slim-tree e $M$-tree no conjunto Sintético6D.
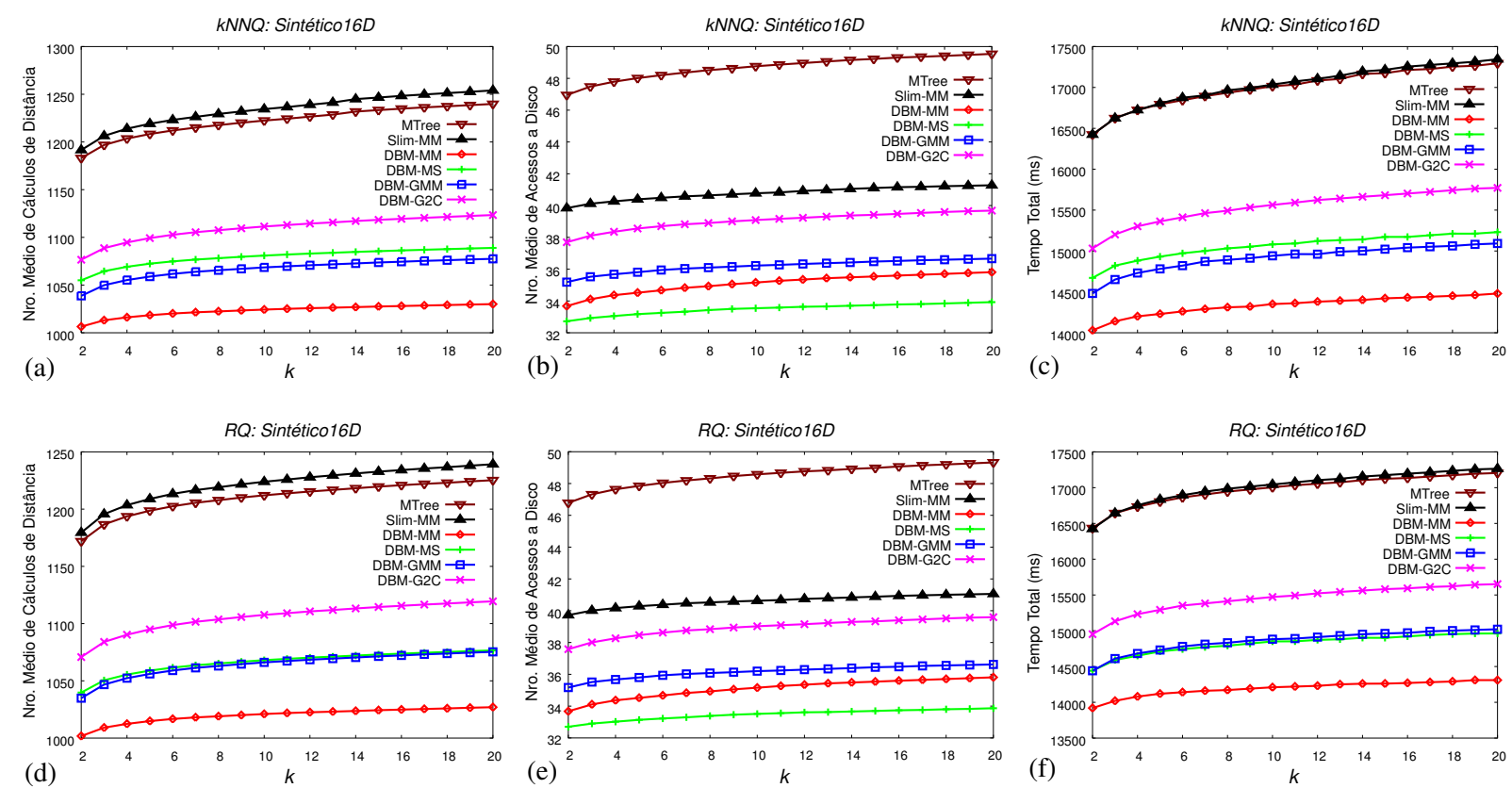

Figura 5.6: Resultados das consultas $k N N Q$ (gráficos (a), (b) e (c)) e $R Q$ (gráficos (d), (e) e (f)), comparando o número médio de cálculos de distância (gráficos (a) e (d)), número médio de acessos a disco (gráficos (b) e (e)) e tempo total de processamento (gráficos (c) e (f)) para 500 consultas utilizando a DBM-tree, Slim-tree e M-tree no conjunto Sintético16D. 

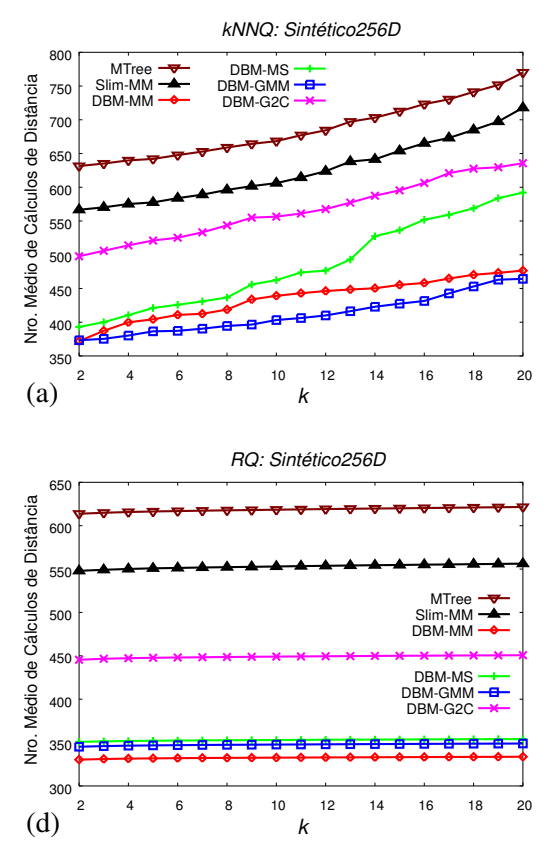

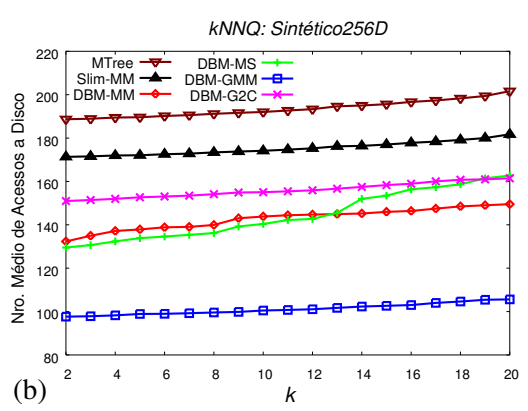

RQ: Sintético256D

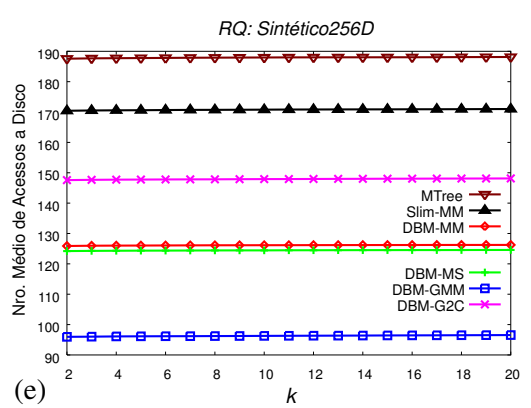

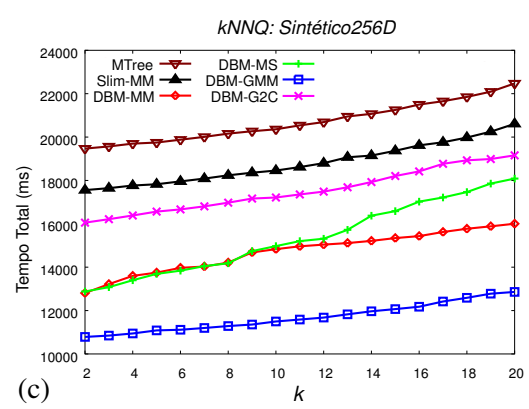

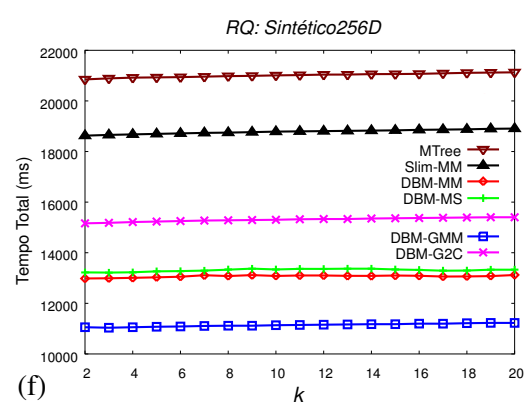

Figura 5.7: Resultados das consultas $k N N Q$ (gráficos (a), (b) e (c)) e $R Q$ (gráficos (d), (e) e (f)), comparando o número médio de cálculos de distância (gráficos (a) e (d)), número médio de acessos a disco (gráficos (b) e (e)) e tempo total de processamento (gráficos (c) e (f)) para 500 consultas utilizando a DBM-tree, Slim-tree e M-tree no conjunto Sintético256D.

\subsubsection{Tempo Total das Consultas}

A importância em se comparar o tempo de consulta vem da possibilidade de analisar as complexidades geradas pelas outras duas medidas juntas, cálculos de distância e acessos a disco, de uma só vez.

Os gráficos (c) e (f) das Figuras 5.1, 5.2, 5.3, 5.4, 5.5, 5.6, 5.7, mostram, respectivamente, o tempo total (em $\mathrm{ms}$ ) durante as consultas $k N N Q$ e $R Q$. Como as 4 configurações da DBM-tree fazem menos cálculos de distância e acessos a disco que a MTree e a Slim-MM, elas conseqüentemente são mais rápidas para responder as duas consultas por similaridade.

Os gráficos mostram que a DBM-tree é até $40 \%$ mais rápida para a $k N N Q$ e $45 \%$ mais rápida para a $R Q$ quando comparadas com a Slim-MM. Já quando comparada com a $M T r e e$, a redução no tempo total das consultas chega a ser $50 \%$ para as consultas $k N N Q$ e $R Q$.

\subsubsection{Otimização da Estrutura}

Foram feito testes para medir a melhoria que a execução do algoritmo DBM-Slim-Down proporcionou nas 4 árvores testadas para todos os conjuntos de dados. Como para todos os conjuntos de dados os resultados foram semelhantes, aqui é mostrado apenas os resultados para o conjunto Sintético16D.

A Figura 5.8 compara o desempenho das consultas antes e depois de executado o 
algoritmo $D B M$-Slim-Down para a $D B M-M M$ e a $D B M-G M M$ (os resultados são semelhantes para a $D B M-M S$ e a $D B M-G 2 C)$.

Todos os gráficos mostram que o algoritmo DBM-Slim-Down melhora as árvores resultantes, principalmente em relação ao número de acessos a disco e tempo total de processamento. O resultado mais expressivo é para a $D B M-G M M$ em relação ao número médio de acessos a disco para as duas consultas, chegado a fazer até $30 \%$ menos acessos a disco que a mesma estrutura não otimizada.

\subsubsection{Escalabilidade}

O comportamento da DBM-tree em relação ao tamanho do conjunto foi avaliado nesta última bateria de testes. O conjunto de dados foi gerado artificialmente de forma a obter um número expressivo de objetos. Foram criados 100.000 objetos com dimensão 16. O processo para gerar os vetores é igual ao descrito para o Sintético16D na Tabela 5.1, diferenciando apenas no número total de objetos. Todos os objetos do conjunto foram considerados durante o processo de amostragem dos dados usados como centro das regiões de busca (500 objetos foram escolhidos aleatoriamente). O conjunto foi divido em 10 partes e após cada décimo inserido (10.000 objetos), a amostra foi usada para efetuar 500 consultas por similaridade com diferentes raios e diferentes valores de $k$. O comportamento das diferentes opções de construção foi equivalente para os diferentes valores de raio e de $k$ e, portanto, será apresentado apenas um exemplo de cada tipo de consulta ( $R Q$ com raio tal que cada consulta retorna 15 objetos e $k=10$ para a $k N N Q$ ).

A Figura 5.9 apresenta o comportamento das 4 opções da DBM-tree para: média de cálculos de distância (gráficos (a) e (d)), média de acessos a disco (gráficos (b) e (e)) e tempo total de consulta (gráficos (c) e (f)). Como pode ser observado, as opções da DBM-tree têm comportamento linear em função do tamanho do conjunto de dados, o que torna o método, em qualquer de suas configurações, muito adequado para indexar conjuntos de dados grandes.

\subsection{Conclusão}

Este capítulo mostrou os experimentos feitos com diversos conjuntos de dados reais e sintéticos, de dimensões e tamanhos variados, visando a comparação do desempenho das consultas por similaridade da $D B M$-tree em relação a $M$-tree e a Slim-tree.

Através dos experimentos, constatou-se que a DBM-tree faz até $45 \%$ menos cálculos de distância, $40 \%$ menos acessos a disco e foi até $45 \%$ mais rápida para responder consultas por similaridade que a Slim-tree, que é uma das melhores e mais otimizada estrutura métrica balanceada existente, e ainda, foi utilizada a melhor configuração de construção e executado o algoritmo de pós-otimização Slim-Down. 

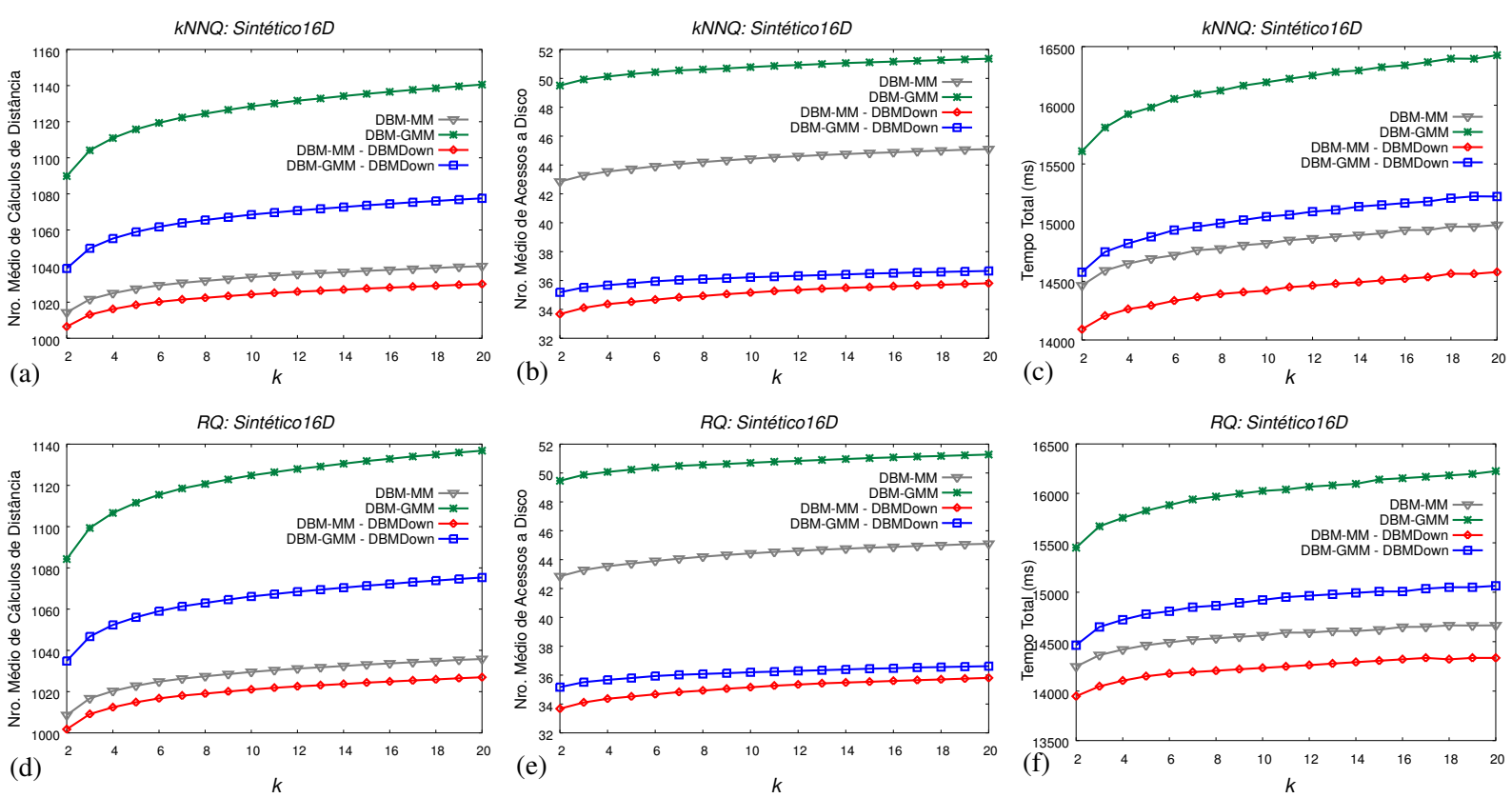

Figura 5.8: Resultados das consultas $k N N Q$ (gráficos (a), (b) e (c)) e $R Q$ (gráficos (d), (e) e (f)), comparando o número médio de cálculos de distância (gráficos (a) e (d)), número médio de acessos a disco (gráficos (b) e (e)) e tempo total de processamento (gráficos (c) e (f)) para 500 consultas utilizando a DBM-tree no conjunto Sintético16D. Os gráficos apresentam a comparação da $D B M-M M$ e da $D B M-G M M$ antes e depois da execução do algoritmo DBM-Slim-Down.
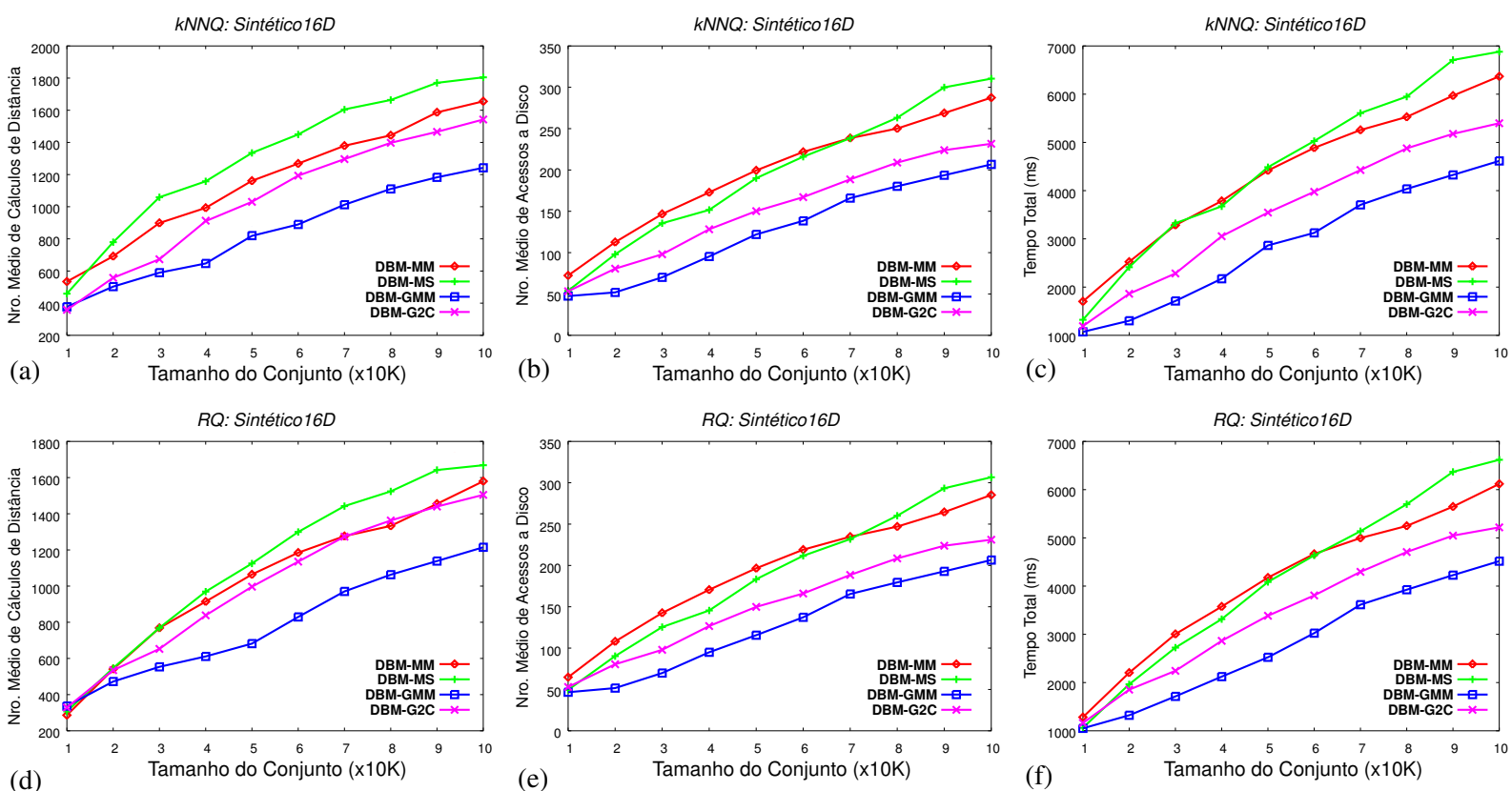

Figura 5.9: Escalabilidade da DBM-tree em relação ao tamanho do conjunto durante as consultas $k N N Q$ (gráficos (a), (b) e (c)) e $R Q$ (gráficos (d), (e) e (f)). Avaliando as medidas de: média de cálculos de distância (gráficos (a) e (d)); média de acessos a disco (gráficos (b) e (e)); e tempo total (gráficos (c) e (f)). O conjunto indexado foi o Sintético16D com 100.000 objetos. 
Também foram mostrados os ganhos que o algoritmo de pós-otimização DBM-SlimDown proporciona nas árvores DBM-tree, chegando a melhorar em até $30 \%$ o número de acessos a disco. Ainda, foi verificado que os algoritmos de consulta da DBM-tree têm comportamento linear em função do número de objetos indexados para: número de cálculos de distância; número de acessos a disco; e tempo total de processamento, para as consultas $k N N Q$ e $R Q$.

Os resultados demonstraram que a diminuição da sobreposição através da flexibilização do balanceamento da DBM-tree é um meio efetivo para melhorar o desempenho de consultas por similaridade em MAMs, mesmo que a altura seja maior que as estruturas balanceadas, tal como a Slim-tree. 


\section{Capítulo \\ 6}

\section{Conclusão}

\subsection{Considerações Finais}

Atualmente, tipos de dados não convencionais, tais como dados multimídia, cadeias de DNA, entre outros, estão sendo armazenados em SGBDs. Estes se utilizam de métodos de acesso, específico para cada domínio de dados, para recuperar os dados de maneira eficiente. Usualmente, os Métodos de Acesso Métricos (MAMs) são utilizados para indexar tais tipos de dados, utilizando apenas a distância (similaridade) entre eles. Devido a característica do ambiente dos SGBDs, estes MAMs necessitam ser dinâmicos e fornecer armazenamento secundário.

Normalmente, os MAMs dinâmicos definem regiões do espaço métrico através de objetos representativos, onde a união destas regiões pode não ser disjunta. Neste caso, os objetos representativos definem regiões que podem estar sobrepostas. Uma conseqüência imediata disto é que consultas localizadas em região onde ocorre sobreposição faz com que todos os nós que cobrem parte ou toda esta região necessitem ser analisados. Isso faz com que as árvores sejam percorridas tanto em largura quanto em profundidade.

O MAM DBM-tree visa diminuir a taxa de sobreposição entre os nós através da flexibilização do balanceamento da estrutura, evitando que várias subárvores sejam analisadas nas consultas. Regiões do espaço métrico que tenham uma maior densidade de objetos faz com que a profundidade da estrutura seja maior. A flexibilização na DBM-tree é controlada para que a estrutura não se degenere, mantendo um equilíbrio entre número de acessos a disco para avaliar múltiplas subárvores e número de acessos a disco para avaliar em profundidade cada subárvore. As possibilidades de construção e otimização na $D B M$-tree são maiores que as estruturas balanceadas, pois é possível ajustar a estrutura 
de acordo com a distribuição dos dados no espaço métrico. Resultados experimentais comprovam que a $D B M$-tree é mais eficiente para responder consultas por similaridade que as principais estruturas balanceadas: M-tree e Slim-tree.

\subsection{Principais Contribuições deste Trabalho}

Entre as contribuições inéditas obtidas por este projeto, deve-se enfatizar:

- Criação de um novo MAM dinâmico com suporte a armazenamento em disco, onde é possível diminuir a sobreposição entre os nós através da flexibilização do balanceamento da estrutura;

- Criação do algoritmo de divisão $N$-Clusters, onde a divisão pode gerar 2 ou mais agrupamentos, cada um associado a um nó;

- Criação de um MAM onde é possível a remoção de objetos sem degenerar a estrutura e, ainda, com diminuição da altura total da estrutura, fato que não ocorre na $M$-tree e na Slim-tree;

- Criação do algoritmo de pós-otimização DBM-Slim-Down, onde são rearranjadas as entradas dos nós de toda a estrutura visando a diminuição da sobreposição entre eles, uma vez a estrutura criada. Este algoritmo pode ser executado diversas vezes durante a evolução da estrutura;

- Extensão do MAM DBM-tree para a visualização da sua estrutura e das consultas $k N N Q$ e $R Q$ através do sistema MAMView;

- Implementação do MAM DBM-tree na biblioteca de MAMs Arboretum, o que permite estar em uma base de comparação justa com outros MAMs;

- Comparação, através de experimentos com dados reais e sintéticos, do MAM DBMtree com os dois principais MAMs dinâmicos encontrados na literatura: $M$-tree e Slim-tree.

\subsection{Proposta para Trabalhos Futuros}

O trabalho de desenvolvimento do MAM DBM-tree abriu ainda a possibilidade de novas frentes de pesquisa, entre as quais encontram-se:

- Implementação de remoção de objetos na DBM-tree, como comentado na Seção 4.7, e posteriores testes de desempenho da estrutura. Pelas características da DBM-tree, a implementação de remoção de objetos não necessita de mudanças nos algoritmos 
de construção e de consultas por similaridade, o que torna fácil a sua implementação. Acredita-se que o desempenho da estrutura melhorará depois de removido um número relativamente grande de objetos, podendo ter desempenho semelhante a de uma estrutura criada com os mesmos dados (sem ter havido nenhuma remoção na estrutura);

- Extensão do algoritmo DBM-Slim-Down para reorganização de todas as entradas dos nós de um mesmo nível da estrutura. Atualmente o DBM-Slim-Down é feito em todas as entradas de um único nó, executado para todos os nós da estrutura. Nesta extensão, as entradas de um mesmo nível poderão migrar para outros nós do mesmo nível, seguindo os mesmos critérios de troca que o atual DBM-SlimDown. Este processo seria aplicado a todos os níveis da estrutura. Acredita-se que o desempenho da estrutura otimizada com este novo algoritmo será melhor que a mesma estrutura otimizada com o atual DBM-Slim-Down;

- Desenvolvimento de um algoritmo de carregamento em lote (bulk loading) para a DBM-tree. Como as possibilidades de construção da DBM-tree são maiores que as estruturas balanceadas, é provável que com o algoritmo de carregamento em lote seja possível criar árvores com desempenho superior as árvores criadas sem este algoritmo;

- O estudo de outras formas de divisão do espaço baseadas no algoritmo $N$-Clusters: É possível utilizar o algoritmo $N$-Clusters e o funcionamento da DBM-tree para dividir o espaço métrico em regiões disjuntas com flexibilização do balanceamento da estrutura. Neste caso, não existe sobreposição entre as regiões definidas pelos nós de um mesmo nível. Com isso, é possível que o desempenho desta nova forma de divisão consiga um melhor desempenho que a atual DBM-tree. 


\section{Referências Bibliográficas}

[Arantes et al., 2003a] Arantes, A. S., Vieira, M. R., Traina, A. J. M., e Traina, Caetano, J. (2003a). The fractal dimension making similarity queries more efficient. In II ACM SIGKDD Workshop on Fractals, Power Laws and Other Next Generation Data Mining Tools, pp. 12-17, Washington, USA.

[Arantes et al., 2003b] Arantes, A. S., Vieira, M. R., Traina, Caetano, J., e Traina, A. J. M. (2003b). Operadores de seleção por similaridade para sistemas de gerenciamento de bases de dados relacionais. In XVIII Simpósio Brasileiro de Banco de Dados (SBBD), pp. 341-355, Manaus, Brasil.

[Baeza-Yates et al., 1994] Baeza-Yates, R. A., Cunto, W., Manber, U., e Wu, S. (1994). Proximity matching using fixed-queries trees. In 5th Annual Symposium on Combinatorial Pattern Matching (CPM), v. 807 of Lecture Notes in Computer Science, pp. 198-212, Asilomar, USA. Springer Verlag.

[Bayer \& McCreight, 1972] Bayer, R. e McCreight, E. M. (1972). Organization and maintenance of large ordered indexes. Acta Informatica, 1(3):173-189.

[Beckmann et al., 1990] Beckmann, N., Kriegel, H.-P., Schneider, R., e Seeger, B. (1990). The $\mathrm{R}^{*}$-tree: An efficient and robust access method for points and rectangles. In Proceedings of the ACM International Conference on Management of Data (SIGMOD), pp. 322-331, Atlantic City, USA. ACM Press.

[Bentley \& Friedman, 1979] Bentley, J. L. e Friedman, J. H. (1979). Data structures for range searching. ACM Computing Surveys (CSUR), 11(4):397-409.

[Berchtold et al., 1996] Berchtold, S., Keim, D. A., e Kriegel, H.-P. (1996). The X-tree: An index structure for high-dimensional data. In Proceedings of the 22nd International Conference on Very Large Data Bases (VLDB), pp. 28-39, Bombay, India. Morgan Kaufmann Publishers.

[Böhm et al., 2001] Böhm, C., Berchtold, S., e Keim, D. A. (2001). Searching in highdimensional space: Index structures for improving the performance of multimedia databases. ACM Computing Surveys (CSUR), 33(3):322-373.

[Bozkaya \& Özsoyoglu, 1997] Bozkaya, T. e Özsoyoglu, Z. M. (1997). Distance-based indexing for high-dimensional metric spaces. In Proceedings of the ACM International 
Conference on Management of Data (SIGMOD), pp. 357-368, Tucson, USA. ACM Press.

[Bozkaya \& Özsoyoglu, 1999] Bozkaya, T. e Özsoyoglu, Z. M. (1999). Indexing large metric spaces for similarity search queries. ACM Transactions on Database Systems (TODS), 24(3):361-404.

[Brin, 1995] Brin, S. (1995). Near neighbor search in large metric spaces. In Dayal, U., Gray, P. M. D., e Nishio, S., editors, Proceedings of the 21st International Conference on Very Large Data Bases (VLDB), pp. 574-584, Zurich, Switzerland. Morgan Kaufmann Publishers.

[Burkhard \& Keller, 1973] Burkhard, W. A. e Keller, R. M. (1973). Some approaches to best-match file searching. Communications of the ACM, 16(4):230-236.

[Chakrabarti \& Mehrotra, 1999] Chakrabarti, K. e Mehrotra, S. (1999). The Hybrid Tree: An index structure for high dimensional feature spaces. In 15th International Conference on Data Engineering (ICDE), pp. 440-447, Sydney, Australia. IEEE Computer Society.

[Chino, 2004] Chino, F. J. T. (2004). Visualizando a organização e o comportamento de estruturas métricas: Aplicações em consultas por similaridade. Dissertação de mestrado, Universidade de São Paulo, Instituto de Ciências Matemáticas e de Computação, São Carlos, Brasil.

[Chiueh, 1994] Chiueh, T.-C. (1994). Content-based image indexing. In Bocca, J. B., Jarke, M., e Zaniolo, C., editors, Proceedings of the 20th International Conference on Very Large Databases (VLDB), pp. 582-593, Santiago de Chile, Chile. Morgan Kaufmann Publishers.

[Chávez et al., 2001] Chávez, E., Navarro, G., Baeza-Yates, R., e Marroquín, J. L. (2001). Searching in metric spaces. ACM Computing Surveys (CSUR), 33(3):273-321.

[Ciaccia \& Patella, 1998] Ciaccia, P. e Patella, M. (1998). Bulk loading the M-tree. In Proceedings of the 9th Australasian Database Conference (ADC), pp. 15-26, Perth, Australia.

[Ciaccia et al., 1997] Ciaccia, P., Patella, M., e Zezula, P. (1997). M-tree: An efficient access method for similarity search in metric spaces. In Jarke, M., editor, Proceedings of 23rd International Conference on Very Large Data Bases (VLDB), pp. 426-435, Athens, Greece. Morgan Kaufmann Publishers.

[Ciaccia et al., 1998] Ciaccia, P., Patella, M., e Zezula, P. (1998). A cost model for similarity queries in metric spaces. In Proceedings of the ACM SIGACT-SIGMOD-SIGART Symposium on Principles of Database Systems (PODS), pp. 59-68, Seattle, USA. ACM Press.

[Comer, 1979] Comer, D. (1979). The ubiquitous B-tree. ACM Computing Surveys (CSUR), 11(2):121-137.

[Dohnal et al., 2003] Dohnal, V., Gennaro, C., Savino, P., e Zezula, P. (2003). D-index: Distance searching index for metric data sets. Multimedia Tools and Applications, 21(1):9-33. 
[Faloutsos, 1997] Faloutsos, C. (1997). Indexing of multimedia data. In Multimedia Databases in Perspective, pp. 219-245. Springer Verlag.

[Faloutsos \& Lin, 1995] Faloutsos, C. e Lin, K.-I. D. (1995). FastMap: A fast algorithm for indexing, data-mining and visualization of traditional and multimedia datasets. SIGMOD Record: Proceedings of the ACM International Conference Management of Data (SIGMOD), 24(2):163-174.

[Folk et al., 1998] Folk, M. J., Zoellick, B., e Riccardi, G. (1998). File structures: An Object-Oriented Approach with $C++$. Addison-Wesley, Reading, USA, 3 edition.

[Fu et al., 2000] Fu, A. W.-c., Chan, P. M.-s., Cheung, Y.-L., e Moon, Y. S. (2000). Dynamic vp-tree indexing for n-nearest neighbor search given pair-wise distances. The VLDB Journal, 9(2):154-173.

[Gaede \& Günther, 1998] Gaede, V. e Günther, O. (1998). Multidimensional access methods. ACM Computing Surveys (CSUR), 30(2):170-231.

[Garcia-Molina et al., 2002] Garcia-Molina, H., Ullman, J. D., e Widom, J. (2002). Database System - The Complete Book, Cap. 13-14, pp. 605-712. Prentice Hall.

[GBDI-ICMC-USP, 2004] GBDI-ICMC-USP (2004). GBDI Arboretum Library. http://gbdi.icmc.usp.br/arboretum/.

[Gennaro et al., 2001] Gennaro, C., Savino, P., e Zezula, P. (2001). Similarity search in metric databases through hashing. In 3rd International Workshop on Multimedia Information Retrieval (MIR'01), pp. 1-5, Ottawa, Canada.

[Guttman, 1984] Guttman, A. (1984). R-tree : A dynamic index structure for spatial searching. In Yormack, B., editor, Proceedings of the ACM International Conference on Management of Data (SIGMOD), pp. 47-57, Boston, USA. ACM Press.

[Hjaltason \& Samet, 2003] Hjaltason, G. R. e Samet, H. (2003). Index-driven similarity search in metric spaces. ACM Transactions on Database Systems (TODS), 28(4):517580 .

[Houaiss \& Villar, 2001] Houaiss, A. e Villar, M. d. S. (2001). Dicionário Houaiss da Lingua Portuguesa. Objetiva, Rio de Janeiro, Brasil.

[Johnson \& Shasha, 1989] Johnson, T. e Shasha, D. (1989). Utilization of B-trees with inserts, deletes and modifies. In Proceedings of the ACM SIGACT-SIGMOD-SIGART Symposium on Principles of Database Systems (PODS), pp. 235-246, Philadelphia, PA. ACM Press.

[Kanth et al., 1999] Kanth, K. V. R., Nevada, S., Sharma, J., e Banerjee, J. (1999). Indexing medium-dimensionality data in Oracle. In Proceedings of the ACM International Conference on Management of Data (SIGMOD), pp. 521-522. ACM Press.

[Katayama \& Satoh, 1997] Katayama, N. e Satoh, S. (1997). The SR-tree: An index structure for high-dimensional nearest neighbor queries. In Peckham, J., editor, Proceedings of the ACM International Conference on Management of Data (SIGMOD), pp. 369-380, Tucson, USA. ACM Press. 
[KDD-UCI, 2004] KDD-UCI (2004). UCI Knowledge Discovery in Databases Archive - University of California, Irvine, Department of Information and Computer Science. http://kdd.ics.uci.edu.

[Knuth, 1973] Knuth, D. E. (1973). The Art of Computer Programming - Sorting and Searching, v. 3, Cap. 6, pp. 389-569. Addison-Wesley, Reading, USA.

[Kruskal, 1956] Kruskal, J. B. (1956). On the shortest spanning subtree of a graph and the traveling salesman problem. Proc. American Mathematic Society, 7:48-50.

[Langsam et al., 1996] Langsam, Y., Augenstein, M. J., e Tenenbaum, A. M. (1996). Data Structures Using C and C++, Cap. 5, pp. 249-328. Prentice Hall, 2 edition.

[Levenshtein, 1966] Levenshtein, V. I. (1966). Binary codes capable of correcting deletions, insertions, and reversals. Cybernetics and Control Theory, 10(8):707-710.

[Micó et al., 1994] Micó, L., Oncina, J., e Vidal, E. (1994). A new version of the nearestneighbor approximating and eliminating search (AESA) with linear processing-time and memory requirements. Pattern Recognition Letters, 15(1):9-17.

[Navarro, 2002] Navarro, G. (2002). Searching in metric spaces by spatial approximation. VLDB Journal, 11(1):28-46.

[Patella, 1999] Patella, M. (1999). Similarity Search in Multimedia Databases. Tese de doutorado, Università a degli Studi di Bologna, Bologna, Italy.

[Robinson, 1981] Robinson, J. T. (1981). The k-d-B-tree: A search structure for large multidimensional dynamic indexes. In Lien, Y. E., editor, Proceedings of the ACM International Conference on Management of Data (SIGMOD), pp. 10-18, Ann Arbor, USA. ACM Press.

[Santos, 2003] Santos, Roberto Figueira, F. (2003). Métodos de Acesso Métricos para suporte a consultas por similaridade: Apresentação da Técnica Omni. Tese de doutorado, Universidade de São Paulo, Instituto de Ciências Matemáticas e de Computação, São Carlos, Brasil.

[Santos et al., 2001] Santos, Roberto Figueira, F., Traina, A. J. M., Traina, Caetano, J., e Faloutsos, C. (2001). Similarity search without tears: The OMNI family of allpurpose access methods. In International Conference on Data Engineering (ICDE), pp. 623-630, Heidelberg, Germany. IEEE Computer Society.

[Sellis et al., 1987] Sellis, T. K., Roussopoulos, N., e Faloutsos, C. (1987). The R ${ }^{+}$-tree: A dynamic index for multi-dimensional objects. In Proceedings of 13th International Conference on Very Large Databases (VLDB), pp. 507-518, Brighton, England. Morgan Kaufmann Publishers.

[Shasha \& Wang., 1990] Shasha, D. e Wang., T. L. (1990). New techniques for best-match retrieval. ACM Transactions on Information Systems, 8(2):140-158.

[Traina et al., 2002a] Traina, A. J. M., Traina, Caetano, J., Bueno, J. M., e Marques, P. M. d. A. (2002a). The metric histogram: A new and efficient approach for contentbased image retrieval. In Sixth IFIP Working Conference on Visual Database Systems $(V D B)$, Brisbane, Australia. 
[Traina et al., 1999] Traina, Caetano, J., Traina, A. J. M., e Faloutsos, C. (1999). Distance exponent : a new concept for selectivity estimation in metric trees. Research Paper CMU-CS-99-110, Carnegie Mellon University - School of Computer Science.

[Traina et al., 2002b] Traina, Caetano, J., Traina, A. J. M., Faloutsos, C., e Seeger, B. (2002b). Fast indexing and visualization of metric datasets using slim-trees. IEEE Transactions on Knowledge and Data Engineering (TKDE), 14(2):244-260.

[Traina et al., 2002c] Traina, Caetano, J., Traina, A. J. M., Santos, Roberto Figueira, F., e Faloutsos, C. (2002c). How to improve the pruning ability of dynamic metric access methods. In Proceedings of the 11th International Conference on Information and Knowledge Management (CIKM), pp. 219-226, McLean, USA. ACM Press.

[Traina et al., 2000] Traina, Caetano, J., Traina, A. J. M., Seeger, B., e Faloutsos, C. (2000). Slim-trees: High performance metric trees minimizing overlap between nodes. In Zaniolo, C., Lockemann, P. C., Scholl, M. H., e Grust, T., editors, International Conference on Extending Database Technology (EDBT), v. 1777 of Lecture Notes in Computer Science, pp. 51-65, Konstanz, Germany. Springer.

[Uhlmann, 1991] Uhlmann, J. K. (1991). Satisfying general proximity/similarity queries with metric trees. Information Processing Letters, 40(4):175-179.

[Vidal Ruiz, 1994] Vidal Ruiz, E. (1994). New formulation and improvements of the nearest-neighbour approximating and eliminating search algorithm (AESA). Pattern Recognition Letters, 15(1):1-7.

[White \& Jain, 1996] White, D. A. e Jain, R. (1996). Similarity indexing with the SStree. In Su, S. Y. W., editor, Proceedings of the 12th International Conference on Data Engineering (ICDE), pp. 516-523, New Orleans, USA. IEEE Computer Society.

[Wilson \& Martinez, 1997] Wilson, D. R. e Martinez, T. R. (1997). Improved heterogeneous distance functions. Journal of Artificial Intelligence Research, 6:1-34.

[Yamamoto et al., 2003] Yamamoto, C. H., Biajiz, M., e Traina, Caetano, J. (2003). Aumento da eficiência das estruturas de indexação métricas com uso de conceitos da lógica nebulosa. In XVIII Simpósio Brasileiro de Banco de Dados (SBBD), pp. 185-199, Manaus, Brasil.

[Yianilos, 1993] Yianilos, P. N. (1993). Data structures and algorithms for nearest neighbor search in general metric spaces. In Proceedings of the 4th Annual ACM-SIAM Symposium on Discrete Algorithms (SODA), pp. 311-321, Austin, USA.

[Yianilos, 1998] Yianilos, P. N. (1998). Excluded middle vantage point forests for nearest neighbor search. Technical report, NEC Research Institute, Princeton, USA.

[Zhou et al., 2003] Zhou, X., Wang, G., Yu, J. X., e Yu, G. (2003). M+'-tree: A new dynamical multidimensional index for metric spaces. In 4th Australasian Database Conference, pp. 1-8, Adelaide, Australia. 
Apêndice

A

\section{Métodos de Acesso para Domínios de Dados com Relação de Ordem}

\section{A.1 Introdução}

Este apêndice apresenta algumas definições sobre árvores e exemplos dos principais Métodos de Acesso (MAs) para dados em domínios com relação de ordem total e para dados multidimensionais.

\section{A.2 Definições sobre Árvores}

De forma geral, uma árvore de indexação é um grafo orientado e conexo, no qual cada nó pode ter uma ou mais ligações de saída, também chamadas de ponteiros, mas apenas uma de entrada, não havendo ciclos. Existe apenas um nó que não possui ligação de entrada, chamado de nó raiz, ou simplesmente raiz. Quando um nó $x$ aponta para um nó $y, x$ é chamado de nó pai de $y$, e $y$ nó filho de $x$. Se $x$ tiver um ou mais filhos ele é chamado de nó interno, caso contrário é chamado de nó folha, ou simplesmente folha. Dois nós são ditos irmãos quando têm um nó pai em comum. O subconjunto composto por $y$ e seus filhos é considerado uma subárvore de $x$, também chamado de ramo, da qual y é a raiz.

Um nó pode possuir (armazenar) um ou mais objetos, chamados de entradas do nó. O número máximo de entradas que um nó pode ter é chamado de capacidade ou cardinalidade $(\boldsymbol{C})$ do nó. O número máximo de ligações de saída que um nó pode ter é chamado de grau. Uma árvore cujo grau é maior que dois é chamada de árvore 

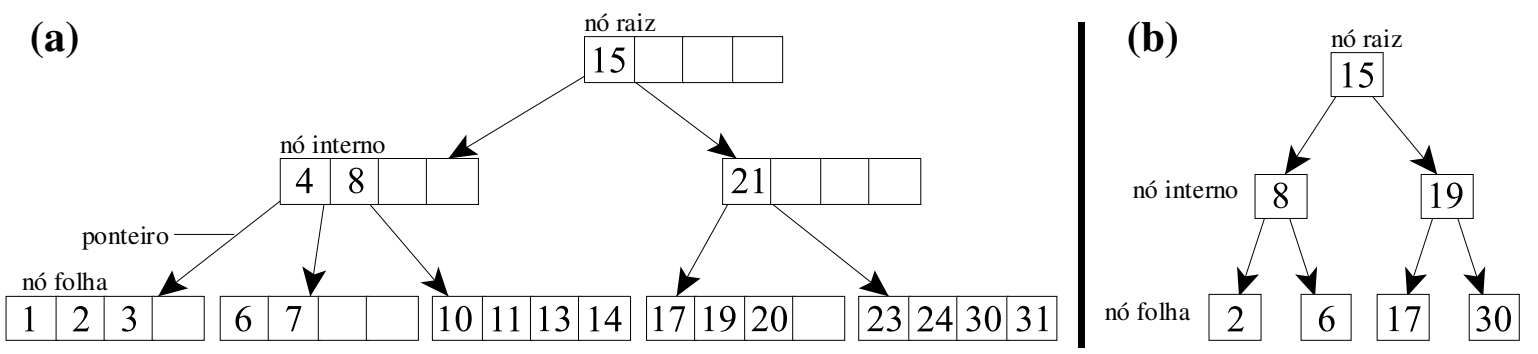

Figura A.1: Exemplo de árvores com dados numéricos: (a) árvore de cardinalidade 4 e grau 5; (b) árvore binária.

multivias. É comum que o grau de uma árvore multivias seja igual à cardinalidade do nó, ou igual à cardinalidade do nó acrescido de uma unidade. Caminho é definido como uma seqüência de nós e ponteiros que precisam ser percorridos para sair de um nó fonte e chegar a um nó destino. O tamanho de um caminho é dado pelo número de nós que o compõem. A altura de uma árvore é definida como o caminho de maior tamanho que pode ser feito a partir da raiz. Os nós que se encontram à mesma distância (com mesmo tamanho de caminho) com relação à raiz são considerados estar no mesmo nível da árvore. Uma árvore no qual todos os nós folhas possuem a mesma altura é dita balanceada em altura, caso contrário ela é não balanceada.

Um caso especial de árvore é quando os nós têm cardinalidade um e grau dois, sendo chamada de árvore binária. Nesse caso, é comum tratar os filhos por filho esquerdo e filho direito. A Figura A.1 apresenta uma árvore multivias com cardinalidade 4 e grau 5 em (a) e uma árvore binária em (b) com dados numéricos.

\section{A.3 Dados em Domínios com Relação de Ordem To- tal}

Os SGBDs tradicionais possuem MAs para dados em domínio com relação de ordem total. Um domínio de dados tem relação de ordem total quando é possível comparar qualquer par de objetos distintos e definir pela precedência de um deles sobre o outro. Por exemplo, a relação de ordem numérica em domínios numéricos, ou a relação de ordem lexicográfica em domínios de cadeias curtas de caracteres são relações de ordem total.

As consultas mais efetuadas sobre esses dados são as que envolvem consulta por intervalo (faixa de valores), por exemplo "obter as pessoas com idade entre 15 e 30 anos", ou por igualdade, por exemplo, "obtenha os dependentes da pessoa de CPF igual a 999.999.999-99".

Existem vários MAs para dados em domínio com relação de ordem total. Entre os mais importantes estão os índices simples (densos ou esparsos) para arquivos ordenados, tabelas Hash e B-tree e seus variantes. Os representantes mais importantes são os baseados em árvores (B-tree, $B^{*}$-tree, $B^{+}$-tree), que são apresentados de forma sucinta nesta seção. 


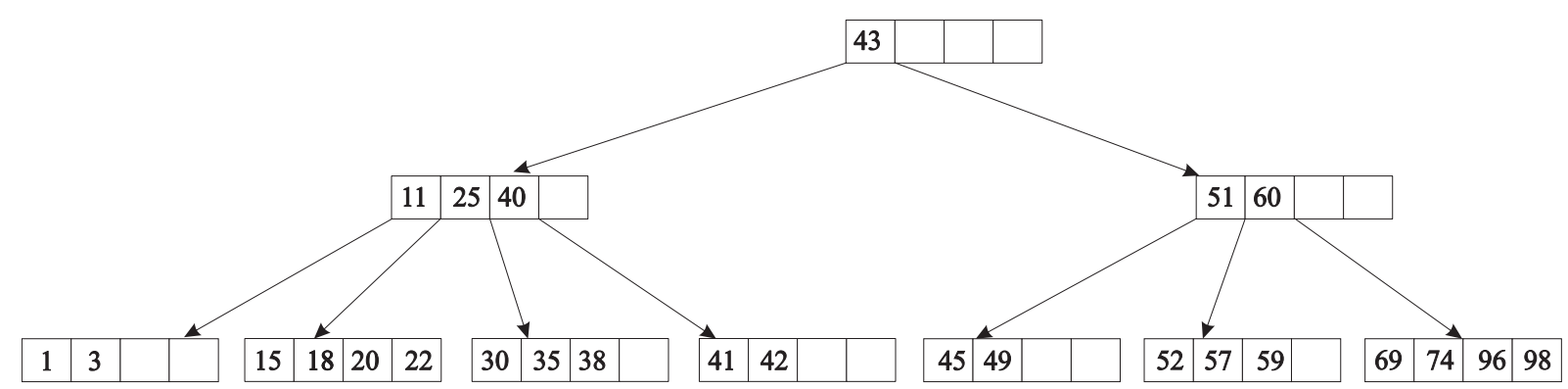

Figura A.2: Exemplo de uma árvore B-tree de grau 5 e cardinalidade 4 contendo dados numéricos.

Uma B-tree [Bayer \& McCreight, 1972] é uma árvore multivias balanceada em função da altura, o que significa que todos os caminhos da raiz até uma folha têm o mesmo comprimento. O algoritmo de inserção garante que cada nó tenha, no mínimo, $50 \%$ da sua cardinalidade ocupada. A única exceção é o nó raiz, que tem o mínimo de uma entrada. O grau de um nó de uma $B$-tree é igual à sua cardinalidade acrescida de uma unidade.

Em um nó raiz ou interno de uma $B$-tree (ver Figura A.2), o ponteiro à esquerda de uma entrada $i$ do nó indica que são encontrados nós com entradas menores que $i$, e o ponteiro à direita indica que são encontrados nós com entradas maiores a $i$. Dessa maneira, uma travessia em ordem simétrica (inorder) na $B$-tree apresenta seus nós em ordem crescente. Por travessia entende-se uma visita sistemática a cada um de seus nós [Langsam et al., 1996]. A Figura A.2 apresenta um exemplo de uma B-tree contendo dados numéricos, na qual a entrada 43 na raiz divide o conjunto de dados em duas partes: um conjunto contendo entradas menores que 43; e outro contendo entradas maiores que 43. O ponteiro dos nós folhas para os registros de dados foi omitido na figura. Fazendo uma travessia em ordem simétrica na B-tree da Figura A.2 temos as seguintes entradas: $1,3,11,15,18,20,22,25,30,35,38,40,41,42,43,45,49,51,52,57,59,60,69,74,96$ e 98.

As inserções são sempre feitas nas folhas, fazendo com que a árvore cresça de baixo para cima (bottom-up). Durante uma inserção a árvore é percorrida partindo da raiz até que uma folha seja atingida. As inserções são feitas de forma ordenada, garantindo que a subárvore apontada pelo ponteiro à esquerda de uma entrada $i$ contenha entradas menores que $i$, e a subárvore apontada pelo ponteiro à direita de $i$ contenha entradas maiores que $i$.

Caso a folha esteja completa (com a quantidade máxima de entradas), as entradas são distribuídas em dois nós (o atual e o novo) e a entrada que se encontraria no centro do nó, após a inserção da nova, é transferida para o nó pai junto com o ponteiro para o novo nó. Se necessário esse processo pode ser repetido nos níveis superiores. No caso extremo, o processo de divisão propaga-se até o nó raiz e a árvore aumenta a sua altura em uma unidade. Somente quando ocorre uma divisão no nó raiz é que a $B$-tree aumenta 


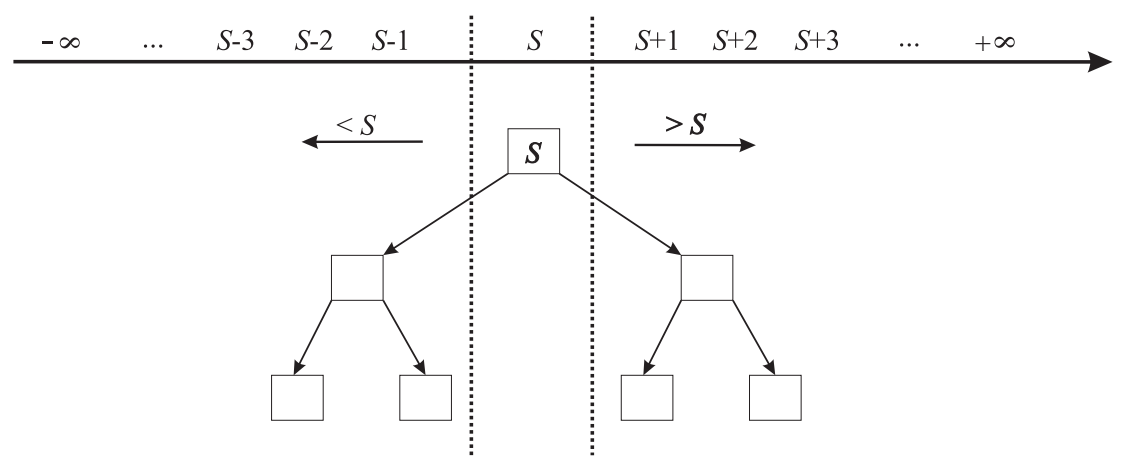

Figura A.3: Divisão do espaço de uma $B$-tree em regiões disjuntas.

a sua altura, e isso garante que ela sempre esteja balanceada.

Cada entrada da $B$-tree divide o espaço (ou domínio das entradas) em duas partes disjuntas (ver Figura A.3): todas as entradas que são menores à entrada em questão e todas as que são maiores. A conseqüência imediata é que, quando uma consulta pontual é efetuada nessa árvore, se o dado de busca for maior que a entrada contida na raiz, a subárvore esquerda pode ser totalmente descartada. A Figura A.3 ilustra uma divisão que uma entrada $\boldsymbol{S}$ faz com o espaço dos dados.

Quando uma subárvore ou uma comparação é descartada diz-se que houve uma "poda". Em uma B-tree é possível descartar não apenas subárvores, mas também comparações com as entradas de um mesmo nó. Isso é possível porque como as entradas do nó se encontram ordenadas, basta comparar até que uma entradas com valor maior que o dado de busca seja encontrado. Dessa forma, a $B$-tree diminui o número de acessos a disco e a quantidade de comparações de entradas em cada nó.

Uma das grandes vantagens da $B$-tree é que ela suporta um grande volume de dados e armazenamento em memória secundária (disco). Por exemplo, uma $B$-tree com cardinalidade 255 e grau 256 pode armazenar cerca de 16,7 milhões de entradas em apenas 3 níveis [Garcia-Molina et al., 2002]. Isto quer dizer que se o nó raiz estiver sempre na memória, com apenas dois acessos a disco é possível recuperar o dado requisitado.

Na literatura ([Knuth, 1973], [Comer, 1979] e [Folk et al., 1998]) são encontradas algumas variações da $B$-tree, tais como a $B^{*}$-tree e a $B^{+}$-tree, que trazem contribuições importantes em relação a $B$-tree original de Bayer e McCreight.

Na $B^{*}$-tree [Knuth, 1973] o algoritmo de inserção emprega um esquema de redistribuição local para adiar a divisão até que dois nós irmãos estejam totalmente cheios. Quando isso ocorre, os dois nós cheios são divididos em três, cada um com $2 / 3$ de suas entradas preenchidas, ou seja, garante uma ocupação de pelo menos $66 \%$ do nó. Isso faz com que haja uma melhora na utilização do espaço de armazenamento e diminuindo o tempo total de busca, uma vez que a altura da árvore resultante é menor.

Já na $B^{+}$-tree [Comer, 1979], todas as entradas residem nos nós folhas e os níveis superiores contêm cópias das entradas das folhas. Os nós internos e raiz consistem apenas de um índice, um "caminho" para permitir a localização rápida do índice e de parte das 


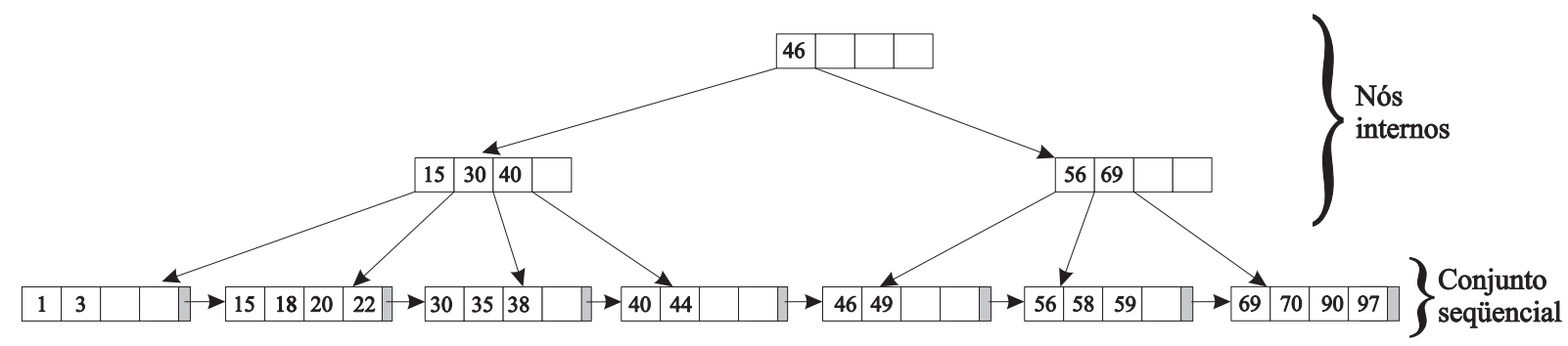

Figura A.4: Uma $B^{+}$-tree com seus nós internos (como uma B-tree) e folhas (conjunto seqüencial - interligado como uma lista ligada).

entradas, sendo organizados como uma $B$-tree. Os nós folhas são ligados da esquerda para a direita como ilustra a Figura A.4. A lista ligada de nós folhas é referenciada como sendo um "conjunto seqüencial" [Comer, 1979], o que permite fácil processamento seqüencial e por intervalos, por isso sendo também chamada de Método de Acesso Seqüencial Indexado (MASI).

Os métodos apresentados nesta seção restringem a dados que possuem relação de ordem total. Já para dados em domínios multidimensionais a relação de ordem total não existe, o que inviabiliza a utilização de métodos como o B-tree. Para resolver este problema, foram desenvolvidos os Métodos de Acesso Multidimensionais, que são tratados na próxima seção.

\section{A.4 Dados Multidimensionais}

Os Métodos de Acesso Multidimensionais, também conhecidos por Métodos de Acesso Espaciais (MAEs), são utilizados para indexar objetos multidimensionais. Em geral, um conjunto de objetos é dito multidimensional, ou $n$-dimensional, se um objeto qualquer desse conjunto pode ser localizado por uma série de $n$ coordenadas ( $n$ maior que 1). Os MAEs têm como premissa o fato dos dados manipulados pertencerem ao domínio dos dados espaciais ou a um espaço de dimensão $n$. Neste espaço, cada dimensão é representada por um atributo da relação.

Os métodos de acesso multidimensionais podem ser classificados em Métodos de Acesso Espaciais para Dados Pontuais, ou simplesmente Métodos de Acesso Espaciais Pontuais (MAEPs), e Métodos de Acesso Espaciais para Dados NãoPontuais, ou simplesmente Métodos de Acesso Espaciais Não-Pontuais (MAENPs). Os MAEPs consideram que os dados são pontos em um espaço, enquanto que os MAENPs consideram os dados como regiões, ou seja, eles possuem extensão espacial [Gaede \& Günther, 1998].

Nesta seção são apresentados o MAEP $k$ - $d$ - $B$-tree [Robinson, 1981] e o MAENP $R$-tree [Guttman, 1984], e alguns variantes dos dois. Eles são os mais representativos de sua categoria e permitem armazenar os dados em disco. Mais detalhes sobre outros MAEs pode ser encontrado em [Gaede \& Günther, 1998]. 


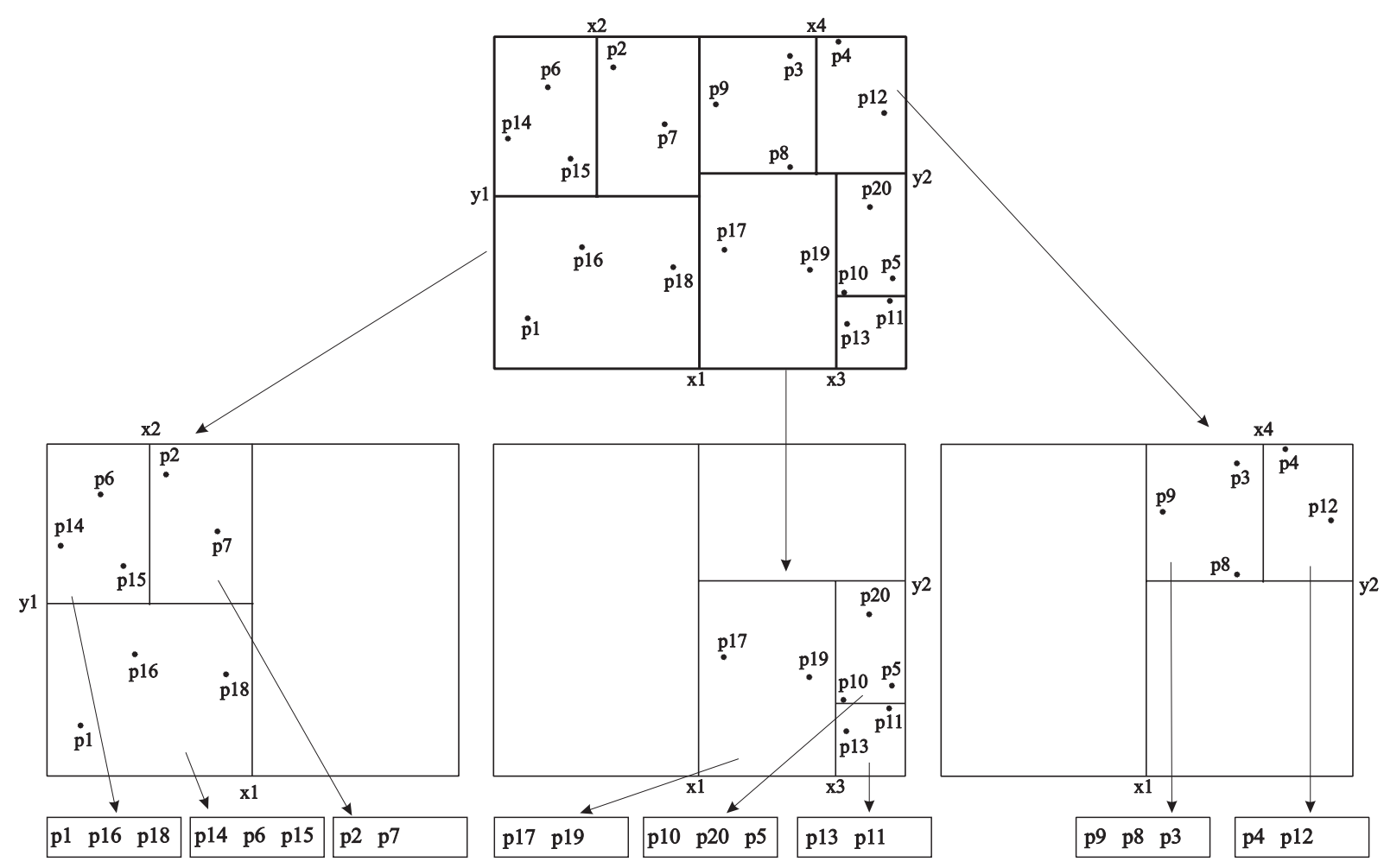

Figura A.5: Exemplo da estrutura lógica de uma $k$ - $d$-B-tree. Os pontos são simbolizados por $p i$ e a dimensão do espaço bidimensional por $x i$ e yi [Gaede \& Günther, 1998].

\section{A.4.1 $k$ - $d$-B-tree}

O $k$-d-B-tree [Robinson, 1981] combina algumas propriedades do $k$-d-tree Adaptativo [Bentley \& Friedman, 1979] e do B-tree [Bayer \& McCreight, 1972] para manipular dados multidimensionais pontuais com suporte a armazenamento secundário. A sigla $k$ - $d$ do seu nome significa árvore $k$-dimensional, cujo $k$ corresponde à dimensão, e o $B$ vem da $B$-tree. Ela divide o espaço em regiões de forma a ter aproximadamente o mesmo número de pontos, associando as regiões resultantes aos nós da árvore. Cada nó interno da árvore corresponde a uma região. As regiões correspondentes a um mesmo nível da árvore são disjuntos e a união deles resulta no espaço inteiro. Os nós internos contêm as dimensões e as coordenadas da divisão formando uma região delimitada por intervalos. Os nós folhas armazenam os pontos de dados que estão localizados na região correspondente. Como a $B$-tree, a $k$ - $d$ - $B$-tree é uma árvore multivias, balanceada pela altura que se adapta bem à distribuição dos dados. A Figura A.5 mostra um exemplo de uma $k$ - $d$ - $B$-tree indexando 20 pontos $\{p 1, \ldots, p 20\}$.

Na inserção de um novo dado, é realizada uma pesquisa para localizar o nó folha onde este deve se inserido. Se o nó folha não estiver completo, o dado é inserido, caso contrário, ocorre uma divisão e metade das entradas são deslocadas para o novo nó. Em [Robinson, 1981] são mostradas várias heurísticas para achar a melhor configuração final do nó. A divisão pode ser propagada nos níveis superiores da árvore, assim como na $B$-tree, caso também não haja espaço suficiente. Na $k$ - $d$-B-tree a divisão de um nó interno 
pode também afetar regiões em níveis inferiores da árvore.

O algoritmo de consulta é semelhante ao da inserção. Em cada nível os valores da divisão das coordenadas são utilizados para buscar o caminho a percorrer, partindo da raiz até chegar ao nó folha no qual o dado consultado pode estar.

Um dos maiores problemas com esse MAEP é que a divisão de um nó interno pode fazer com que os nós filhos sejam também divididos, ou seja, a divisão pode ser propagada tanto árvore acima quanto abaixo. Como conseqüência, não há garantias quanto à ocupação mínima de um nó, podendo gerar nós vazios [Gaede \& Günther, 1998], bem como uma carga de processamento considerável na reorganização provocada pela inserção de um dado.

Uma variante da árvore $k$-d-B-tree é a Hybrid-tree [Chakrabarti \& Mehrotra, 1999]. A estrutura dos nós é semelhante à definida pelo $k$ - $d$-B-tree, mas permite que a divisão do espaço gere regiões sobrepostas (não disjuntas), podendo resultar em árvores não balanceadas pela altura. Com isso, é possível evitar que a divisão de um nó interno propague para seus nós filhos.

\section{A.4.2 R-tree}

O mais importante método desenvolvido para indexar dados não pontuais foi o $R$-tree [Guttman, 1984]. Sua importância é corroborada pelo número de citações que tem recebido e por ser usado como base de comparação para avaliar o desempenho de novas estruturas, mesmo nos dias atuais [Santos, 2003]. Além disso, existem diversas implementações deste MA, ou variantes, em SGBDs comerciais [Kanth et al., 1999]. Ainda, o R-tree pode trabalhar com dados não pontuais. E outros fatores de seu sucesso são a simplicidade de sua proposta, o que facilita a implementação, e a possibilidade de armazenamento em memória secundária.

O $R$-tree pode ser visto como uma adaptação do $B$-tree para indexar dados multidimensionais não pontuais. Os objetos são armazenados nas folhas, e a interseção das regiões definidas pelas subárvores de um mesmo nível pode não ser vazia. Ou seja, a divisão do espaço não gera regiões disjuntas como na B-tree. Cada nó possui cardinalidade e grau iguais, e as estruturas dos nós folhas e internos são diferentes. Em um nó folha, cada entrada possui um código de identificação do objeto (object identification - OId) e um Minimum Bounding Rectangle (MBR), ou seja, o retângulo mínimo que envolve o objeto desta entrada. O MBR é uma aproximação retangular do formato real dos objetos (ver Figura A.6). Já para um nó interno, cada entrada contém o MBR que envolve toda sua subárvore e um ponteiro para ela.

Para a inserção de um novo objeto, uma subárvore é escolhida e percorrida recursivamente, até que se chegue a uma folha, no qual ele é inserido. A subárvore na qual é feita a inserção é aquela que possua um MBR que necessite expandir o menos possível. Caso um nó folha ou interno exceda sua capacidade máxima, ocorre uma divisão e um 
(a)
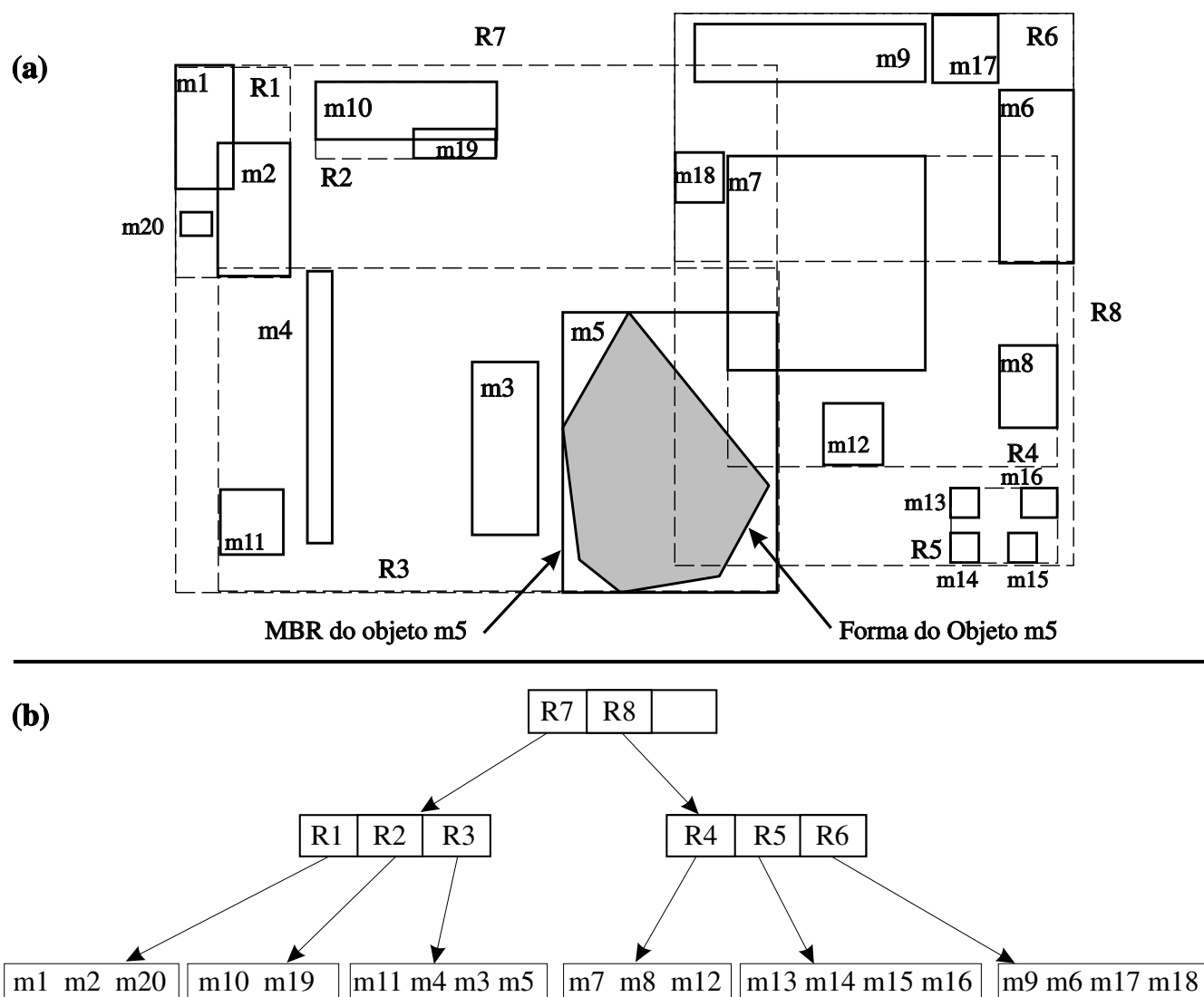

Figura A.6: Exemplo da árvore $R$-tree: (a) representação dos nós em MBR; (b) representação da estrutura lógica da árvore.

novo nó é criado. Dois MBRs são calculados de forma a minimizar o volume dos dois nós, e cada um passa a ocupar um dos nós (novo e antigo). No nó pai é inserido uma nova entrada para o novo nó e atualizada a entrada para o antigo. Esse processo de divisão pode continuar árvore acima (bottom-up). A Figura A.6 apresenta um exemplo da disposição dos MBRs e a respectiva estrutura lógica da $R$-tree, onde $m i$ denota o MBR do objeto e $R i$ o MBR no nó pai.

Durante uma $R Q()$, as subárvores cujos MBRs fazem interseção com a região de busca são percorridas até as folhas. Os objetos que fizerem interseção com a região de busca serão inseridos no conjunto resposta. Como o espaço dividido pode não ser disjunto, quanto mais os MBRs estiverem sobrepostos, maior é a chance de precisar percorrer várias subárvores durante uma consulta. Procurando minimizar esse problema, a $R$-tree usa o critério de escolha da subárvore na inserção e do algoritmo de divisão dos nós de forma a minimizar o volume.

Após a criação do $R$-tree, outras propostas surgiram procurando melhorar seu desempenho. As mais importantes foram o $R^{+}$-tree [Sellis et al., 1987] e o $R^{*}$-tree [Beckmann et al., 1990]. Com a intenção de evitar a sobreposição dos MBRs, o $R^{+}$-tree "quebra" os objetos e armazena seus "pedaços" em diferentes nós. Apesar de resolver o problema da sobreposição, o algoritmo de divisão de nós fica prejudicado, passando a ser necessário propagar a divisão árvore abaixo. Outro problema é que, para recuperar um 
objeto, vários nós podem ser acessados em busca dos seus "pedaços". Isso agrava inclusive a remoção, pois vários nós precisam ser reajustados quando um objeto é removido.

Dentre as principais melhorias apresentadas pelo $R^{*}$-tree, estão: um novo algoritmo de inserção, no qual alguns objetos são escolhidos para reinserção antes de se dividir um nó, chamado forced reinsertion; e um novo algoritmo de divisão de nós onde, ao contrário do proposto pelo $R$-tree que procurava apenas minimizar a área dos nós gerados pela divisão, sua proposta é minimizar o perímetro e maximizar a ocupação dos novos nós. Em [Beckmann et al., 1990] é mostrado que essa estrutura consegue uma diminuição no tempo para responder a consultas em até $50 \%$ comparado a $R$-tree original.

Outra evolução do R-tree foi apresentada em [Berchtold et al., 1996]. O X-tree, como é chamado, define um supernó ( super node) para tratar a questão da sobreposição de MBRs. Quando o índice de sobreposição é alto, os nós são concatenados em um supernó de tamanho variado (geralmente um múltiplo do tamanho original). Essa abordagem é interessante apenas quando é possível acessar o disco com páginas de tamanho diferentes, pois assim há uma diminuição no número de acessos a disco. No entanto, se a página de disco é de tamanho fixo, o número de acessos a disco aumenta e o desempenho passa a ser próximo ao do $R$-tree [Santos, 2003].

Em [White \& Jain, 1996] é apresentado o MAE SS-tree, cuja principal diferença em relação ao $R$-tree é que ele usa hiperesferas em vez de hiper-retângulos para delimitar as regiões dos nós. Como para definir uma esfera em um espaço $n$-dimensional é necessário apenas o ponto central e o raio, o grau da $S S$-tree é maior que a $R$-tree. Com isso, pode-se ter um melhor desempenho em espaços de alta dimensionalidade em comparação com a $R$-tree [Patella, 1999]. No entanto, o desempenho de buscas é prejudicado pela alta sobreposição entre as hiperesferas e pelo alto volume das regiões de cobertura dos nós.

Para superar os problemas do SS-tree, em [Katayama \& Satoh, 1997] é proposto o MAE SR-tree (Sphere-Rectangle tree). Ele usa intersecção de hiperesferas e hiperretângulos como regiões dos nós. Cada nó armazena uma hiperesfera e um hiper-retângulo delimitadores. Isso reduz a sobreposição das regiões dos nós, diminuindo o tempo de processamento durante as consultas [Patella, 1999]. No entanto, como cada nó tem que armazenar a definição da hiperesfera e do hiper-retângulo, o grau dos nós é reduzido em comparação com a SS-tree.

\section{A.4.3 Utilizando MAEs para indexar dados multimídia}

A principal aplicação dos MAEs é a indexação de dados em um espaço multidimensional, porém eles também podem ser utilizados para indexar tipos de dados complexos, como por exemplo dados multimídia. Resumidamente, a idéia é extrair $n$ características numéricas dos objetos de interesse e construir um índice através desses vetores de características, sendo esse índice baseado em um MAE. O trabalho de Böhm et al. em [Böhm et al., 2001] é uma boa referência para estudos que requeiram uma abordagem 
mais detalhada e abrangente do uso de MAEs para indexação de dados multimídia.

Os vetores de características são vistos como pontos no espaço, cuja dimensão é definida pela quantidade de elementos que os compõem. As consultas são aceleradas através de um MAE, que organiza os pontos em um espaço $n$-dimensional [Faloutsos, 1997]. Uma consulta por similaridade é feita a partir do índice gerado considerando que, dada uma métrica, quanto mais próximos espacialmente esses pontos estão do objeto de consulta, mais semelhante serão os objetos. A função de distância Euclidiana é a mais utilizada.

Para um espaço de baixa dimensionalidade, muitos MAEs conhecidos funcionam eficientemente. No entanto, para os exemplos de aplicações citadas anteriormente, o número de características por objetos pode chegar até a mais de 1000. Embora os MAEs possam ser estendidos para dimensões mais altas, eles usualmente requerem tempo e/ou espaço que crescem exponencialmente com o aumento do número de dimensões [Chávez et al., 2001]. Resultados experimentais mostram que o MAE $R$-tree se torna ineficiente para espaços com dimensão maior que 20 [Bozkaya \& Özsoyoglu, 1997]. Portanto, em alguns casos é melhor usar a busca seqüencial para responder a consultas por similaridade do que um índice baseado em um MAE.

Outro problema dos MAEs é que eles não podem ser utilizados para indexar dados adimensionais, para os quais não é possível identificar os objetos do conjunto através de uma dimensão fixa. Um bom exemplo seria um conjunto de imagens, cujos objetos são dimensionais mas não podem ser naturalmente identificados por um vetor de coordenadas. Apesar das características extraídas de uma imagem poderem constituir um vetor com um determinado número de elementos e portanto tenham uma "dimensão" individualmente, seu conjunto é adimensional, pois o vetor de características delas extraídas pode variar de imagem para imagem, não permitindo colocar o conjunto todo em um espaço com a mesma dimensão.

A maioria dos conjuntos adimensionais pode ser descrito em espaços métricos, bastando para isso conhecer uma função de distância adequada. Um outro exemplo de espaço métrico composto por objetos adimensionais é formado pelo conjunto de palavras de um dicionário e pela métrica $L_{E d i t}$.

O problema gerado pela alta dimensionalidade nos MAEs e o fato dos mesmos não suportarem o tratamento de dados adimensionais (como palavras e imagens) impulsionou o desenvolvimento de Métodos de Acesso Métricos (MAMs). Eles usam técnicas de indexação baseadas em distância (grau de similaridade) entre os objetos ao invés de sua posição absoluta no espaço. Eles evitam qualquer referência a coordenadas para evitar o problema da alta dimensionalidade, apenas considerando a distância relativa entre pares de objetos. 
Apêndice

B

\section{A Biblioteca de MAMs Arboretum}

\section{B.1 Introdução}

Como descrito no Capítulo 5, o MAM DBM-tree foi implementado na biblioteca de MAMs Arboretum [GBDI-ICMC-USP, 2004]. Esta biblioteca foi implementada utilizando a linguagem $\mathrm{C}++$, podendo ser compilada em ambientes Windows e Linux. Seu código fonte, bem como a sua documentação completa estão disponíveis no seguinte endereço:

http://gbdi.icmc.usp.br/arboretum

\section{B.2 Arquitetura da biblioteca de MAMs Arboretum}

A biblioteca de MAMs Arboretum foi desenvolvida para ser uma base uniforme de comparação entre MAMs. Ela foi desenvolvida para ser uma biblioteca portável entre vários sistemas e compiladores, fácil de usar e estender, ser orientado a objetos, e o principal, ser um framework completo para a implementação de MAMs.

A versão atual contem 2 MAMs completos (Slim-tree e DBM-tree), uma implementação de busca seqüencial (Dummy-tree) e um MAM sob desenvolvimento (Partition-tree).

A biblioteca está dividida em 3 camadas distintas:

- Camada do Usuário: Define os objetos e as funções de distância métricas. As classes desta camada devem ser fornecidas pelos desenvolvedores da aplicação. A biblioteca já possui algumas funções de distâncias e objetos básicos implementados, que podem ser utilizados pelo desenvolvedores. Esta camada define apenas as 
interfaces stObject e stMetricEvaluator, que devem ser utilizadas pelos desenvolvedores de aplicação para implementar o objeto e a métrica para construir as árvores;

- Camada Estrutural: Esta camada é o núcleo da biblioteca. Ela contém as classes que implementam os MAMs, além de outras classes de estatísticas e de respostas para as consultas. A DBM-tree e a Slim-tree pertencem a esta camada;

- Camada de Armazenamento: Classes que fornecem acesso aos dispositivos de armazenamento (memória e disco). Elas fornecem os serviços de gerenciamento de páginas de disco e de memória para a Camada Estrutural.

A Figura B.1 ilustra a arquitetura da biblioteca Arboretum. Apenas algumas classes são ilustradas em cada camada. As setas indicam o fluxo de informações entre as camadas.

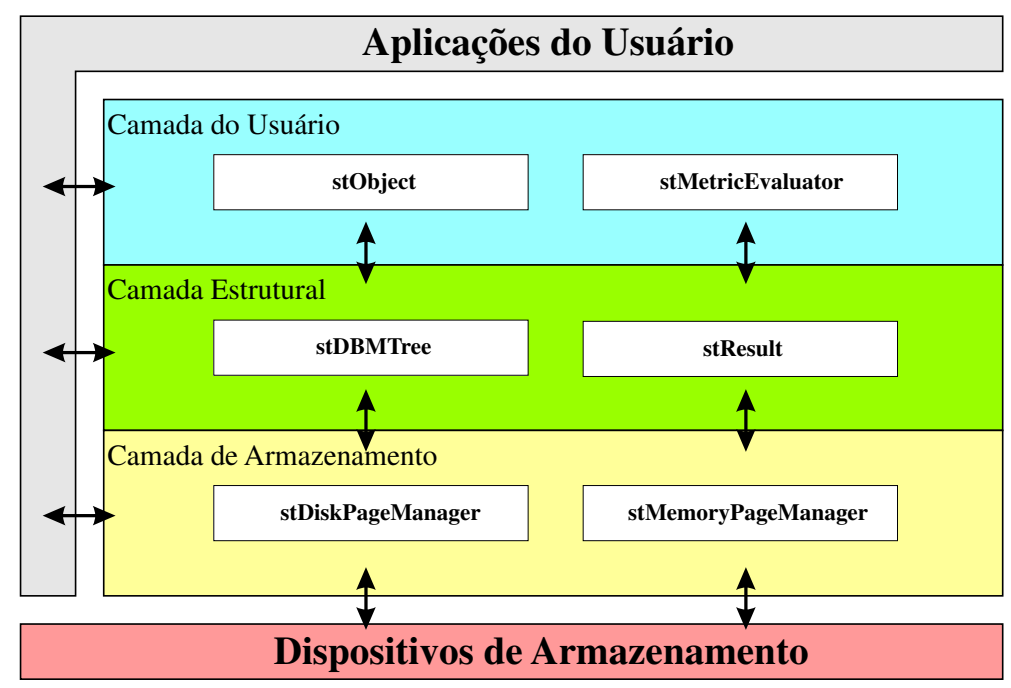

Figura B.1: Arquitetura da biblioteca Arboretum e suas principais classes/interfaces de cada camada. As setas representam as interações entre as camadas.

\section{B.2.1 Interfaces e Classes da biblioteca Arboretum}

As principais interfaces e classes das 3 camadas são descritas a seguir. Apenas os principais métodos de cada interface/classe são descritos.

\section{B.2.1.1 Interface stObject}

A interface stObject fornece os métodos requeridos pela Camada Estrutural para manipulação de objetos. Ela define os seguintes métodos: stObject(), stobject * Clone(), bool IsEqual(stObject * obj), stSize GetSerializedSize(), stByte * Serialize() e Unserialize(stByte * data, stSize dataSize). 


\section{B.2.1.2 Interface stMetricEvaluator}

A interface stMetricEvaluator fornece os métodos requeridos pela Camada Estrutural para manipulação das funções de distância métricas. Ela define apenas 2 métodos: stDistance GetDistance() e stDistance GetDistance2().

\section{B.2.1.3 Classe stResult}

Esta classe implementa o conjunto resposta de uma consulta por similaridade. Seus métodos para manipulação são: stResult(), bool AddPair(tObject * object, stDistance distance), bool IsEqual (stResult * result), stResult * Intersection(stResult $*$ result1, stResult $*$ result2), stResult $*$ Union(stResult * result1, stResult * result2), stCount GetNumOfEntries(), stDistance GetMaximumDistance() e stDistance GetRadius().

\section{B.2.1.4 Classe DBM-tree}

Esta classe implementa o MAM DBM-tree. Sua interface obedece aos padrões estabelecidos pela biblioteca Arboretum.

\section{Construtor:}

- stDBMTree (stPageManager * pageman): cria uma árvore DBM-tree associada à instância de gerenciamento de páginas pageman.

\section{Métodos de Manipulação:}

- bool Add(tObject * newObject): Adiciona um objeto na árvore DBM-tree. Retorna true caso a inserção tenha ocorrido com sucesso, false caso contrário.

- void Optimize(): Executa o algoritmo de otimização DBM-Slim-Down.

\section{Métodos de Consulta por Similaridade:}

- tResult * RangeQuery(tObject * sample, stDistance range): Executa uma consulta por abrangência na DBM-tree.

- tResult * NearestQuery(tObject * sample, int k, bool tie): Executa uma consulta aos k-vizinhos mais próximos na DBM-tree.

- bool PointQuery(tObject * sample): Executa uma consulta pontual na DBMtree. Retorna true em caso de existência do objeto na árvore, false caso contrário. 


\section{Métodos de Informações sobre a árvore:}

- double GetMinOccupation(): Retorna a ocupação mínima dos nós da estrutura em porcentagem do tamanho do nó.

- int GetHeight(): Retorna a altura máxima da estrutura.

- long GetNumberOfObjects(): Retorna o número total de objetos da estrutura.

\section{B.2.1.5 Classe stDiskPageManager}

Classe para manipulação de páginas em disco. Através dela é possível obter estatísticas sobre a utilização das páginas de disco, tal como número de leitura e escrita em disco, além de ser possível ler árvores gravadas em disco. Ela define os seguintes métodos: stDiskPageManager(), GetPage(stPageID pageId), ReleasePage(stPage * page), GetNewPage(), WritePage(stPage * page), ResetStatistics(), GetDiskReadCount(), GetDiskWriteCount() e GetDiskAccessCount()

\section{B.2.1.6 Classe stDiskPageManager}

Classe para manipulação de páginas em memória. Ela define os seguintes métodos: stMemoryPageManager(), GetPage (stPageID pageId), ReleasePage (stPage * page), GetNewPage() e ResetStatistics(). 


\section{Apêndice}

\section{Usando a Desigualdade Triangular}

Dado um domínio de objetos $\mathfrak{D}$, uma função de distância $d: \mathfrak{D} \times \mathfrak{D} \rightarrow \mathbb{R}^{+}$e os objetos $\left\{o_{1}, o_{2}, o_{3}\right\} \in \mathfrak{D}$, temos a inequação da desigualdade triangular:

$$
d\left(o_{1}, o_{2}\right) \leq d\left(o_{1}, o_{3}\right)+d\left(o_{3}, o_{2}\right)
$$

Esta inequação permite inferir os limites superior e inferior de uma das três distâncias envolvidas conhecendo apenas os valores das outras duas distâncias.

Suponha que as distâncias $d\left(o_{1}, o_{3}\right)$ e $d\left(o_{2}, o_{3}\right)$ são conhecidas e deseja-se inferir o valor da distância $d\left(o_{1}, o_{2}\right)$, que será denotada por $x$ para facilitar a compreensão. Usando a Equação C.1 temos:

$$
x \leq d\left(o_{1}, o_{3}\right)+d\left(o_{3}, o_{2}\right)
$$

mas também:

$$
d\left(o_{1}, o_{3}\right) \leq x+d\left(o_{3}, o_{2}\right) \Rightarrow x \geq d\left(o_{3}, o_{2}\right)-d\left(o_{1}, o_{3}\right)
$$

e

$$
d\left(o_{3}, o_{2}\right) \leq d\left(o_{1}, o_{3}\right)+x \Rightarrow x \geq d\left(o_{1}, o_{3}\right)-d\left(o_{3}, o_{2}\right)
$$

Sabendo que $x \geq 0$, as Equações C.3 e C.4 podem ser combinadas, formando:

$$
x \geq\left|d\left(o_{1}, o_{3}\right)-d\left(o_{3}, o_{2}\right)\right|
$$

pois se $d\left(o_{1}, o_{3}\right)>d\left(o_{3}, o_{2}\right)$, o limite inferior será a Equação C.4, caso contrário, será a 
Equação C.3.

Combinando as Equações C.2 e C.5, temos:

$$
\left|d\left(o_{1}, o_{3}\right)-d\left(o_{3}, o_{2}\right)\right| \leq x \leq d\left(o_{1}, o_{3}\right)+d\left(o_{3}, o_{2}\right)
$$

ou seja:

$$
\left|d\left(o_{1}, o_{3}\right)-d\left(o_{3}, o_{2}\right)\right| \leq d\left(o_{1}, o_{2}\right) \leq d\left(o_{1}, o_{3}\right)+d\left(o_{3}, o_{2}\right)
$$

A Equação C.7 pode ser utilizada para descartar objetos pertencentes a consultas realizadas em MAMs. Considerando uma consulta por abrangência com raio $r_{q}$, objeto central da consulta $o_{1}$, objeto candidato $o_{2}$ e representativo de uma região $c$, temos:

$$
\begin{aligned}
& d\left(o_{1}, o_{2}\right) \leq r_{q}, o_{2} \in \text { resposta } \\
& d\left(o_{1}, o_{2}\right)>r_{q}, o_{2} \notin \text { resposta }
\end{aligned}
$$

Sabendo apenas $d\left(o_{1}, o_{3}\right)$ e $d\left(o_{3}, o_{2}\right)$ é possível afirmar que $o_{2}$ só pode ser candidato a resposta desta consulta se, e somente se:

$$
\left|d\left(o_{1}, o_{3}\right)-r_{q}\right| \leq d\left(o_{3}, o_{2}\right) \leq d\left(o_{1}, o_{3}\right)+r_{q}
$$

partindo disto, sabe-se que $d\left(o_{3}, o_{2}\right)$ não se encontrar dentro deste intervalo, $d\left(o_{1}, o_{2}\right)$ certamente será maior que $r_{q}$ e portanto pode ser descartado sem a necessidade de calcular seu valor. Caso contrário, o limite superior de $d\left(o_{1}, o_{2}\right)$ será $2 d\left(o_{1}, o_{3}\right)+r_{q}$. Neste caso, $d\left(o_{1}, o_{2}\right)$ deve ser calculado para que possa ser comparado com $r_{q}$, descartando ou não o objeto da resposta dependendo de seu valor. 
Este documento foi preparado com o formatador de textos $\mathrm{HT}_{\mathrm{E}} \mathrm{X}$. 